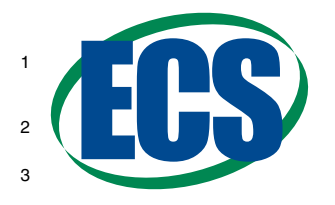

Jes Focus Issue on Advances in Modern Polymer Electrolyte Fuel Cells in Honor of Shimshon Gottesfeld

\title{
Through-the-Membrane Transient Phenomena in PEM Fuel Cells: A Modeling Study
}

\author{
Alireza Goshtasbi, $\oplus^{1, *}$ Pablo García-Salaberri, ${ }^{2}$ Jixin Chen, ${ }^{3, z}$ Krishan Talukdar, ${ }^{4}$ \\ Daniel G. Sanchez, ${ }^{4}$ and Tulga Ersal $\circledast^{1, z}$ \\ ${ }^{1}$ Department of Mechanical Engineering, University of Michigan, Ann Arbor, Michigan 48109, USA \\ ${ }^{2}$ Depto. de Ingeniería Térmica y de Fluidos, Universidad Carlos III de Madrid, Leganés 28911, Spain \\ ${ }^{3}$ Ford Motor Company, Dearborn, Michigan 48121, USA \\ ${ }^{4}$ Deutsches Zentrum für Luft und Raumfahrt (DLR), Institute of Engineering Thermodynamics, 70569 Stuttgart, \\ Germany
}

\begin{abstract}
This paper presents a 2D, fully coupled and comprehensive transient model that accounts for micro-structural features of various cell layers. The model benefits from state of the art sub-models for reaction kinetics and incorporates the polymer relaxation dynamics. Furthermore, a mixed wettability model is utilized to simulate the transient two phase conditions in the porous layers. The model is validated with transient experimental data under various conditions. A comprehensive simulation study is presented to investigate the impact of operating temperature and relative humidity on the transient response. The effects of cathode Pt loading and operation mode, i.e., current control versus voltage control, are also studied. The cell response is found to be dominated by water transport through its thickness. Additionally, it is found that reducing the Pt loading can influence the performance by changing the water balance in the cell, which has rarely been highlighted in the literature. In particular, at low temperature more water is transported toward the anode when the cathode Pt loading is reduced, since the resistance to water back diffusion is lowered with reduced thickness of the cathode catalyst layer. This trend is reversed at a higher temperature due to increased volumetric heat generation with reduced thickness. The model can help in understanding various transport phenomena and is expected to be useful for inspecting spatio-temporal temperature, potential, and species distributions across the cell's thickness and optimizing the cell design and choice of materials.

(C) The Author(s) 2019. Published by ECS. This is an open access article distributed under the terms of the Creative Commons Attribution 4.0 License (CC BY, http://creativecommons.org/licenses/by/4.0/), which permits unrestricted reuse of the work in any medium, provided the original work is properly cited. [DOI: 10.1149/2.0181907jes]

(cc) BY
\end{abstract}

Manuscript submitted January 11, 2019; revised manuscript received March 14, 2019. Published 00 0, 2019. This paper is part of the JES Focus Issue on Advances in Modern Polymer Electrolyte Fuel Cells in Honor of Shimshon Gottesfeld.

Some of the significant technological challenges to commercialization of polymer electrolyte membrane (PEM) fuel cells have been addressed in the past two decades through extensive theoretical and experimental research. As a result, the PEM fuel cell technology has advanced considerably. In particular, the amount of precious metal used in the catalyst layers (CL) has been significantly reduced while achieving remarkable performance improvements. ${ }^{1,2}$ Nevertheless, important challenges related to cost and durability remain. While further material development is indeed beneficial, some of the existing issues may be addressed through effective control and hybridization of these systems. This will require a good understanding of the processes that govern the fuel cell dynamics. Moreover, in-depth studies of the transients can improve the current understanding of various electrochemical and transport phenomena. Therefore, there is a need for better understanding of the transient response to further enhance performance and lifetime of PEM fuel cells.

Arguably, the dynamic studies of PEM fuel cells have been overshadowed by the significant efforts dedicated to steady state measurements and modeling. However, fuel cell transient response has attracted some attention lately, as it can be used to elucidate and deconvolve complex transport phenomena. ${ }^{3-8}$ Several transient models have also been proposed in the literature. ${ }^{9-15}$ These models usually use simplified reaction kinetics and do not account for the microstructure of various cell layers and the anisotropic material properties. Therefore, these models typically do not have the required fidelity to allow detailed investigation of the transient phenomena affecting the cell performance. Accordingly, it is the main objective of this work to develop a transient model that captures the most salient features of the cell's dynamics across its thickness. Furthermore, we execute the model under a variety of operating conditions to delineate the critical transient phenomena that determine the overall cell dynamics. It should be noted that the model presented here is only helpful in understanding transient phenomena through the thickness of a unit cell

*Electrochemical Society Student Member.

${ }^{z}$ E-mail: jchen186@ford.com; tersal@umich.edu with small active area. In other words, the compressor and channel flow dynamics, along the channel redistributions, and stack thermal dynamics are not discussed here. Nevertheless, the results of this work may be extended along the flow channel and across multiple cells to study the transients at those scales.

Specific to our objective is creating a model that, as much as possible, directly translates the physically measurable parameters and operating conditions into the knowledge about spatio-temporal distributions of critical variables such as temperature and water concentration in different layers. To this end, it is imperative to effectively capture the physical characteristics of the porous layers including the catalyst layers and diffusion media (DM). It is worth pointing out that, as has recently been shown, a representative elementary volume (REV) cannot be clearly defined in the through-plane direction for commercial $\mathrm{DM}^{16}$ and the REV for the in-plane direction is on par with the land-channel sizes used in fuel cells. ${ }^{16,17}$ Therefore, while the macroscopic models can capture the aggregate behavior, their predictions may significantly deviate from the local predictions by microscopic models. ${ }^{16,18}$ This result bears significance, as it points to the need for more elaborate description of transport in the porous layers. Nevertheless, the excessively high cost of such simulations limits their application to very few conditions and a limited material set. Therefore, the macroscopic models remain the main tool to investigate the internal distributions in a full cell model and including some level of description of the microstructure is the approach adopted in this work to improve their prediction capability. This is achieved here by using a recently developed mixed wettability model for the porous layers. ${ }^{19,20}$ To the best of the authors' knowledge, this is the first time that a full implementation of the mixed wettability model is being used in a $2 \mathrm{D}$ transient model. In addition to the mixed wettability model for porous layers, the presented model accounts for ionomer relaxation dynamics and CL micro-structure, which have been neglected in most of the previous models. Moreover, the effective material and transport properties of the different layers are identified through an extensive literature review of commercially available materials. Therefore, this model is expected to offer higher fidelity than the state of the art models for 


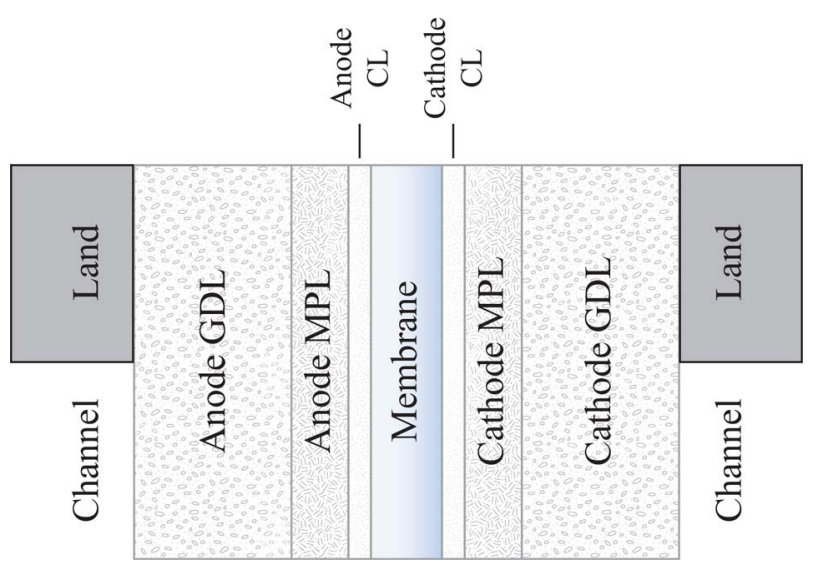

Figure 1. Modeling domain.

100 the purpose of studying transient phenomena that impact performance 101 and durability. ${ }^{21}$

The rest of the paper is organized as follows: First, the model for103 mulation is presented along with a detailed review of the literature 104 relevant to each sub-model to justify the choices made during model 105 development. Simulation results and discussions are provided next, 106 followed by a brief summary and concluding remarks. Model vali107 dation with experimental data from the literature is presented in the 108 accompanying Supplementary Information.

\section{$109 \quad$ Model Formulation}

110 The modeling domain of interest is shown in Fig. 1. The model 111 draws from prior work by Balliet et al., ${ }^{10}$ Zenyuk et al., ${ }^{22}$ and Zhou 112 et al..$^{23}$ with modifications to several sub-models. Therefore, the model 113 is presented here in its entirety for completeness. A complete list of 114 model parameters is provided in the accompanying Supplementary 115 Information.

116 Governing equations.-The comprehensive 2D model solves the 117 following governing equations, where the various source terms are 118 given in Tables I and II:

$$
\begin{gathered}
\varepsilon_{g} \frac{\partial c_{i}}{\partial t}=\nabla \cdot\left(c_{g} D_{i}^{\mathrm{eff}} \nabla x_{i}\right)-\nabla \cdot\left(c_{g} x_{i} \boldsymbol{u}_{g}\right)+S_{i}, \\
\frac{\partial\left(\rho_{l} \varepsilon_{l}\right)}{\partial t}=\nabla \cdot\left(\frac{\rho_{l} K_{l}^{\mathrm{eff}}}{\mu_{l}} \nabla p_{l}\right)+S_{\text {liquid }}, \\
\frac{\partial\left(\rho_{g} \varepsilon_{g}\right)}{\partial t}=\nabla \cdot\left(\frac{\rho_{g} K_{g}^{\mathrm{eff}}}{\mu_{g}} \nabla p_{g}\right)+S_{\mathrm{gas}},
\end{gathered}
$$

$$
\begin{gathered}
\varepsilon_{\text {ion }} \frac{\rho_{\text {ion }}}{E W} \frac{\partial \lambda}{\partial t}=\nabla \cdot\left(\boldsymbol{N}_{\mathrm{w}, \mathrm{mb}}\right)+S_{\lambda}, \\
\sum_{\alpha} \varepsilon_{\alpha} \rho_{\alpha} c_{p, \alpha}\left(\frac{\partial T}{\partial t}+\boldsymbol{u}_{\alpha} \cdot \nabla T\right)=\nabla \cdot\left(k_{T}^{\mathrm{eff}} \nabla T\right)+S_{T}, \\
\nabla \cdot\left(\sigma_{1}^{\mathrm{eff}} \nabla \phi_{1}\right)=S_{e^{-}}, \\
\nabla \cdot\left(\sigma_{2}^{\mathrm{eff}} \nabla \phi_{2}\right)=S_{H^{+}} .
\end{gathered}
$$

The first equation describes species transport in the microporous layers 119 (MPLs), gas diffusion layers (GDLs), and CLs, where $\varepsilon_{g}$ is the porosity 120 of the layer available for gas transport $\left(\varepsilon_{g}=\varepsilon(1-s)\right.$, with $s$ the 121 liquid saturation and $\varepsilon$ the compressed layer porosity), $c_{g}$ is the total 122 gas concentration, $\boldsymbol{u}_{g}=-\frac{K_{g}^{\text {eff }}}{\mu_{g}} \nabla p_{g}$ is the velocity of the gas phase, ${ }_{123}$ and $c_{i}, D_{i}^{\text {eff }}$, and $x_{i}$ denote the concentration, the effective diffusivity, 124 and the molar fraction of species $i$, respectively. The first and second 125 terms on the right hand side model the diffusive and convective fluxes, $\quad 126$ respectively, while the last term $\left(S_{i}\right)$ is the relevant source term for ${ }_{127}$ the specific gas species (see Table I). In the anode, the equation is ${ }_{128}$ solved for water vapor molar fraction $\left(x_{\mathrm{H}_{2} \mathrm{O}}\right)$ and the hydrogen molar ${ }_{129}$ fraction $\left(x_{\mathrm{H}_{2}}\right)$ is calculated by $x_{\mathrm{H}_{2}}=1-x_{\mathrm{H}_{2} \mathrm{O}}$. On the cathode side, 130 this equation is solved for water vapor $\left(x_{\mathrm{H}_{2} \mathrm{O}}\right)$ and oxygen $\left(x_{\mathrm{O}_{2}}\right)$ and ${ }_{131}$ the nitrogen molar fraction is found from $x_{N_{2}}=1-x_{\mathrm{O}_{2}}-x_{\mathrm{H}_{2} \mathrm{O}}$. 132

Equations 2 and 3 describe the mass conservation of the liquid and ${ }_{133}$ gas phases, respectively. These equations model the pressure drop of ${ }_{134}$ each phase in the CLs, MPLs, and GDLs according to Darcy's law. ${ }_{135}$ Here, $\rho_{\alpha}, \varepsilon_{\alpha}, K_{\alpha}^{\text {eff }}, \mu_{\alpha}$, and $p_{\alpha}$ denote the density, volume fraction, effec- ${ }_{136}$ tive permeability (relative permeability times absolute permeability), ${ }_{137}$ viscosity, and pressure of phase $\alpha$. Note that $\varepsilon_{g}=\varepsilon(1-s)$ and $\varepsilon_{l}=\varepsilon s . \quad 138$ Finally, $S_{\text {liquid/gas }}$ denotes the source term for the corresponding phase 139 (see Table I). Note that liquid saturation that appears in these equations 140 through the volume fractions is a variable that depends on capillary 141 pressure. Therefore, closure equations that relate the saturation level 142 to the capillary pressure are required. In this work, the mixed wetta- ${ }_{143}$ bility model is used to derive water retention curves (liquid saturation 144 vs. capillary pressure) as well as effective property values such as gas 145 and liquid permeability for the different layers (see Mixed wettability 146 model for porous layers section).

Equation 4 governs water transport in the ionomer phase throughout the catalyst coated membrane (CCM). Therefore, its domain of application is the anode and cathode catalyst layers and the membrane. In this equation, $\varepsilon_{\text {ion }}, \rho_{\text {ion }}$, and $E W$ denote the ionomer volume fraction, density, and equivalent weight, respectively, while $\lambda$ is the dimensionless number that quantifies the water content in the ionomer, i.e., the number of water molecules per sulfonic acid group. Finally,

\begin{tabular}{|c|c|c|c|c|}
\hline Domain & $\mathrm{S}_{\mathrm{H}_{2} \mathrm{O}}$ & $S_{\text {liquid }}$ & $S_{\text {gas }}$ & $S_{\lambda}$ \\
\hline $\begin{array}{l}\text { Anode CL (ACL) } \\
\text { Cathode CL (CCL) } \\
\text { MPL and GDL } \\
\end{array}$ & $\begin{array}{c}S_{\mathrm{pc}}-S_{\mathrm{ad}} \\
S_{\mathrm{pc}}-S_{\mathrm{ad}} \\
\quad S_{\mathrm{pc}}\end{array}$ & $\begin{array}{l}-M_{\mathrm{H}_{2} O} S_{\mathrm{pc}} \\
-M_{\mathrm{H}_{2} O} S_{\mathrm{pc}} \\
-M_{\mathrm{H}_{2} O} S_{\mathrm{pc}} \\
\end{array}$ & $\begin{array}{c}-M_{\mathrm{H}_{2}} \frac{i_{\mathrm{HOR}}}{2 F}+M_{\mathrm{H}_{2} O}\left(S_{\mathrm{pc}}-S_{\mathrm{ad}}\right) \\
M_{\mathrm{O}_{2}} \frac{i_{\mathrm{ORR}}}{4 F}+M_{\mathrm{H}_{2} O}\left(S_{\mathrm{pc}}-S_{\mathrm{ad}}\right) \\
M_{\mathrm{H}_{2} O} S_{\mathrm{pc}} \\
\end{array}$ & $\begin{array}{c}S_{\mathrm{ad}} \\
S_{\mathrm{ad}}-\frac{i_{\mathrm{ORR}}}{2 F} \\
- \\
\end{array}$ \\
\hline
\end{tabular}
$S_{\lambda}$ is the source term (see Table I) and $\boldsymbol{N}_{\mathrm{w}, \mathrm{mb}}$ is the water flux in the ionomer phase across the CCM, which includes the effects of electro-

\begin{tabular}{|c|c|c|c|}
\hline Domain & $S_{T}$ & $S_{H^{+}}$ & $S_{e^{-}}$ \\
\hline Anode CL (ACL) & $-M_{H_{2} O} S_{\mathrm{pc}} H_{\mathrm{pc}}+S_{\mathrm{ad}} H_{\mathrm{ad}}+H_{\mathrm{HOR}}+\frac{i_{1} \cdot i_{1}}{\sigma_{1}^{\text {eff }}}+\frac{i_{2} \cdot i_{2}}{\sigma_{2}^{\text {eff }}}$ & $i_{\mathrm{HOR}}$ & $-i_{\mathrm{HOR}}$ \\
\hline Cathode CL (CCL) & $-M_{H_{2} O} S_{\mathrm{pc}} H_{\mathrm{pc}}+S_{\mathrm{ad}} H_{\mathrm{ad}}+H_{\mathrm{ORR}}+\frac{i_{1}^{1} \cdot i_{1}}{\sigma_{1}^{\text {eff }}}+\frac{i_{2}^{2} \cdot i_{2}}{\sigma_{2}^{\text {eff }}}$ & $i_{\mathrm{ORR}}$ & $-i_{\mathrm{ORR}}$ \\
\hline Membrane & $\frac{i_{2} \cdot i_{2}}{\sigma^{\text {efft }}}$ & 0 & - \\
\hline MPL and GDL & $-M_{\mathrm{H}_{2} O} S_{\mathrm{pc}} H_{\mathrm{pc}}$ & - & 0 \\
\hline
\end{tabular}
osmotic drag (EOD), diffusion, and thermo-osmosis and is calculated as follows:

$$
N_{\mathrm{w}, \mathrm{mb}}=-n_{d} \frac{\sigma_{2}^{\mathrm{eff}}}{F} \nabla \phi_{2}-\frac{\rho_{\mathrm{ion}}}{E W} D_{\mathrm{w}, \mathrm{mb}}^{\mathrm{eff}} \nabla \lambda+D_{T, \mathrm{mb}} \nabla T,
$$

Table II. Energy and charge conservation source terms. 
159 where $n_{d}$ is the EOD coefficient, $\phi_{2}$ is the ionic potential, $F$ is the 160 Faraday's constant, $\sigma_{2}^{\text {eff }}$ is the effective conductivity in the ionic phase, $161 D_{\mathrm{w}, \mathrm{mb}}^{\text {eff }}$ is the effective water diffusion coefficient in the membrane 162 and $D_{T, \mathrm{mb}}$ is the thermal water diffusivity in the membrane. Note 163 that thermo-osmosis is shown to drive water from the cold to the hot 164 side for a hydrophilic membrane. ${ }^{24}$ As a convention, a positive flux 165 denotes water flux toward the cathode. The membrane water transport 166 properties are given in Table III.

167 Equation 5 is the energy conservation equation, which governs 168 the temperature distribution. In this equation, $\rho_{\alpha}, \varepsilon_{\alpha}, c_{p, \alpha}$, and $\boldsymbol{u}_{\alpha}=$ $169-\frac{K_{\alpha}^{\text {eff }}}{\mu_{\alpha}} \nabla p_{\alpha}$ are the density, volume fraction, specific heat capacity, and 170 velocity of phase $\alpha$, where $\alpha$ can be the gas, liquid, or solid phase. 171 In addition, $k_{T}^{\text {eff }}$ is the effective thermal conductivity (see Calculation 172 of effective properties sec.) and $S_{T}$ denotes the heat source term (see 173 Table II). Note that this equation captures heat transfer by conduction 174 (first term on the right hand side) as well as convection (second term 175 on the left hand side).

$176 \quad$ Equations 6 and 7 are the Ohm's law for electronic $\left(\phi_{1}\right)$ and ionic $177\left(\phi_{2}\right)$ potentials, respectively. Here, $\sigma_{1}^{\text {eff }}$ and $\sigma_{2}^{\text {eff }}$ denote the effective 178 conductivities of the respective phases and $S_{H^{+} / e^{-}}$is the relevant source 179 term (see Table II).

180 The source terms for mass conservation equations (Equations 1-4) 181 are given in Table I. Here, $M_{i}$ is the molar mass of species $i, i_{\mathrm{HOR} / \mathrm{ORR}}$ 182 is the volumetric HOR/ORR reaction current density, and $S_{\mathrm{pc}}$ is the 183 source term due to phase change and is given by: ${ }^{19}$

$$
S_{\mathrm{pc}}=\left\{\begin{array}{l}
k_{\mathrm{evp}} a_{\mathrm{LG}}\left[\frac{p_{v}-p_{\mathrm{sat}}^{K}\left(p_{c}, T\right)}{p_{\mathrm{sat}}^{K}\left(p_{c}, T\right)}\right] \text { if } p_{v}>p_{\mathrm{sat}}^{K}\left(p_{c}, T\right) \\
k_{\mathrm{cnd}} a_{\mathrm{LG}}\left[\frac{p_{v}-p_{\mathrm{sat}}^{K}\left(p_{c}, T\right)}{p_{\mathrm{sat}}^{K}\left(p_{c}, T\right)}\right] \text { if } p_{v} \leq p_{\mathrm{sat}}^{K}\left(p_{c}, T\right)
\end{array}\right.
$$

184 where $k_{\mathrm{evp} / \mathrm{cnd}}$ denotes the rate of evaporation/condensation, $a_{\mathrm{LG}}$ is the 185 interfacial area between the liquid and gas phases (calculated by the 186 mixed wettability model), $p_{v}$ is the vapor pressure, and $p_{\mathrm{sat}}^{K}\left(p_{c}, T\right)$ 187 is the corrected saturation pressure that takes the Kelvin effect into 188 account. The corrected saturation pressure is given by:

$$
p_{\text {sat }}^{K}\left(p_{c}, T\right)=p_{\text {sat }}(T) \exp \left(\frac{M_{H_{2} O} p_{c}}{R \rho_{v} T}\right) .
$$

189 In the above equation, $p_{c}$ is the capillary pressure $\left(p_{c}=p_{l}-p_{g}\right), R$ is 190 the universal gas constant, $\rho_{v}$ is the density of water vapor, and $p_{\text {sat }}(T)$ 191 is the saturation pressure as a function of temperature given by:

$$
p_{\text {sat }}(T)=0.61121 \exp \left[\left(18.678-\frac{T}{234.5}\right) \frac{T}{257.14+T}\right]
$$

192 where $T$ is in Celsius and the calculated pressure is in $\mathrm{kPa}$.

193 In Table I, $S_{\text {ad }}$ denotes the source term due to water exchange 194 (absorption/desorption) between the ionomer phase and the pore space and is given by:

$$
S_{\mathrm{ad}}=\frac{k_{\mathrm{ad}} \cdot \rho_{\mathrm{ion}}}{\delta_{\mathrm{CL}} \cdot E W}\left(\lambda^{*}-\lambda\right),
$$

where $k_{\text {ad }}$ is the interfacial water transfer coefficient (see Table III), 196 $\delta_{\mathrm{CL}}$ denotes the CL thickness, and $\lambda^{*}$ is the dynamic variable for equi- ${ }_{197}$ librium water content in the ionomer (see Ionomer water uptake Sec.). 198 Note that water production with electrochemical reaction contributes 199 to $S_{\lambda}$. In other words, the produced water is assumed to be in absorbed 200 phase. This is in agreement with the assumed structure for the CL in 201 this work and has also been used by others. ${ }^{9}$

The source terms for energy and charge conservation (Equations 203 5-7) are given in Table II. In the table, $\boldsymbol{i}_{1}$ and $\boldsymbol{i}_{2}$ are the electronic and 204 ionic current densities, respectively:

$$
\begin{aligned}
& \boldsymbol{i}_{1}=-\sigma_{1}^{\text {eff }} \nabla \phi_{1} \\
& \boldsymbol{i}_{2}=-\sigma_{2}^{\text {eff }} \nabla \phi_{2}
\end{aligned}
$$

Moreover, $H_{\mathrm{HOR} / \mathrm{ORR}}$ denotes the reversible and irreversible heat of 206 reaction given by:

$H_{\mathrm{HOR}}=i_{\mathrm{HOR}}\left(\eta_{\mathrm{HOR}}+\Pi_{\mathrm{HOR}}\right)=i_{\mathrm{HOR}}\left[\left(\phi_{1}-\phi_{2}-E_{\mathrm{rev}}^{\mathrm{an}}\right)-0.013 \frac{T}{298.15}\right]$

$H_{\mathrm{ORR}}=i_{\mathrm{ORR}}\left(\eta_{\mathrm{ORR}}+\Pi_{\mathrm{ORR}}\right)=i_{\mathrm{ORR}}\left[\left(\phi_{1}-\phi_{2}-E_{\mathrm{rev}}^{\mathrm{ca}}\right)-0.24 \frac{T}{298.15}\right]$

where $\Pi_{\mathrm{HOR} / \mathrm{ORR}}$ is the Peltier coefficient for HOR/ORR, ${ }^{30} E_{\mathrm{rev}}^{\mathrm{an}}=0, \quad 209$ and $E_{\mathrm{rev}}^{\mathrm{ca}}=1.229-8.5 \times 10^{-4} \times(T-298.15)+\frac{R T}{4 F} \ln \left(p_{O_{2}}\right)$ are the 210 reversible potentials in each electrode.

The enthalpy of phase change, $H_{\mathrm{pc}}$, is :

$$
\begin{aligned}
& H_{\mathrm{pc}}=-2.367 \times 10^{-5} T^{4}+1.882 \times 10^{-2} T^{3}-4.672 T^{2} \\
& -2.098 \times 10^{3} T+3.178 \times 10^{6}[\mathrm{~J} / \mathrm{kg}],
\end{aligned}
$$

where $T$ is in Kelvin. Finally, $H_{\text {ad }}$ is the heat of sorption (due to water 213 exchange between the ionomer and the pore space, i.e., water vapor) 214 and is given by: ${ }^{31}$

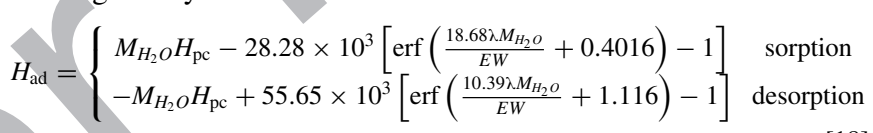

Ionomer water uptake.-It is imperative for any transient model 216 of a PEM fuel cell to properly capture the dynamics of water sorp- 217 tion, desorption, and transport across the membrane. Historically, 218 diffusive $^{29}$ and hydraulic ${ }^{32}$ type models have been used for this pur- 219 pose. However, there is abundant evidence in the literature suggest- 220 ing that interfacial transport phenomena as well as swelling of the 221

$$
\text { Table III. Membrane water transport and uptake properties. }
$$

\begin{tabular}{cc} 
Property [Units] & Equation \\
\hline$n_{d}[-]^{25}$ & $1.2 \tanh \left(\frac{\lambda}{2.5}\right)$ \\
$D_{\mathrm{w}, \mathrm{mb}}^{\mathrm{eff}}\left[\frac{\mathrm{cm}^{2}}{\mathrm{~s}}\right]^{26}$ & $0.0539 \times\left(1+\frac{M_{H_{2} O \rho_{\text {ion }}}}{E W}\right)^{-2}\left(1+0.0027 \lambda^{2}\right)\left[1+\tanh \left(\frac{\lambda-2.6225}{0.8758}\right)\right] \exp \left(\frac{-3343}{T}\right)$ \\
$D_{T, \mathrm{mb}}\left[\frac{\mathrm{mol}}{\mathrm{cm} \cdot \mathrm{K})}\right]^{24}$ & $\frac{1.04 \times 10^{-4}}{M_{\mathrm{w}}} \exp \left(-\frac{2362}{T}\right)$ \\
$k_{\mathrm{ad}}\left[\frac{\mathrm{cm}}{\mathrm{s}}\right]^{27}$ & $1.14 \times 10^{-5} f_{v} \exp \left[2416\left(\frac{1}{303}-\frac{1}{T}\right)\right]$ for absorption \\
& $4.59 \times 10^{-5} f_{v} \exp \left[2416\left(\frac{1}{303}-\frac{1}{T}\right)\right]$ for desorption \\
& $f_{v}=\frac{18 \lambda}{\frac{E W}{\rho_{\text {ion }}}+18 \lambda}$ is the water volume fraction in ionomer \\
& $(1-s)\left[\lambda_{303}+\frac{\lambda_{353}-\lambda_{303}}{50}(T-303)\right]+22 s$ \\
$\lambda_{\text {eq }}[-]^{27-29}$ & $\lambda_{303}=0.043+17.81 a-39.85 a^{2}+36.0 a^{3}$ \\
& $\lambda_{353}=0.300+10.8 a-16.0 a^{2}+14.1 a^{3}$ \\
& $a=R H$, and $s$ is the local liquid saturation
\end{tabular}


222 polymer backbone may play a significant role in water uptake and 223 transport dynamics. ${ }^{33,34}$ In particular, the gravimetric water uptake 224 experiments conducted by Satterfield et al. have shown very long time 225 constants for membrane water sorption while the desorption time con226 stants were found to be an order of magnitude smaller. ${ }^{34}$ They sug227 gested that the sorption behavior may be explained through the con228 tributions of interfacial water transport and stress relaxation in the 229 polymer, whereas the desorption dynamics are dominated by the in230 terfacial phenomena. Their experiments included a step in the hu231 midity from fully dry to fully saturated conditions that resulted in 232 significant relaxation behavior. Other studies have found much less 33 pronounced impact of the relaxation dynamics when the membrane 34 was subjected to smaller changes in the humidity conditions. ${ }^{35}$ Similar 35 results have been reported for ionomer thin films. ${ }^{36}$ Dynamic vapor 36 sorption (DVS) experiments by Kusoglu et al. have also shown rela237 tively long water uptake times with a time constant that increases with membrane hydration. ${ }^{37,38}$ Their results also indicate that the asymmetry between sorption and desorption is not as pronounced as that observed in Satterfield et al.'s experiments. Such significant difference was also challenged by Silverman et al. who found the desorption to be only about twice faster than sorption. ${ }^{39}$ In situ measurements of membrane swelling and hydration by GM researchers have also found the hydration and dehydration rates to be similar. ${ }^{40}$

Based on the preceding discussion, it stands to reason to incorporate the slow ionomer water uptake process into the model. Silverman et al. have developed a coupled transport and mechanical model that captures such phenomena. ${ }^{31,39}$ However, adding the mechanical model will result in additional complexity that must be avoided for the purpose of performance modeling. Therefore, we simply use a dynamic variable to represent the quasi-equilibrium water content: ${ }^{15,41,42}$

$$
\lambda^{*}=(1-\varphi) \lambda_{\text {eq }}+s_{\text {relax }},
$$

252 where $\varphi$ determines the contribution of relaxation phenomena to the 253 ionomer water uptake (a value of 0.15 is used for the simulations in 254 this work), and $s_{\text {relax }}$ is a variable accounting for the dynamics of stress 255 relaxation. In particular, its dynamics are assumed to be first order:

$$
\dot{s}_{\text {relax }}=-\frac{1}{\tau}\left(s_{\text {relax }}-\varphi \lambda_{\text {eq }}\right),
$$

256 where $\lambda_{\text {eq }}$ is the equilibrium water content given in Table III and $\tau$ is 257 the relaxation time constant defined as:

$$
\tau=\exp (2+0.2 \lambda) \text {. }
$$

258 Note that the time constant was chosen to vary with the ionomer 259 water content in accordance with evidence in the literature for this 260 dependence. ${ }^{37}$ Moreover, the stress relaxation is supposedly a ther261 mally activated process. ${ }^{34,43}$ Therefore, it would be reasonable to as262 sume an Arrehnius type temperature dependence for the associated 263 time constant, which is not included here. Moreover, the effects of 264 compressive stresses on membrane water uptake, ${ }^{40,44}$ and the con265 tentiously debated discrepancy between water uptake by ionomer thin 266 film and bulk ionomer ${ }^{36,37}$ are not taken into account in the model. 267 Future parametric studies should aim at investigating these effects 268 along with the effects of changes to the relaxation model parameters 269 to understand their impact on the overall dynamic response of the cell.

Catalyst layer model.-Conventional catalyst layers of PEM fuel 271 cells consist of Pt catalyst particles dispersed on ionomer bound car272 bon primary particles. The Pt particle size is in the range of $2-15 \mathrm{~nm}$, 273 while the primary carbon particles may have sizes of up to $80 \mathrm{~nm}$ based 274 on the type of carbon support used. Early models of PEM fuel cells 275 regarded CLs as interfaces with no consideration of their structural 276 features. However, the significance of these structural features to the 277 cell performance has been established. A particularly important issue 278 that has resulted in significant efforts in CL modeling is the additional 279 transport resistance observed at lowered Pt loading or with high loaded 280 electrodes after degradation inducing cycles. ${ }^{45,46}$ The experimental ap281 proach has utilized limiting current measurements with varying gas 282 composition and/or pressure to separate the pressure dependent and pressure independent transport resistances. ${ }^{47}$ The transport resistance 283 in the CL is almost entirely independent of pressure and can be esti- ${ }_{284}$ mated with such limiting current measurements. Using this approach, 285 it has been found that the CL transport resistance increases at lower Pt 286 loadings $s^{48-53}$ and this increase is strongly dependent on the available 287 $\mathrm{Pt}$ area for reaction. Therefore, the resistance appears to be due to 288 the increased flux near each active site at lower loadings. ${ }^{1}$ Tempera- 289 ture sensitivities were used to determine the contributions of Knudsen 290 diffusion and permeation through the ionomer thin film to the elec- 291 trode transport resistance. ${ }^{54}$ The ionomer thin film was found to be the 292 dominant cause of transport resistance in the CL. More recently, the 293 impact of carbon support and its porous structure on the local reactant 294 and bulk protonic transport resistances have been highlighted. ${ }^{2,55}$ Par- 295 ticularly, micro-pores with an opening smaller than $2 \mathrm{~nm}$ have been 296 found to limit the reactant access to the Pt deposited inside the carbon 297 pores. Despite such efforts, the root cause of the increased resistance 298 remains largely unknown. ${ }^{56}$ Several hypotheses have been made, but 299 neither has been thoroughly validated.

Numerous models have been proposed to investigate the distribution of critical variables throughout the CLs and unveil the cause of increased transport resistance at lower loadings. The agglomerate model has been the most popular one for this purpose. In this model, the Pt particles are assumed to be dispersed on the primary carbon particles, many of which are assumed to aggregate during the fabrication process to form larger agglomerates covered by an ionomer thin film. The pore space in the CL is divided into two parts: the primary pores between carbon particles in each agglomerate, and the secondary pores formed between the agglomerates. Several yariations of this model have been proposed where the intra-agglomerate space is either filled with water (i.e., water-filled agglomerates) ${ }^{57,58}$ or ionomer (i.e., ionomer-filled agglomerates). ${ }^{59,60}$

Initially, a wide range of agglomerate sizes $(100-1000 \mathrm{~nm})$ had been used and significant variations of the ionomer film thickness $(10-100 \mathrm{~nm})$ had been reported to match the experimental data. ${ }^{61,62}$ Cetinbas et al. have developed a hybrid method for reconstruction of CL microstructure ${ }^{63,64}$ and reported an agglomerate size distribution between 25 to $300 \mathrm{~nm}$ with most agglomerates having a radius in the range of 75 to $200 \mathrm{~nm} .{ }^{64}$ Furthermore, the upper limit of the modeling values for the agglomerate size and film thickness is not corroborated by microscopy studies. ${ }^{65}$ Therefore, the validity of this structural picture has come under further scrutiny. In light of these experimental observations, some have argued that the agglomerates probably do not exist and have proposed homogeneous models for the electrode. ${ }^{62}$ Others have continued to use the agglomerate models with agglomerate radii as small as $40 \mathrm{~nm},{ }^{22,66}$ which is essentially the size of a carbon primary particle. Of particular interest is the work by Nissan researchers ${ }^{66}$ who showed that the conventional flooded-agglomerate model is not capable of reproducing experimental results with small agglomerate size and partial ionomer coverage. They modified the model to incorporate transport resistance near the electrochemical surface and showed that the modified model successfully predicted the experimental trends. Generally, more recent models rely on interfacial resistance at either the ionomer-gas or the Pt-ionomer interface or both to reproduce experimental transport resistance values. Jinnouchi et al. used molecular dynamics simulations to associate such resistance with a dense ionomer layer near the Pt surface ${ }^{67}$ Overall, attributing the additional resistance to interfacial phenomena has become increasingly common in the literature.

Despite its commonality, the interfacial resistance has not been experimentally verified. In fact, Liu et al. measured transport resistance in ionomer thin films and found no evidence of interfacial resistance when $3 \mathrm{D}$ diffusion was taken into account. ${ }^{68}$ The uncertainty surrounding ionomer thin film properties, such as water uptake, ${ }^{36,69-71}$ ionic conduction, ${ }^{72}$ and gas permeation, ${ }^{65}$ which can be significantly affected by confinement and substrate interactions, ${ }^{73}$ has further contributed to the ambiguity of the source of this increased resistance. Some recent works have disputed the interfacial resistances or downplayed its significance. Darling has proposed an agglomerate model in which the increased resistance is mostly attributed to the 303 5 86 8 9 1 2 3 295 296 298 300 301 302 304 305 306 307 308 309 310 311 312 
352 spherical diffusion through the agglomerate. ${ }^{74}$ Others have investi353 gated the inhomogeneity of mass fluxes near the Pt particles in ag354 glomerates and the overlap between several agglomerates as possible 355 culprits. $^{75,76}$ Most recently, Muzaffar et al. ${ }^{77}$ have investigated litera356 ture data with a previously developed agglomerate model ${ }^{78}$ and found 357 that the reduction in Pt loading probably leads to higher levels of flood358 ing in both the CL and GDL due to reduced vaporization capability of 359 the CL with decreased thickness. They also elevated the fact that both ${ }_{360}$ experimental ${ }^{79}$ and numerical studies ${ }^{80,81}$ show only partial coverage 361 of catalyst particles with ionomer, leaving an alternative transport path 362 for oxygen to reach the active sites without facing the interfacial re363 sistance at the Pt-ionomer interface. Therefore, they concluded that 364 the increased transport resistance may be attributable to reduced oxy365 gen diffusivity due to pore blocking effects of liquid water and the 366 interfacial resistance does not play a significant role. The importance 367 of water management in successful use of low loaded electrodes was 368 also pointed out by Srouji et al. ${ }^{82}$

369 The preceding literature review shows that the structural picture of 370 the electrodes and the understanding of the factors that contribute to 371 the transport resistance are still incomplete. Therefore, further model 372 development and experimental investigations are required. Neverthe373 less, it should be noted that for the purpose of a full cell simulation, 374 most of the proposed models can be parameterized to capture the lo375 cal oxygen transport resistance, which is the most critical outcome 376 of such models. Moreover, Kulikovsky has demonstrated that under 377 certain conditions that are most relevant to typical fuel cell operation, 378 the agglomerate model is not required. ${ }^{83}$ Therefore, unless the goal 379 of the model is to investigate different electrode designs at the nano380 scale, a homogeneous model will be sufficient. Here, we use the model 381 proposed by Hao et al., ${ }^{62}$ which was shown to appropriately capture 382 the increased resistance at lower loadings. The model achieves this 383 by assuming full ionomer coverage and introducing rather significant 384 interfacial resistances, which, in light of the above discussion, are dis385 putable. Nevertheless, it is the general trend of the variations in the 386 transport resistance that is required for our purposes. The model is 387 briefly presented here and the reader is referred to the original publi388 cation for further details. ${ }^{62}$

The model assumes Pt particles are deposited on primary carbon 390 particles that are covered by an ionomer thin film. Liquid water in the 391 pores of the electrode forms a thin film on top of the ionomer. This 392 structural picture is used to derive the volume fraction of each phase 393 (Pt, carbon, ionomer, and pore space) in both the anode and cathode 394 CLs. However, the local transport resistance to hydrogen in the anode $395 \mathrm{CL}$ is assumed negligible and the calculations are only carried out for 396 oxygen transport resistance. The oxygen in the pore space has to (1) 397 dissolve in water, (2) diffuse through the water film, (3) dissolve in 398 ionomer, (4) diffuse through the ionomer film, and (5) be adsorbed 399 on the Pt surface. The model does not account for spherical diffusion, 400 but uses instead a 1D diffusion equation to calculate the local flux of 401 oxygen:

$$
N_{O_{2}}=\frac{c_{O_{2}}^{\text {pore }}-c_{O_{2}}^{\mathrm{Pt}}}{R_{\mathrm{T}}}
$$

402 where $\mathrm{N}_{\mathrm{O}_{2}}, c_{\mathrm{O}_{2}}^{\text {pore }}$, and $c_{\mathrm{O}_{2}}^{\mathrm{Pt}}$ are the oxygen flux near the Pt surface, 403 oxygen concentration in the $\mathrm{CL}$ pore space, and its concentration at 404 the Pt surface, respectively. $R_{\mathrm{T}}$ is the total local transport resistance:

$$
R_{\mathrm{T}}=R_{\mathrm{w}, \text { int }}+\frac{\delta_{\mathrm{w}}}{D_{\mathrm{O}_{2}, \mathrm{w}}}+R_{\mathrm{ion}, \text { int }}+\frac{\delta_{\mathrm{ion}}^{\text {eff }}}{D_{\mathrm{O}_{2}, \text { ion }}}+R_{\mathrm{Pt}, \text { int }}^{\mathrm{eff}},
$$

405 where the first, third, and last terms describe the interfacial resistances 406 at the liquid film, ionomer film, and Pt surfaces, respectively. The 407 fractional terms denote diffusional resistance through the water and 408 ionomer thin films. A key argument made in developing the model 409 is a geometrical one, where an effective diffusion length through the 410 ionomer is calculated based on the effective surface area of a single 411 Pt particle and the effective ionomer surface area available for that 412 particle:

$$
A_{\mathrm{Pt}}^{\mathrm{eff}}=4 \pi r_{\mathrm{Pt}}^{2} \theta_{\mathrm{Pt}}
$$

$$
A_{\mathrm{ion}}^{\mathrm{eff}}=\frac{4 \pi\left(r_{\mathrm{c}}+\delta_{\mathrm{ion}}\right)}{n_{\mathrm{Pt}}},
$$

where $r_{\mathrm{Pt}}$ and $r_{\mathrm{c}}$ are the $\mathrm{Pt}$ and carbon primary particle radii, respec- $\quad 413$ tively, $\theta_{\mathrm{Pt}}$ denotes the fraction of Pt surface not covered with oxide 414 species (see Reaction kinetics Sec.), $\delta_{\text {ion }}$ is the ionomer film thick- 415 ness, and $n_{\mathrm{Pt}}$ is the number of Pt particles deposited on a single carbon $\quad 416$ particle. The effective ionomer film thickness is then calculated by: ${ }_{417}$

$$
\delta_{\text {ion }}^{\text {eff }}=\frac{A_{\text {ion }}^{\text {eff }}}{A_{\mathrm{Pt}}^{\text {eff }}} \delta_{\text {ion }} .
$$

The same scaling factor is used to scale the interfacial resistance at 418 the Pt surface:

$$
R_{\mathrm{Pt}, \text { int }}^{\mathrm{eff}}=\frac{A_{\mathrm{ion}}^{\mathrm{eff}}}{A_{\mathrm{Pt}}^{\text {eff }}} R_{\mathrm{Pt} \text {,int }} .
$$

This scaling is one of the most important features of the model as it 420 compensates for the fact that 3D spherical diffusion is neglected, and 421 allows for the effects of high fluxes near sparsely deposited Pt particles 422 to be captured by the model. It is imperative, however, to be cautious 423 and not put too much emphasis on the source of the local transport 424 resistance in this model. As mentioned earlier, the electrode structure 425 assumed in this model is contentious. Nevertheless, on a macro-level, 426 the predictions match the experimental observations, which is the most $\quad 427$ important aspect for full cell simulations.

Finally, another important assumption made in the model is that the ${ }_{429}$ interfacial resistances are proportional to the diffusional resistances. 430 This is done due the lack of measured data for the interfacial resistances 431 at various interfaces. In particular, three fitting parameters $k_{1}, k_{2}$, and 432 $k_{3}$ are introduced:

$$
R_{\text {ion, int }}=k_{1} \frac{\delta_{\text {ion }}}{D_{O_{2}, \text { ion }}}, R_{\mathrm{Pt} \text {,int }}=k_{2} \frac{\delta_{\text {ion }}}{D_{O_{2}, \text { ion }}}, R_{\mathrm{w}, \text { int }}=k_{3} \frac{\delta_{\mathrm{w}}}{D_{O_{2}, \mathrm{w}}}
$$

Therefore, the various terms contributing to the transport resistance 434 are identified. Noting that:

$$
N_{O_{2}}=-\frac{i_{\mathrm{ORR}}}{4 F a_{c} x}
$$

where $i_{\mathrm{ORR}}$ is the volumetric ORR current density, $a_{c}$ is the volumetric 436 surface area of the ionomer, and $x$ is the number fraction of carbon ${ }_{437}$ supported Pt particles (used to model the effects of catalyst dilution by bare carbon), Equation 22 can be written as:

$$
R_{\mathrm{T}}=\frac{4 F a_{c} x\left(c_{\mathrm{O}_{2}}^{\text {pore }}-c_{\mathrm{O}_{2}}^{\mathrm{Pt}}\right)}{i_{\mathrm{ORR}}} .
$$

This algebraic equation can be solved numerically to find the oxygen 440 concentration at the Pt surface. It is worth pointing out that an ana- 441 lytical solution is possible in the case that reaction order is assumed 442 to be unity for ORR. ${ }^{62}$ Nevertheless, such an assumption may be un- ${ }_{443}$ realistic and in some cases inconsistent with the ORR kinetics model 444 (see Reaction kinetics sec.). Therefore, we use the numerical solu- 445 tion with no assumption on the reaction order for ORR to avoid such 446 inconsistencies.

It is also important to have a consistent set of structural parameters for the CLs. In particular, volume fraction of different phases ought to be known. These volume fractions can be calculated as follows: ${ }^{: 0,63}$

$$
\begin{gathered}
\varepsilon_{\mathrm{c}}=\frac{1}{\rho_{\mathrm{c}}} \frac{L_{\mathrm{c}}}{\delta_{\mathrm{CL}}}, \\
\varepsilon_{\mathrm{Pt}}=\frac{1}{\rho_{\mathrm{Pt}}} \frac{L_{\mathrm{Pt}}}{\delta_{\mathrm{CL}}}, \\
\varepsilon_{\text {ion }}=(I / C) \varepsilon_{\mathrm{c}} \frac{\rho_{\mathrm{c}}}{\rho_{\text {ion }}}\left(1+\frac{M_{\mathrm{H}_{2} O} \rho_{\mathrm{ion}}}{\rho_{l} E W} \lambda\right),
\end{gathered}
$$

where $\varepsilon_{i}$ is the volume fraction of $i, L_{\mathrm{c} / \mathrm{PT}}$ is the carbon/Pt loading, 451 $\rho_{i}$ is the density of $i, \delta_{\mathrm{CL}}$ is the CL thickness, and $(I / C)$ denotes the 452 ionomer to carbon ratio. The remaining CL volume constitutes its pore 453 
454 space $\left(\varepsilon_{\mathrm{CL}}=1-\varepsilon_{\mathrm{c}}-\varepsilon_{\mathrm{Pt}}-\varepsilon_{\mathrm{ion}}\right)$. Finally, the ionomer and liquid water 455 film thicknesses are given by:

$$
\begin{gathered}
\delta_{\text {ion }}=r_{\mathrm{c}}\left[\left(\frac{\varepsilon_{\text {ion }}}{\varepsilon_{\mathrm{c}}}+1\right)^{(1 / 3)}-1\right], \\
\delta_{\mathrm{w}}=\left[s \varepsilon_{\mathrm{CL}}\left(\frac{r_{\mathrm{c}}^{3}}{\varepsilon_{\mathrm{c}}}\right)+\left(r_{\mathrm{c}}+\delta_{\text {ion }}\right)^{3}\right]^{(1 / 3)}-\left(r_{\mathrm{c}}+\delta_{\text {ion }}\right) .
\end{gathered}
$$

456 This completes the CL model used in this work. The reader is referred 457 to $^{62}$ for further details about this model. As for the parameter values, 458 an $I / C$ ratio of 1.1 and an electrochemically active area (ECSA) of 65 $459 \mathrm{~m}_{\mathrm{Pt}}^{2} / \mathrm{gr}_{\mathrm{Pt}}$ are assumed for both anode and cathode CLs. The anode $\mathrm{Pt}$ 460 loading is assumed to be $0.1 \mathrm{mg} / \mathrm{cm}^{2}$ with a $\mathrm{Pt} / \mathrm{C}$ weight percentage 461 of $30 \%$, while the cathode Pt loading is changed between 0.4 and 0.05 $462 \mathrm{mg} / \mathrm{cm}^{2}$, considering a $\mathrm{Pt} / \mathrm{C}$ weight percentage of $40 \%$ in all cases.
463

464
Reaction kinetics.-Accurate models for the HOR and ORR half reactions are required for the model. HOR is known to have facile kinetics and does not result in significant performance loss under most typical conditions. Therefore, it is typically described using a simplified Butler-Volmer kinetics model. Here, we use the dual-pathway kinetics model proposed by Wang et al., ${ }^{84}$ where the volumetric current density is found by:

$$
\begin{aligned}
& i_{\mathrm{HOR}}=a_{\mathrm{Pt}} \frac{c_{\mathrm{H}_{2}}}{c_{H_{2}}^{\mathrm{ref}}}\left[i_{0 T}\left(1-\exp \left(-\frac{2 F \eta_{\mathrm{HOR}}}{\vartheta R T}\right)\right)\right. \\
& \left.+i_{0 H}\left(\exp \left(\frac{F \eta_{\mathrm{HOR}}}{\vartheta R T}\right)-\exp \left(-\frac{F \eta_{\mathrm{HOR}}}{\vartheta R T}-\frac{F \eta_{\mathrm{HOR}}}{2 R T}\right)\right)\right],
\end{aligned}
$$

470 where $a_{\mathrm{Pt}}$ is the active volumetric surface area of Pt, $i_{0 T}$ and $i_{0 H}$ are 471 the exchange current densities for the Tafel and Heyrovsky pathways, 472 respectively, $\vartheta$ is a potential constant, and $\eta_{\mathrm{HOR}}$ is the anode overpo473 tential.

474 The ORR kinetics are more complicated than the HOR and require 475 further attention. Again, various forms of the Butler-Volmer model 476 have been used to describe the ORR kinetics. More recently, the effects 477 of surface coverage have been considered to derive a modified Tafel 478 expression: ${ }^{85}$

$$
i_{\mathrm{ORR}}=-i_{0, \mathrm{ca}} a_{\mathrm{Pt}}\left(1-\theta_{\mathrm{PtO}}\right)\left(\frac{c_{O_{2}}^{\mathrm{Pt}}}{c_{O_{2}}^{\mathrm{ref}}}\right)^{\gamma_{\mathrm{ca}}} \exp \left[-\frac{\alpha_{\mathrm{ca}}}{R T} F \eta_{\mathrm{ORR}}-\frac{\omega \theta_{\mathrm{PtO}}}{R T}\right],
$$

479 where $i_{0, \mathrm{ca}}, \alpha_{\mathrm{ca}}, \eta_{\mathrm{ORR}}, \gamma_{\mathrm{ca}}$, are the cathode exchange current density, 480 transfer coefficient, ORR overpotential and reaction order, respec481 tively, and $\omega$ denotes the energy parameter for the Temkin isotherm. 482 The model results in a potential dependent Tafel slope. The oxide 483 coverage is potential and time dependent as cyclic voltammograms 484 (CV) show considerable difference between the anodic and cathodic 485 sweeps. ${ }^{85}$ A simple sigmoidal curve can be fitted to steady-state 486 measurements: ${ }^{62}$

$$
\theta_{\mathrm{PtO}}=\frac{1}{1+\exp [22.4(0.818-E)]},
$$

487 where $E$ is the cathode potential vs. reference hydrogen electrode 488 (RHE).

489 A more elaborate model for ORR kinetics is the double trap (DT) 490 model originally proposed by Wang et al. ${ }^{86,87}$ The model includes 491 two pathways for oxygen adsorption: a reductive adsorption (RA) and 492 a dissociative adsorption (DA) pathway. The latter is followed by a 493 reductive transition (RT) to adsorbed $\mathrm{OH}$. In either case, the adsorbed ${ }_{494} \mathrm{OH}$ is desorbed through a reductive step (RD) to form water. The 495 original formulation neglected the reverse RD step and concluded that 496 ORR activity is limited by the desorption of strongly adsorbed $\mathrm{O}$ and $497 \mathrm{OH}$. Moore et al. ${ }^{88}$ modified the model by including the backward 498 reactions and refitting the parameters and found ORR to be adsorption 499 limited. Moreover, the coverage of adsorbed species predicted by the 500 modified model tends to zero at high overpotentials, whereas a constant nonzero value was predicted with the original model..$^{86}$ The modified 501 model is in better agreement with the experimental coverage values 502 reported by Subramanian et al. ${ }^{85}$

Other modifications to the DT model have been proposed as well. 504 Markiewicz et al. ${ }^{89}$ added two elementary reactions to the model: a 505 reductive addition of a proton to oxygen molecule, producing an ad- 506 sorbed protonated superoxide, and another reductive addition of proton 507 followed by dissociation into adsorbed $\mathrm{OH}$. Through these modifica- 508 tions, they reported a significant coverage of Pt sites by adsorbed $\mathrm{HO}_{2} \quad 509$ species at high overpotentials. More recently, Jayasankar et al. ${ }^{90}$ re- 510 placed the DA step with an associative adsorption (AA) into adsorbed 511 $\mathrm{HO}_{2}$, which is followed by dissociative transition steps into adsorbed 512 $\mathrm{O}$ and $\mathrm{OH}$. They have also extended the model to include oxide growth 513 mechanisms. Their results corroborate those of Markiewicz et al., as 514 they also find an increase in $\mathrm{HO}_{2}$ coverage at high overpotentials. 515 This can have significance for studies with low loaded catalysts, as 516 it provides another possible explanation for the reduced performance 517 observed experimentally.

In this work, we use the modified DT model proposed by Moore, ${ }^{88}$ as it has been parameterized for fuel cell polarization curves and used by others in full cell simulation. ${ }^{19,22}$ In this model, the ORR current can be described as the current from a single RD step:

$$
i_{\mathrm{ORR}}=a_{\mathrm{Pt}} i^{*}\left[\exp \left(-\frac{\Delta G_{\mathrm{RD}}^{*}}{k T}\right) \theta_{\mathrm{OH}}-\exp \left(-\frac{\Delta G_{-\mathrm{RD}}^{*}}{k T}\right)\left(1-\theta_{\mathrm{O}}-\theta_{\mathrm{OH}}\right)\right],
$$

where $i^{*}$ is a reference prefactor (similar to the exchange current den- ${ }_{523}$ sity in the Butler-Volmer model), $k$ is the Boltzmann constant, $\Delta G_{\mathrm{RD}}^{*} \quad 524$ and $\Delta G_{-\mathrm{RD}}^{*}$ are the potential dependent activation energies of the for- ${ }_{525}$ ward and backward RD step, respectively, and $\theta_{i}$ denotes the coverage 526 of species $i$. The expressions for the activation energies and species 527 coverage can be found in Ref. 88

The DT model is used for simulation case studies. However, when 529 comparing with experimental data, we have chosen to work with the 530 Tafel model in Equation 37 as its parameters are more intuitive and 531 allow for easier parameterization of the model and can also reproduce 532 the kinetic current predicted by the DT model with a varying reaction 533 order. $^{91}$

It should be noted that several effects have been neglected to simplify the model and avoid ambiguity in the results. First, the steadystate coverage profiles are used in the kinetic equations and the dynamics of oxide growth are ignored. These dynamics can be very slow as observed in low frequency impedance spectra ${ }^{92,93}$ and coulometric measurements. ${ }^{94}$ Such dynamics can result in a hysteresis loop in the Tafel plot obtained through CVs even when a low potential prehold is used to reduce the oxide layer. ${ }^{95}$ Therefore, oxide growth dynamics can have a profound impact on current transients, especially at higher potentials. However, including these dynamics adds to the complexity of a model, whose main focus is on mass transport and hydration effects. Hence, the oxide growth dynamics are neglected in this work. It should also be pointed out that the ORR activity is shown to be affected by presence of ionomer. ${ }^{96-98}$ This effect is not explicitly taken into account in the current model, since doing so will add to the uncertainty in the parameter set. Nevertheless, the exchange current density values (or the reference prefactor in the case of the DT model) used are supposed to capture this reduced activity.

Finally, the dependence of ORR kinetics on the relative humidity $(\mathrm{RH})$ is also neglected in this work. This effect was reported by Xu et al. ${ }^{99}$ to be significant, resulting in up to $100 \mathrm{mV}$ difference at dry condition, even when protonic resistance in the $\mathrm{CL}$ was taken into account. ${ }^{100}$ However, work by GM shows much less pronounced effects of RH on ORR kinetics. ${ }^{101,102}$ This discrepancy in the reported values could also be partly due to the effects of RH on water oxidization and subsequent catalyst poisoning. ${ }^{103}$ The accessibility of Pt in the inner pores of porous carbon support is also shown to decrease at low $\mathrm{RH}$ values, which can result in loss of electrochemically active area. ${ }^{104}$ Regardless, the RH effects on ORR kinetics may be included in the model by scaling the exchange current density in the BV model $\left(i_{0}\right)$ or 7 533

0

1

2

4

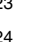
6 530
531

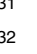


565 the reference prefactor in the DT model $\left(i^{*}\right)$. A scaling factor varying 566 linearly with ionomer water content has been used for this purpose 567 by Gerteisen et al. ${ }^{9}$ More recently, a scaling factor that changes with 568 ionomer water content in a sigmoidal fashion has been proposed, ${ }^{42}$ 569 which is in a better agreement with the experimental trends. Such 570 scaling factors may be treated as fitting parameters in performance 571 models to enhance the predictive capabilities. Nevertheless, we have 572 chosen to leave this factor out, in order to simplify the model and allow 573 for a clearer understanding of the transport phenomena.

$574 \quad$ Mixed wettability model for porous layers.-The main goal of 575 a model for the porous layers is to define a mapping from operat576 ing conditions and material properties to effective charge, heat, and 577 mass transport properties. This problem has been studied on a variety 578 of length scales ranging from microscopic lattice Boltzmann ${ }^{16}$ and 579 pore network modeling studies ${ }^{105}$ to macroscopic models with empir580 ical relationships. ${ }^{106}$ The microscopic models, along with significant 581 advances in experimental techniques to characterize porous layers at 582 higher resolutions, can be used to develop a fundamental understand583 ing of various transport phenomena in such layers. Even though such 584 models cannot be used in full cell simulations due to significant com585 putational requirements, they can be utilized to refine the macroscopic 586 models of lower complexity.

587 Understanding the water phase change process and its transport 588 through the porous layers is also of crucial importance. To this end, 589 one particular model for porous layers that has gained more popularity 590 in recent years is the mixed wettability pore size distribution (PSD) 591 model that was proposed by Weber et al. ${ }^{107}$ The model represents the 592 pores as bundles of cylindrical capillaries that are randomly joined 593 together using log-normal distributions. The key feature of the model 594 is that it accounts for mixed wettability of the layers, which is ignored 595 for the most part in many of the macroscopic models. Therefore, both 596 hydrophilic $(\mathrm{HI})$ and hydrophobic $(\mathrm{HO})$ pores are considered to de597 rive PSDs and contact angles. The original implementation by Weber 598 et al. ${ }^{107}$ assumed the HI and HO PSDs to be identical. Furthermore, a 599 two-point discrete contact angle distribution was assumed. A similar 600 model was used by Eikerling for transport studies in the cathode CL, 601 although he did not consider mixed wettability, choosing to investigate 602 the PSDs due to primary and secondary pores in the CL. ${ }^{108}$ More re603 cently, Villanueva studied effects of different PSDs for the HI and HO 604 pores. ${ }^{20}$ However, recent implementation of the model in a full cell 605 simulation by the same group seems to be using similar PSDs for both $606 \mathrm{HI}$ and $\mathrm{HO}$ pores. ${ }^{19}$ It is worth mentioning that this model was further 607 extended by Weber to include a continuous contact angle distribution 608 (CAD). ${ }^{109}$ This extension was shown to improve the predictive capa609 bilities as well as the numerical robustness of the model for use in full 610 cell simulations. A continuous CAD with a discrete PSD was used by

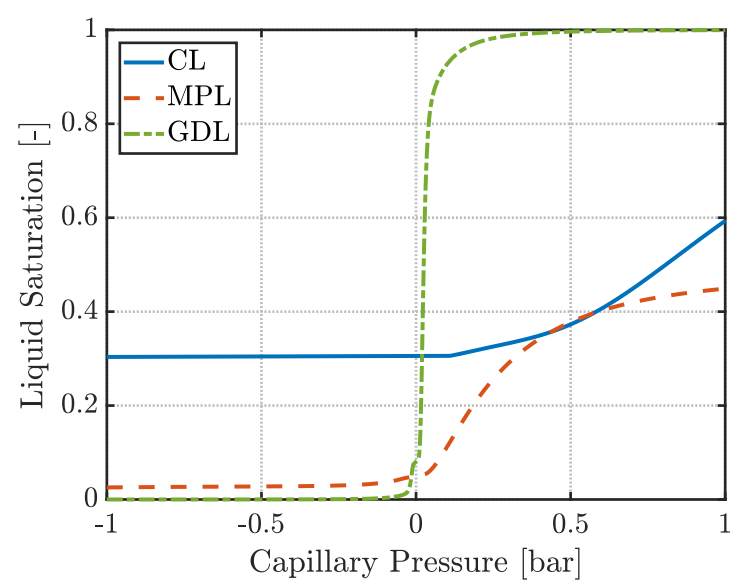

Figure 2. Water retention curves used in this work for the different porous layers.

Cheung et al. ${ }^{110}$ Nevertheless, adoption of the continuous CAD has 611 remained minimal in the literature due to unavailability of CAD for 612 most of the porous layers of interest.

This work utilizes the mixed wettability model with an implemen- 614 tation that allows for different PSDs to be used for HI and HO pores 615 and also includes the continuous CAD. However, we obtain PSDs and 616 contact angles from the literature, and therefore our implementation 617 coincides with the original implementation by Weber et al. ${ }^{107}$ when 618 continuous CAD is not available.

The model equations can be found in the literature ${ }^{20,109}$ and are 620 omitted here for space considerations. The inputs to the model include 621 the PSDs, the fraction of HI pores, and CADs (currently two-point 622 discrete CADs are used). The model is used to obtain water retention 623 curves (liquid saturation vs. capillary pressure), relative permeabilities 624 of the gas and liquid phases, Knudsen radii, and liquid-gas interfacial 625 area available for phase change in the CLs, MPLs, and GDLs. The 626 model calculations are conducted off-line and the resulting curves 627 are used in the full cell simulations using cubic-spline fitting. The ${ }_{628}$ model parameters used for the simulation case studies in this work 629 are presented in Table IV and the resulting water retention curves 630 are shown in Fig. 2. The CL parameters used in this study are those 631 reported by Mashio et al. ${ }^{111}$ who obtained experimental PSDs through 632 nitrogen adsorption. In particular, the PSD for a CL with graphitized 633 Ketjen Black carbon support and an ionomer to carbon ratio of 0.9634 is used here. The MPL and GDL PSDs are those reported by Zhou 635

\begin{tabular}{|c|c|c|c|c|}
\hline \multirow[b]{2}{*}{ Parameter } & & \multicolumn{3}{|c|}{ Value } \\
\hline & & $\mathrm{CL}(\mathrm{GKB})^{111}$ & MPL (SGL 24) $)^{23}$ & GDL $(\text { SGL } 24)^{19}$ \\
\hline \multirow[t]{4}{*}{ Characteristic pore radii $[\mu \mathrm{m}]$} & $r_{1}$ & 0.002 & 0.072 & 14.2 \\
\hline & $r_{2}$ & 0.006 & 0.125 & 34 \\
\hline & $r_{3}$ & 0.025 & 2 & - \\
\hline & $r_{4}$ & 0.080 & - & - \\
\hline \multirow[t]{4}{*}{ Characteristic pore widths } & $s_{1}$ & 0.60 & 0.35 & 1.00 \\
\hline & $s_{2}$ & 0.60 & 0.50 & 0.35 \\
\hline & $s_{3}$ & 0.45 & 0.90 & - \\
\hline & $s_{4}$ & 0.80 & - & - \\
\hline \multirow[t]{4}{*}{ Characteristic pore fractions } & $f_{1}$ & 0.05 & 0.45 & 0.28 \\
\hline & $f_{2}$ & 0.12 & 0.10 & 0.72 \\
\hline & $f_{3}$ & 0.73 & 0.45 & - \\
\hline & $f_{4}$ & 0.10 & - & - \\
\hline Hydrophilic volume fraction & $F_{\mathrm{HI}}$ & 0.30 & 0.05 & 0.08 \\
\hline Hydrophilic contact angle & $\theta_{\mathrm{HI}}$ & 55 & 84 & 70 \\
\hline Hydrophobic contact angle & $\theta_{\mathrm{HO}}$ & 91 & 110 & 122 \\
\hline
\end{tabular}


636 et al. ${ }^{19,23}$ for SGL 34 series that are also applicable for the SGL 24 637 series used in this work.

${ }_{638}$ It should be noted that, as has been shown by Zenyuk et al., ${ }^{17}$ 639 the GDL PSD changes with compression. Therefore, it seems rea640 sonable to use a PSD corresponding to higher compression under the 641 land compared to the one used under the channel. However, using the 642 PSDs that were reported for SGL series by Zenyuk et al. under various 643 compressions, ${ }^{17}$ we found that the effective transport properties of in644 terest show little change with the PSD variations at the compression 645 levels of interest ( 1 to $1.5 \mathrm{MPa}$ ). Therefore, the changes in the PSD 646 with compression under the land are ignored in this work. Finally, as 647 it has been alluded to by Weber, ${ }^{109}$ the bundle of capillaries model 648 breaks down for wide PSDs, which in turn results in very low relative 649 permeabilities predicted by the model. We have found this to be es650 pecially problematic for the MPL. Therefore, a 5-th order power law 651 is used to estimate the liquid and gas phase relative permeabilities for 652 the MPL.

Calculation of effective properties.-To complete the model for654 mulation, effective properties, such as gas diffusivity and thermal con655 ductivity values are needed. Some of the layers demonstrate rather 656 considerable anisotropy due to their heterogeneous structure, which 657 should be taken into account. Furthermore, the effects of nonuniform 658 compression under the channel and lands should be considered to ob659 tain an accurate in-plane distribution of the variables of interest. ${ }^{40,112}$ 660 Accordingly, we have carefully examined the literature for the reported 661 values of such transport properties. When applicable, the land-channel 662 variations in parameter values are applied in a continuous fashion us663 ing sigmoid functions. This is in better agreement with the observed 664 pressure distribution and also simplifies numerical convergence.

665 In this work, we use SGL 24BC and Nafion 211 as the diffusion 666 media and membrane, respectively. These materials are chosen due to 667 their standard application in the fuel cell literature and an abundance 668 of experimental characterization data available for them. The layer 669 thickness and porosities are listed in Table V. Note that a compressed 670 GDL thickness is assumed based on a compressive load of $1 \mathrm{MPa}$, 671 which is expected to result in a strain of about $0.2 .{ }^{115}$ While a uniform 672 thickness is used for both the channel and land locations, the collapse 673 of pore space is applied to the land area, where a reduced porosity 674 of 0.69 is used for the GDL. The CL, and MPL are assumed to be 675 incompressible. Furthermore, note that Nafion 211 has no reinforce676 ment, yielding $\varepsilon_{\text {ion }}=1$ in the membrane region. Finally, it should 677 be pointed out that an intermediate composite region is believed to 678 exist between the MPL and GDL with transport properties that are 679 considerably different from those of either layers. Since the proper680 ties of this intermediate region are not well known, it is not explicitly 681 modeled in this work. The material property variations between adja682 cent layers are taken into account using smooth sigmoid functions to 683 improve convergence. A detailed discussion of the effective transport 684 properties used in the simulation studies follows

685 - In calculating the diffusivity of species $i$ 686 contributions from both molecular and Knudsen diffusion are taken 687 into account: where $D_{\mathrm{Kn}, i}$ is the Knudsen diffusivity and $D_{\text {mix }, i}$ is the molecular diffusion coefficient. Knudsen diffusivity is given by:

$$
D_{\mathrm{Kn}, i}=\frac{2 r_{\mathrm{Kn}}}{3} \sqrt{\frac{8 R T}{\pi M_{i}}},
$$

where $r_{\mathrm{Kn}, i}$ is the Knudsen radius of the porous layer, which is obtained 690 from the mixed wettability model in this work, and $M_{i}$ is the molecular 691 mass of species $i$. The molecular diffusion coefficient is given by: ${ }^{16}$

$$
D_{\text {mix }, i}=\left(\sum_{j=1, j \neq i}^{N_{s}} \frac{x_{j}}{D_{i, j}}\right)^{-1}
$$

where $x_{j}$ is the molar fraction of species $j$ and $D_{i, j}$ denotes the binary 693 diffusion coefficient of species $i$ in $j .{ }^{117}$ With $D_{i}$ available, the effective ${ }^{694}$ diffusivity is calculated as

$$
D_{i}^{\mathrm{eff}}=f(\varepsilon) g(s) D_{i},
$$

which accounts for the tortuous pathway for gas transport inside the 696 porous layers as well as the pore blocking effects of liquid water ac- 697 cumulation. Several microstructure-property functional relationships 698 have been proposed for both $f(\varepsilon)$ and $g(s)$ in the literature, most of 699 which take the form of a power law. ${ }^{118,119}$ Zamel et al. provide a good 700 review of the relevant literature on this topic. ${ }^{120}$ In this work, since 701 we consider SGL $24 \mathrm{BC}$ as the diffusion medium, we have used the following relationship for $f(\varepsilon)$ recently suggested by Holzer et al.: ${ }^{121}$

$$
\begin{aligned}
& f(\varepsilon)_{\mathrm{IP}}=1.074 \varepsilon-0.335, \\
& f(\varepsilon)_{\mathrm{TP}}=0.906 \varepsilon-0.252,
\end{aligned}
$$

where the subscripts IP and TP stand for the in-plane and through- 704 plane directions, respectively. These relationships were suggested for 705 SGL 25BA series, which do not have the MPL coating. Due to lack of 706 data, the same relationships are used for the MPL. The reader should 707 be cautious in applying these relationships to other types of diffusion 708 layers, as they are explicitly derived for SGL carbon papers. Typi- 709 cal power laws are better applicable in general and are suggested for 710 different types of diffusion layers.

$$
\text { As for } g(s) \text {, the following relationships are used: }:^{118}
$$

$$
\begin{aligned}
& g(s)_{\mathrm{IP}}=(1-s)^{2.25}, \\
& g(s)_{\mathrm{TP}}=(1-s)^{2.15} .
\end{aligned}
$$

These relationships were determined for Toray carbon papers and are 713 used here due to lack of data for SGL series. It should be noted that 714 the nearly isotropic relationships were developed for local conditions, 715 i.e., domains with flat saturation distributions. ${ }^{122}$ In contrast, Niu et al. 716 found a more significant difference between the liquid saturation ef- 717 fects on the in-plane and through-plane diffusion coefficients, fitting 718 the results with cubic and quadratic power laws, respectively. ${ }^{119}$ There- 719 fore, such functional relationships should not be taken for granted. 720 Rather, we believe that it is a better practice to leave the order of de- 721 pendence as a fitting parameter when experimental performance data are available.

Finally, the correction factor for effective diffusivity calculations in the CL is calculated as follows: ${ }^{19,108}$

$$
f(\varepsilon) g(s)=(1-s)^{2}\left(\frac{\varepsilon-\varepsilon_{p}}{1-\varepsilon_{p}}\right)^{2} H\left(\varepsilon(1-s)-\varepsilon_{p}\right),
$$

Table V. Thickness and porosity of cell layers.

Layer

MB

ACL

CCL

MPL

GDL

$$
D_{i}=\left(\frac{1}{D_{\mathrm{Kn}, i}}+\frac{1}{D_{\text {mix }, i}}\right)^{-1},
$$
1 692 694 96

.

.

701
5 715
716 18 19 720

\section{(}


726 where $\varepsilon_{p}$ is the percolation threshold, which is assumed to be 0.25 in 727 this work, and $H$ is the Heaviside function.

- Absolute permeability - A range of values for absolute gas and 729 liquid permeabilities are reported in the literature. In most of the cases, 730 the absolute permeability of the GDL is found to be on the order of $73110^{-11} \mathrm{~m}^{2} .{ }^{123}$ The MPL permeability values are typically one to two 732 orders of magnitude smaller than those for the GDL. ${ }^{124}$ In spite of 733 such measurements, it has been shown that these permeability val734 ues will result in a negligible pressure drop across the porous layers 735 due to oversimplification of the capillary dominated transport through 736 the use of Darcy's law. ${ }^{22,125}$ Therefore, it has been suggested that the 737 experimentally reported values should be reduced by several orders 738 of magnitude to obtain a realistic pressure drop. ${ }^{22}$ In addition to these 739 considerations, Holzer et al. recently found that the through-plane per740 meability values are slightly higher than the in-plane values for SGL 741 25BA GDLs. ${ }^{123}$ Taking these into account, the absolute permeabilities 742 assumed in the model are given in Table VI.

- Thermal conductivity and heat capacity - There is an exten744 sive literature on the thermal conductivity of the PEM fuel cell layers 745 through both modeling and experimental means with somewhat scat746 tered results. In selecting the thermal transport parameters, one has to 747 pay attention to the changes in thermal conductivity with liquid satu748 ration, in addition to the anisotropy and compression effects. Another 749 difficulty is in distinguishing between the thermal properties of the 750 MPL and the GDL from the data obtained from a composite layer. 751 Here we briefly review the existing literature for SGL papers.

752 One of the earliest works in this area was by Khandelwal et al. 753 who measured the TP thermal conductivities of various cell layers. ${ }^{126}$ 754 They reported a value of $0.31 \mathrm{~W} /(\mathrm{m} \cdot \mathrm{K}$ ) for SGL BA series (with no 755 MPL). Unfortunately, they did not report the number specification of 756 the GDL. This can bear some significance as the SGL 24 series have 757 more binder that can improve the fiber to fiber contact and increase 758 the thermal conductivity. ${ }^{127}$ Nevertheless, this value is well within 759 the range of $0.26-0.37 \mathrm{~W} /(\mathrm{m} \cdot \mathrm{K})$ reported by others for the same 760 type of GDL. ${ }^{127-130}$ Accordingly, the base value of GDL TP thermal 761 conductivity is set to $0.3 \mathrm{~W} /(\mathrm{m} \cdot \mathrm{K})$ under the channel and to 0.45 $762 \mathrm{~W} /(\mathrm{m} \cdot \mathrm{K})$ under the land due to the inhomogeneous compression. ${ }^{130}$ 763 As for the IP thermal conductivity, a base value of $12 \mathrm{~W} /(\mathrm{m} \cdot \mathrm{K})$ 764 is used ${ }^{131,132}$ for both the channel and land locations as the effect of 765 compression on IP conductivity is assumed to be minimal.

766 For the MPL thermal conductivity, the reported values are far more 767 inconsistent than those for the GDL. Such discrepancies stem mostly 768 from unknown contact resistances, uncertainties about the MPL thick769 ness in a combined layer, assumed compressibility or incompressibil770 ity of the MPL with applied pressure, and the nature of the transi771 tion region between the MPL and GDL. These have resulted in re772 ported values for the TP thermal conductivity ranging from $0.035^{133}$ 773 to $0.6 \mathrm{~W} /(\mathrm{m} \cdot \mathrm{K}) .{ }^{130}$ An interesting observation was made by Burheim 774 et al., ${ }^{134}$ who argued that the MPL has a lower thermal conductivity 775 than the GDL $(0.08 \mathrm{~W} /(\mathrm{m} \cdot \mathrm{K}))$, with an intermediate composite re776 gion between the two layers that has the highest thermal conductivity 777 with an essentially flat temperature distribution. Here we use a value 778 of $0.15 \mathrm{~W} /(\mathrm{m} \cdot \mathrm{K})$ for both the channel and land locations. This is 779 based on the assumption of incompressibility of the MPL, which has been questioned recently. ${ }^{134,135}$ Nevertheless, this value is in the range 780 of reported values in the literature. The base value for the IP thermal 781 conductivity of the MPL is chosen to be $3 \mathrm{~W} /(\mathrm{m} \cdot \mathrm{K})$ based on the 782 literature. ${ }^{131}$

The reported TP thermal conductivities for the CL range from 784 $0.04^{136}$ to $0.34 \mathrm{~W} /(\mathrm{m} \cdot \mathrm{K}) .{ }^{137}$ In this work, we use the base value 785 of $0.27 \mathrm{~W} /(\mathrm{m} \cdot \mathrm{K})$ reported by Khandelwal et al. ${ }^{126}$ for both the IP 786 and TP thermal conductivities assuming no anisotropy for the CL. ${ }^{137}{ }_{787}$

Liquid accumulation in the pores can alter the thermal conductivity 788 of the porous layers. In this work, we use the following approximation 789 to capture this effect for the TP thermal conductivity of the GDL: ${ }^{115}$

$$
k_{T}^{\mathrm{eff}}=k_{T, \text { base }}+1.44 s,
$$

where $k_{T, \text { base }}$ is the base value reported in Table VI. For the TP thermal 791 conductivity of other layers (CL and MPL) and the IP conductivity of 792 all porous layers, volume averaging is employed:

$$
k_{T}^{\text {eff }}=k_{T, \text { base }}+\varepsilon s k_{T, l},
$$

where $k_{T, l}=0.569 \mathrm{~W} /(\mathrm{m} \cdot \mathrm{K})$ is the thermal conductivity of liquid 794 water.

Finally, the thermal conductivity of the membrane in both the IP 796 and TP directions is given by: ${ }^{138}$

$$
k_{T, \mathrm{mb}}^{\mathrm{eff}}=0.177+3.7 \times 10^{-3} \lambda \quad[\mathrm{W} /(\mathrm{m} \cdot \mathrm{K})] .
$$

The volumetric specific heat capacities $\left(\rho c_{p}\right)$ used in the model are: 798 $1.9,1.562,{ }^{10} 1.98,{ }^{10,139}$ and $1.5827^{139,140} \mathrm{~J} /\left(\mathrm{cm}^{3} \cdot \mathrm{K}\right)$ for the membrane, 799 CL, MPL, and GDL, respectively.

- Electronic and ionic conductivity - The electronic conductivity 801 of the porous layers should be subject to similar considerations as the 802 thermal conductivity. The values used for the various layers in this 803 work are obtained from the work of Sadeghifar et al. ${ }^{141}$ and are listed 804 in Table VI. As for the ionic conductivity of the membrane and the 805 CLs, the conductivity is calculated as: ${ }^{107}$

$$
\sigma_{2}^{\text {eff }}=\varepsilon_{\text {ion }}^{1.5} \cdot 0.35\left(f_{y}-0.045\right)^{1.5} \exp \left[\frac{15000}{R}\left(\frac{1}{303.15}-\frac{1}{T}\right)\right] \text {. }
$$

The debated suppression of ionic conductivity in thin ionomer films 807 is not taken into account in this work. ${ }^{142}$ Future work should aim at 808 investigating such effects through parametric studies.

- Evaporation and condensation rates -A value of $2 \times 10^{-2}{ }_{810}^{809}$ $\mathrm{mol} /\left(\mathrm{cm}^{2} \cdot \mathrm{s}\right)$ is used for the condensation rate to avoid the non- 811 physical case of oversaturated gas phase. ${ }^{19}$ The evaporation rate is 812 set to $2 \times 10^{-3} \mathrm{~mol} /\left(\mathrm{cm}^{2} \cdot \mathrm{s}\right)$. Even though this value is lower than 813 the condensation rate, it yields rather fast evaporation kinetics, which 814 agrees with the experimental findings of Zenyuk et al. ${ }^{143}$ that showed 815 the evaporation to be transport-limited. The discrepancy between the 816 evaporation and condensation rates is corroborated by experimental 817 findings in the literature. ${ }^{144}$ Furthermore, the rate of phase change is 818 expected to decline with temperature, ${ }^{144}$ which is not taken into ac- 819 count in this work. It should be noted that the evaporation rate is a 820 critical parameter and may have a significant impact on water balance 821 in the cell depending on the operating conditions. Future work should 822

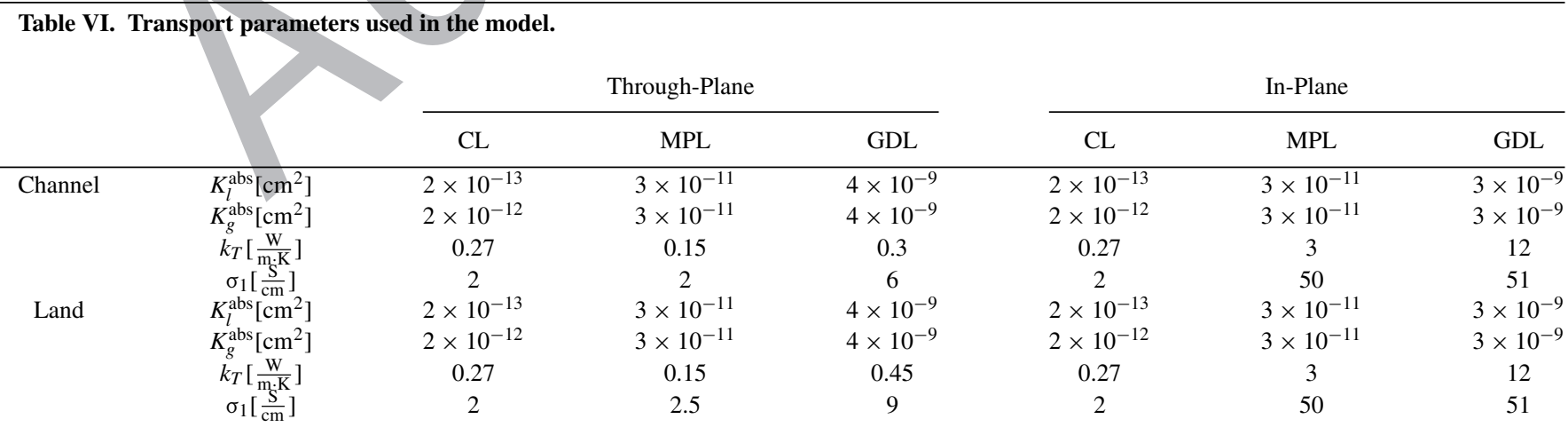


823 aim at a sensitivity analysis for this parameter to better understand its 824 impact on the performance in the two phase regime.

825 826 are given in Table VII, where $\boldsymbol{n}$ denotes the unit normal vector. Sym827 metry boundary conditions (i.e., zero flux) are applied at the top and 828 bottom boundaries of the modeling domain shown in Fig. 1. The tem829 perature BCs include two heat flux BCs at the channel and land loca830 tions. The channel heat flux corresponds to convective heat transport 831 with the gas stream $\left(h_{\text {conv }}=0.2 \frac{\mathrm{W}}{\mathrm{cm}^{2} \cdot \mathrm{K}}\right)$, while the land $\mathrm{BC}$ accounts for 832 the thermal contact resistance $\left(R_{T, \text { cont }}=2 \frac{\mathrm{cm}^{2} \cdot \mathrm{K}}{\mathrm{W}}\right)$ between the plate 833 and the GDL. The molar fractions of gas species are also modeled 834 with mass flux BCs at the channel location to account for the con835 vective mass transport resistance. In the corresponding equation, $D_{i, j}^{\text {free }}$ 836 denotes the bulk diffusivity of species $i$ in species $j, S h$ is the dimen837 sionless Sherwood number $(=2.7)$, and $D_{h}$ is the hydraulic diameter 838 of the channel. Dirichlet BCs are used for gas pressures at the channel 839 boundaries. The liquid pressure BC requires further attention. Various 840 types of BCs have been used for this purpose, including Dirichlet BC 841 for liquid saturation or capillary pressure, ${ }^{145}$ as well as Neumann type 842 BC. ${ }^{9}$ In this work, we use the following BC:

$$
-\boldsymbol{n} \cdot\left(-\frac{\rho_{l} K_{l}^{\mathrm{eff}}}{\mu_{l}} \nabla p_{l}\right)=N_{l}=-k_{l, \text { flux }} s\left[0.5\left(1+\tanh \left(\frac{s-s_{0}}{\sigma_{s}}\right)\right)\right],
$$

843 where $k_{l, \text { flux }}$ is a parameter determining rate of water outflow, $s_{0}$ con844 trols the liquid saturation at which water outflow begins, and $\sigma_{s}$ is 845 a dimensionless parameter used to smooth the transition between no 846 flux BC and the outflow BC. Note that the parameter $s_{0}$ essentially ac847 counts for the break-through pressure, which is the capillary pressure 848 required for liquid water to flow out of the porous GDL. The values 849 of the three parameters used in this work are: $k_{l, \text { flux }}=8 \times 10^{-4} \frac{\mathrm{g}}{\mathrm{cm}^{2} \cdot \mathrm{s}}$, ${ }_{850} s_{0}=0.1$, and $\sigma_{s}=0.01$. It should be pointed out that this BC can be 851 parameterized to be identical to the BC used by Zhou et al. ${ }^{19}$ However, 852 it has the advantage that the parameters are more intuitive, which can 853 simplify the parameterization process.

$854 \quad$ Numerical implementation and model validation.-The model 855 is implemented in the commercial finite element software COMSOL 856 Multiphysics 5.3a. A mapped mesh consisting of 5080 quadrilateral 857 elements is used throughout the domain with increased mesh density 858 in the membrane and catalyst layers. Furthermore, the mesh density is 859 exponentially increased near the boundaries between adjacent layers to 860 accommodate the different material properties. The backward differ861 entiation formula (BDF) method is used for time stepping and the max862 imum time step size is limited to 200 milliseconds. The resulting linear 863 system is solved using the MUMPS direct solver provided in COM864 SOL. To improve the computational efficiency, an under-relaxation 865 scheme is employed, where the value of liquid saturation at the pre${ }_{866}$ vious time step is used to calculate effective properties such as the 867 diffusion coefficients at the current time step. This was achieved us868 ing the Previous Solution operator in COMSOL 5.3a. In a preliminary 869 study, it was found that the under-relaxation scheme can result in up to five times faster solutions in the two-phase regime. The results for the 870 340 seconds long simulation case studies in this paper were computed 871 in 5 to 12 hours depending on the condition, with the most difficult 872 cases being the ones where the transition from dry to wet conditions 873 takes a long time. The simulations were run on a desktop computer 874 with a $3.5 \mathrm{GHz}$ processor and $16 \mathrm{~GB}$ of RAM.

The model is validated with experimental data by Gerteisen et al. ${ }^{9}$ The results can be found in the Supplementary Information accompanying this paper.

\section{Simulation Case Studies}

To better understand the transient behavior of the cell, several sim- 880 ulations are conducted using the model developed in this work. In 881 particular, the transient performance under a variety of temperature 882 and humidity conditions as well as different Pt loadings in the cath- 883 ode CL is investigated. Furthermore, we investigate the cell dynamics 884 under both potential and current control operating modes. The former 885 constitutes running the model with voltage as an input, while the lat- 886 ter takes the cell current density as the input. As will be shown, the ${ }_{887}$ dynamics of the cell response can be dramatically different depending 888 on the operating condition. All of the simulations in this work were 889 conducted at a pressure of 1.5 bar for both sides. The gas feeds are 890 assumed to be pure hydrogen and air for the anode and cathode sides, 891 respectively. Finally, same RH values are used for both the anode and cathode sides and initial conditions for all simulations are identical.

Potentio-dynamic simulations. - The first set of simulations are 894 those under voltage control or potentio-dynamic mode of operation. 895 Here a voltage profile is applied and the current density is allowed to 896 vary with time. The time varying current density also means that the ${ }_{897}$ rate of water production changes with time, which complicates the 898 analysis of the dynamics to some extent. Nevertheless, useful insights can be obtained from these simulations.

The voltage profile for these simulations is shown in Fig. 3. The profile is made up of the following voltage steps: $0.8-0.6 \mathrm{~V}, 0.6-0.4 \mathrm{~V}$, $0.4-0.6 \mathrm{~V}$, and $0.6-0.8 \mathrm{~V}$. Note that the step changes are smooth and happen over a period of 1 second for numerical convergence. This profile allows us to inspect the transients during both load increments and decrements. The 100 second hold time used at 0.6 and $0.4 \mathrm{~V}$ does not allow the system to fully reach its steady state conditions. Nevertheless, this hold time is limited due to computational reasons and is long enough for the model to settle to a quasi steady state before another change in the load.

Overall, 36 simulations are conducted under the potentio-dynamic mode based on a full factorial design for variations in $\mathrm{RH}(30,60$, and $90 \%$ ), operating temperature $\left(40,60\right.$, and $\left.80^{\circ} \mathrm{C}\right)$, and cathode $\mathrm{Pt}$ loading $\left(0.4,0.2,0.1\right.$, and $\left.0.05 \mathrm{mg} / \mathrm{cm}^{2}\right)$. Note that the CL thickness is assumed to scale linearly with the Pt loading. The resulting current density dynamics for all 36 simulations are shown in Fig. 4. The corresponding average water contents in the membrane for all the cases are shown in Fig. 5. Furthermore, for the conditions that result in liquid buildup in the GDL, the average liquid saturations in the cathode 891 892 898 899 900 901 902 903 904 905 906 907 908 909 910 911 912 913 914 915 916 917 918 919

\section{3 \\ 874
875 876 877 878} 71

2

3

5

6

87
88
9 5 6

\begin{tabular}{|c|c|c|c|c|}
\hline Variable & $\mathrm{CH}$ & LAND & $\mathrm{MPL} \| \mathrm{CL}$ & $\mathrm{CL} \| \mathrm{MB}$ \\
\hline$\phi_{1}$ & * & an: 0, ca: $E_{\text {cell }} / i_{\text {cell }}$ & - & * \\
\hline$\phi_{2}$ & - & - & * & - \\
\hline$T$ & $-\boldsymbol{n} \cdot\left(-k_{T}^{\mathrm{eff}} \nabla T\right)=h_{\mathrm{conv}}\left(T_{\text {cell }}-T\right)$ & $-\boldsymbol{n} \cdot\left(-k_{T}^{\mathrm{eff}} \nabla T\right)=\frac{1}{R_{T, \mathrm{cont}}}\left(T_{\text {cell }}-T\right)$ & - & - \\
\hline$x_{i}$ & $-\boldsymbol{n} \cdot\left(-c_{g} D_{i, j}^{\mathrm{free}} \nabla x_{i}\right)=\frac{S h}{D_{h}}\left(c_{g, \mathrm{CH}} x_{i, \mathrm{CH}}-c_{g} x_{i}\right)$ & * & - & - \\
\hline$p_{l}$ & $-\boldsymbol{n} \cdot\left(-\frac{\rho_{l} K_{l}^{\text {eff }}}{\mu_{l}} \nabla p_{l}\right)=N_{l}$ & * & - & * \\
\hline$p_{g}$ & $p_{\mathrm{CH}}$ & $*$ & - & $*$ \\
\hline$\lambda$ & - & - & * & - \\
\hline
\end{tabular}




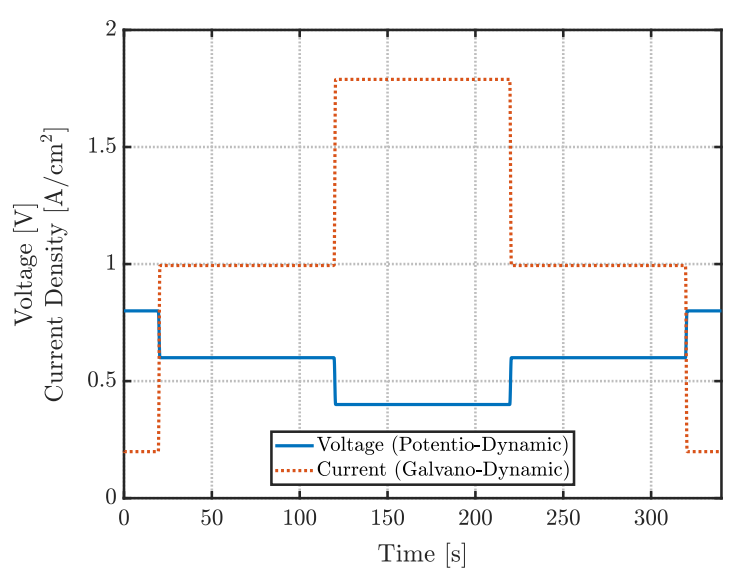

Figure 3. Voltage and current profiles used for potentio- and galvano-dynamic simulations, respectively.

$920 \mathrm{GDL}$ are shown in Fig. 6 (the cases with $\mathrm{T}=60^{\circ} \mathrm{C}$, $\mathrm{RH}=60 \%$ and $\mathrm{Pt}$ 921 loadings of 0.4 and $0.2 \mathrm{mg} / \mathrm{cm}^{2}$ also result in some liquid saturation 922 during the voltage hold at $0.4 \mathrm{~V}$, but are not shown in the figure). The 923 anode side remains dry for the simulated conditions, which is mostly 924 due to the high EOD.

925 Based on these results, several conclusions can be made about the 926 through-the-membrane phenomena affecting the transient response of 927 the cell. The following analysis of the average response is organized based on the step change in the load. Discussions on the distribution 928 of the critical variables are provided later in the paper.

Voltage step from 0.8 to $0.6 \mathrm{~V}$.- - During this step change, the 930 current responds monotonically with varying settling times that de- 931 crease with channel RH, i.e., a faster response for more humidified 932 conditions, which can be attributed to sufficient membrane humidifi- 933 cation. This can be observed in Fig. 5, which shows the membrane 934 water content dynamics, where the transient response is found to sig- 935 nificantly depend on the operating conditions. In particular, under dry 936 conditions that dry out the membrane prior to the voltage step down, 937 the membrane water content increases monotonically with the step 938 change in voltage. This increase is less pronounced at higher temper- 939 atures, where further increase in temperature at higher loads results in 940 lower water uptake by the membrane. As the humidity increases and 941 the membrane holds enough water in its initial state prior to the step 942 change, we observe some cases with reverse response, i.e., an initial 943 decrease in the membrane water content followed by an increasing 944 trend (see, for example, the case with $\mathrm{T}=40^{\circ} \mathrm{C}, \mathrm{RH}=60 \%$ and a Pt 945 loading of $0.4 \mathrm{mg} / \mathrm{cm}^{2}$ in Fig. 5). This reverse response is due to EOD 946 that tends to dry out the anode side of the membrane and is only seen 947 at higher current densities. Another observation is that the changes in 948 the membrane hydration are much more pronounced at lower temper- 949 ature, where slight variations in water production rate can significantly 950 alter the membrane water content. The slow relaxation dynamics dis- 951 cussed in the Model Formulation section are also evident in Fig. 5. 952 In particular, we note that the relaxation dynamics become slower at 953 higher water contents. These relaxation effects are not observable in 954 the current dynamics, since the ohmic drop at this relatively low load 955
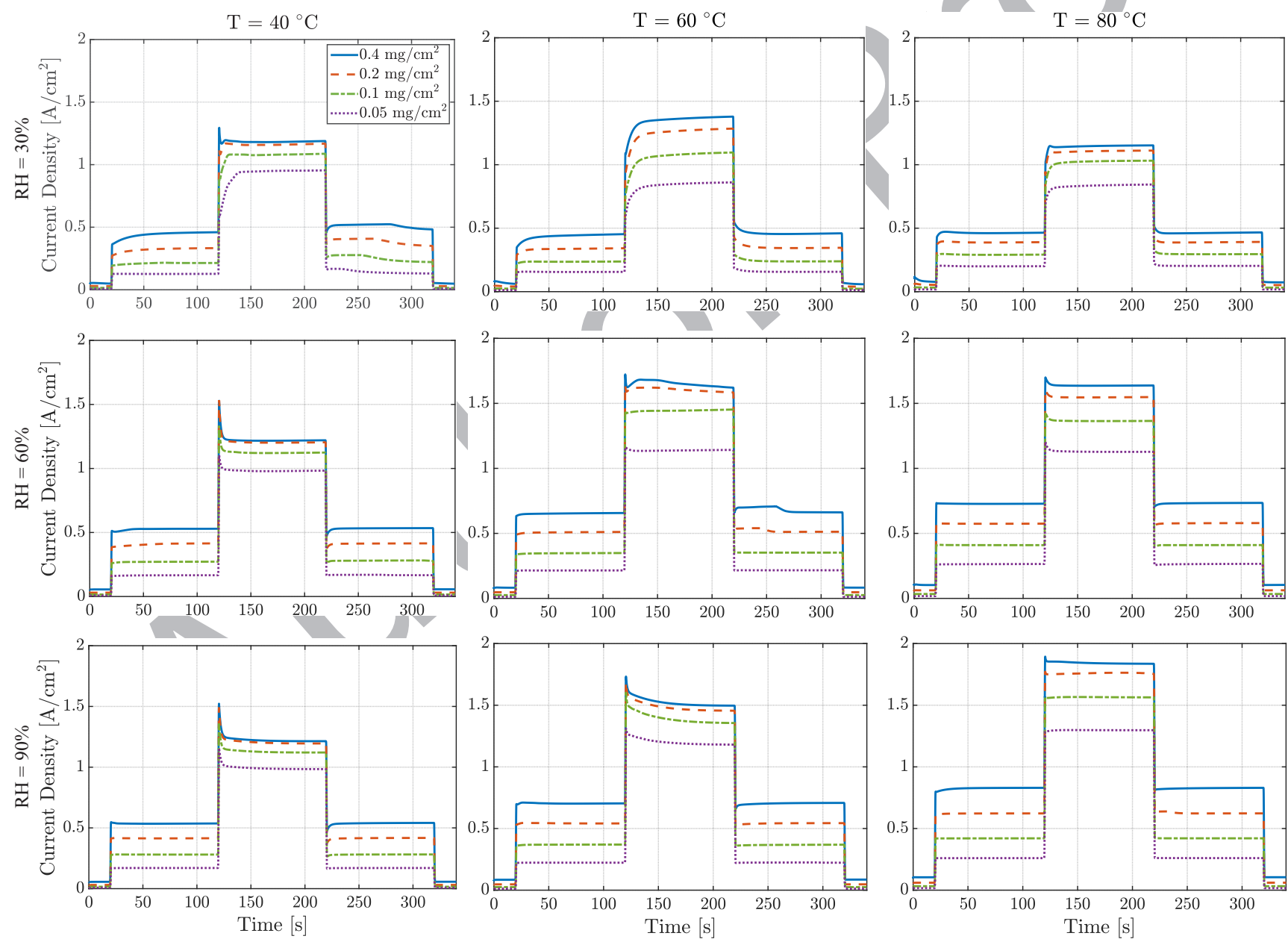

Figure 4. Average current dynamics for the potentio-dynamic simulations. 

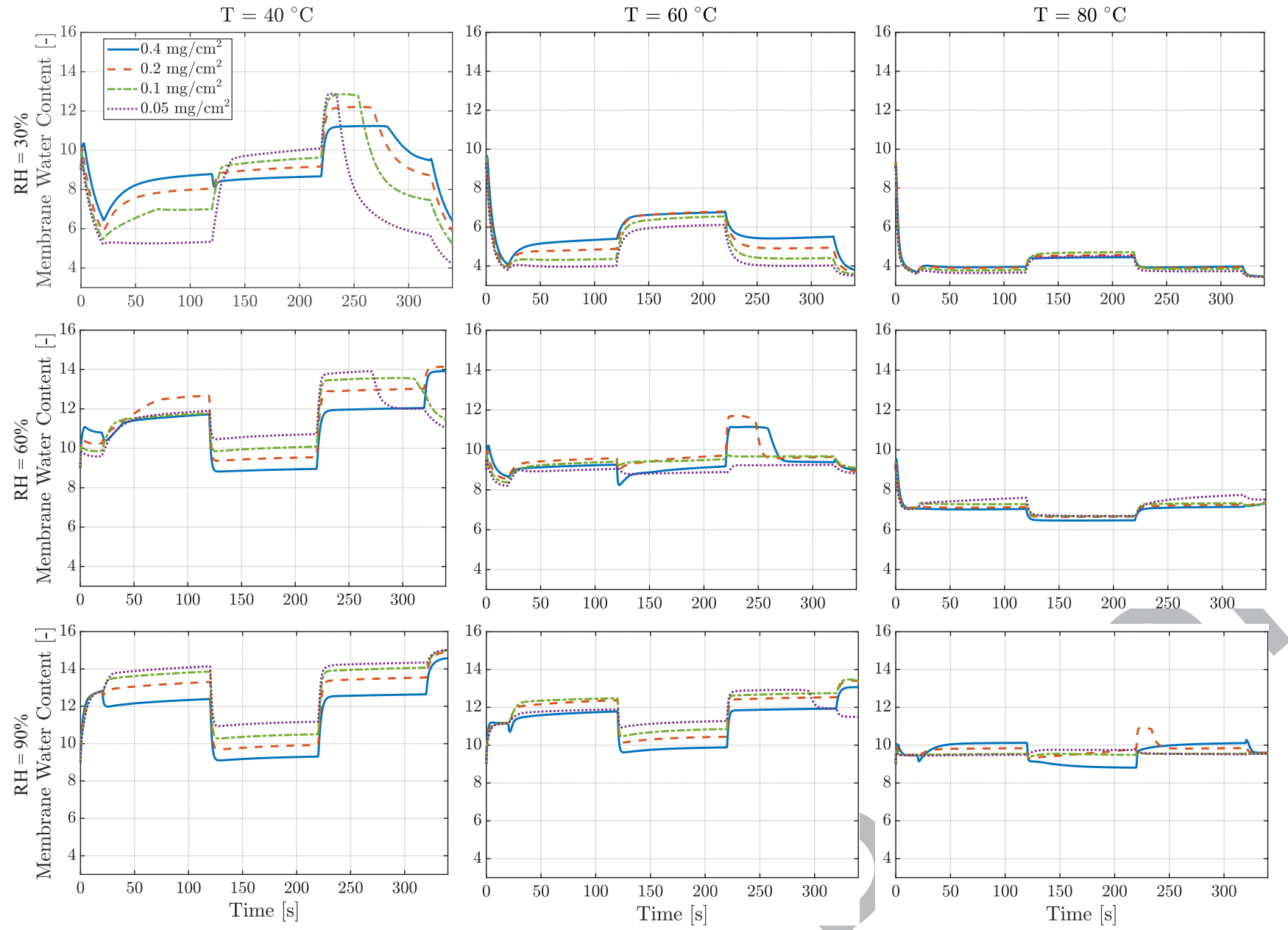

Figure 5. Average membrane water content dynamics for the potentio-dynamic simulations.

956 is insignificant. Finally, as shown in Fig. 6, some liquid water builds 957 up in the cathode GDL after the voltage step down for three condi958 tions with low temperature and high humidity. As expected, the build 959 up of liquid is faster under cooler and wetter conditions, while for 960 some conditions the dynamics are slow and the liquid saturation does 961 not reach a steady state within the 100 second hold at $0.6 \mathrm{~V}$ (see, for 962 example, the case with $\mathrm{T}=40^{\circ} \mathrm{C}, \mathrm{RH}=60 \%$ and a Pt loading of 0.4 $963 \mathrm{mg} / \mathrm{cm}^{2}$ in Fig. 6).

964 The figures also demonstrate that the cathode Pt loading has an im965 pact on the transient response by influencing the current generation, 966 membrane hydration, and liquid saturation dynamics. More specif967 ically, Fig. 4 shows that higher current densities are achieved with 968 higher loadings, which in turn affect the membrane humidification 969 process, especially under drier conditions, where the membrane is 970 humidified with the electrochemically generated water. This can be 971 clearly seen in Fig. 5 for $\mathrm{T}=40^{\circ} \mathrm{C}$ and $\mathrm{RH}=30 \%$. It is observed that 972 with higher loadings, the water generation is high enough to humidify 973 the membrane, whereas with a loading of $0.05 \mathrm{mg} / \mathrm{cm}^{2}$, the membrane 974 remains dry after the step change in the voltage. Additionally, Fig. 5 975 shows that the membrane water content is indeed influenced by the 976 Pt loading, which can be associated with different levels of current 977 and heat generation as well as a change in the overall water balance in 978 the cell with the CL thickness. It can also be observed that the cases 979 with higher cathode Pt loading show higher levels of liquid saturation 980 in the GDL (Fig. 6). This can be attributed to the fact that higher Pt 981 loading results in higher current density and therefore higher rate of 982 water generation. In addition, the resulting variations in the CL thick983 ness with changes in Pt loading mean that lower loaded CLs generate 984 more heat on a volumetric basis, which creates a stronger drive for water evaporation. The impact of Pt loading on the overall water bal- 985 ance in the cell is discussed in further detail below as well as in the 986 discussion of the galvano-dynamic simulations, where the results are 987 not convoluted by varying levels of water generation.

Voltage step from 0.6 to $0.4 \mathrm{~V}$.-The second voltage step results 989 in more involved dynamics in some cases, but the current response 990 can be categorically identified as being monotonically increasing or 991 displaying an overshoot. In particular, the drier conditions tend to re- 992 sult in a monotonic increase in the current density (see the first row 993 of Fig. 4). Similar to the previous step, this monotonic response is 994 associated with a hydrating membrane. This is mostly evident, for in- 995 stance, at $\mathrm{T}=60^{\circ} \mathrm{C}$ and $\mathrm{RH}=30 \%$, where the relaxation dynamics 996 for the membrane water uptake also play a role in the slow increase 997 in current density. Under wetter conditions, however, the gas phase 998 in the cathode CL is saturated with vapor and the membrane protonic 999 resistance is low enough prior to the step change. This low protonic re- 1000 sistance can support high current generation immediately after the step 1001 change. The high current density dries out the anode side of the mem- 1002 brane with EOD and increases the protonic resistance, which results 1003 in a performance drop as seen in Fig. 4. The overshoot response due to 1004 EOD is relatively fast and settles within 5 seconds of the step change, 1005 when the generated water on the cathode side diffuses back toward the 1006 anode and rehydrates the dry portion of the membrane. ${ }^{146}$ It is also ob- 1007 served that the overshoot becomes progressively less significant as the 1008 temperature increases. The large overshoots at low temperatures can 1009 be attributed to the high sensitivity of the membrane hydration state 1010 to changes in the current density. This high sensitivity stems from 1011 more rapid changes in the environmental conditions (T and RH) in the 1012 

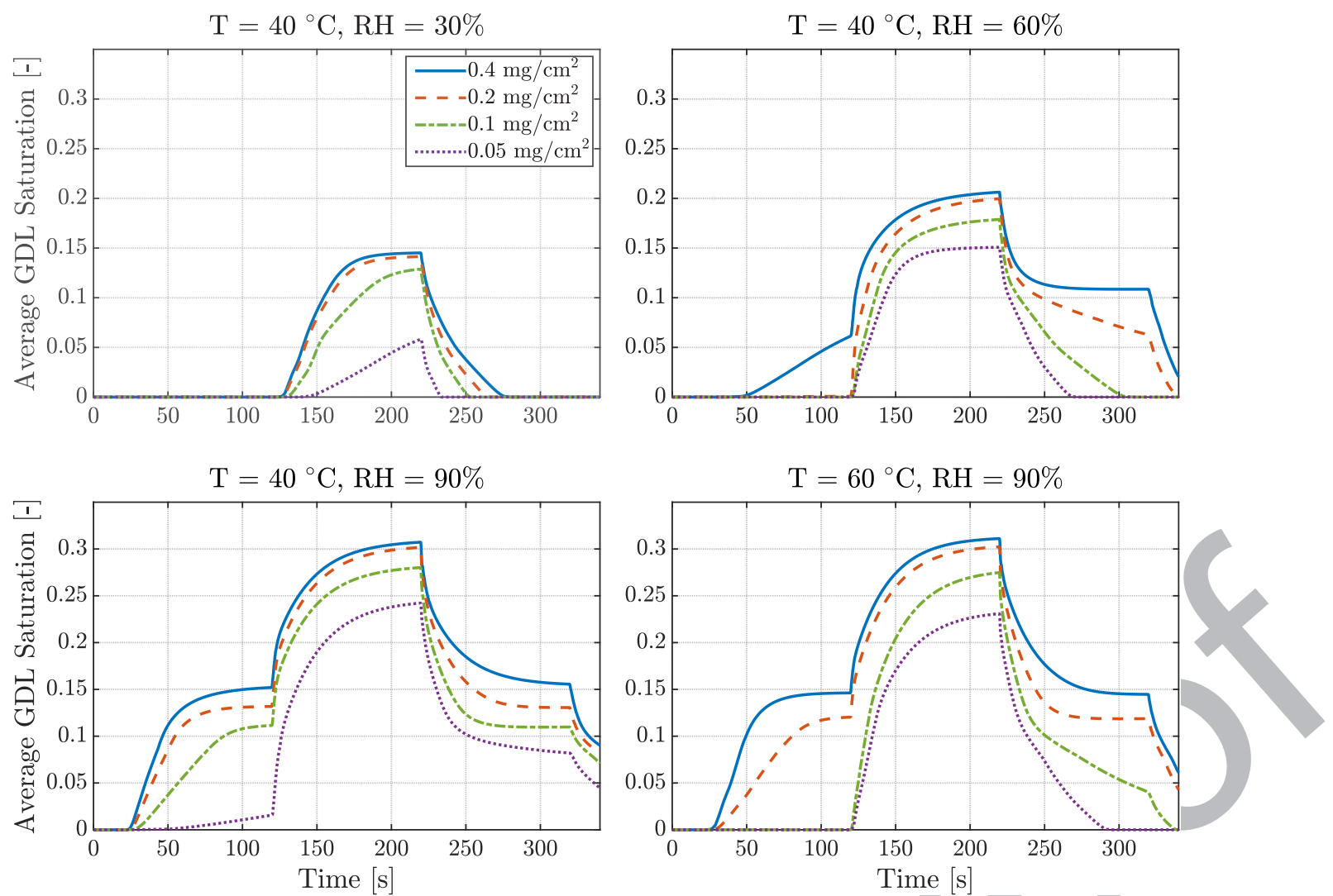

Figure 6. Average liquid saturation dynamics in the cathode GDL for the potentio-dynamic simulations.

$1013 \mathrm{CL}$ and the increased protonic resistance at these lower temperatures. 1014 It should be noted that flooding of the porous layers, discharging of 1015 the electrochemical double layer, and mass transport limitations are 1016 also believed to lead to this type of behavior. ${ }^{4}$ However, the over1017 shoot in the presented results is due to membrane dry out with EOD, 1018 which is in agreement with other experimental results. ${ }^{146}$ Following 1019 this overshoot, the wetter conditions display a relatively slow drop in 1020 performance during the hold at $0.4 \mathrm{~V}$ (e.g., see the case with $\mathrm{T}=60^{\circ} \mathrm{C}$ 1021 and $\mathrm{RH}=90 \%$ in Fig. 4). This slow drop in performance is attributable 1022 to liquid build up in the GDL that incurs a mass transport resistance 1023 and is most significant for the cases where the current density goes 1024 above $1.5 \mathrm{~A} / \mathrm{cm}^{2}$.

1025 The case with $\mathrm{T}=60^{\circ} \mathrm{C}, \mathrm{RH}=60 \%$, and a Pt loading of 0.4 $1026 \mathrm{mg} / \mathrm{cm}^{2}$ displays interesting dynamics after the yoltage step. An ini1027 tial overshoot due to EOD is observed that causes the current density 1028 to drop by about $0.1 \mathrm{~A} / \mathrm{cm}^{2}$ within 2 seconds of the step change. 1029 This drop is then followed by an increase of about $0.06 \mathrm{~A} / \mathrm{cm}^{2}$ during 1030 the next 15 seconds. This increase is due to liquid accumulation in 1031 the CL that helps the membrane humidification without causing mass 1032 transport limitations. Afterwards, the slow current decay due to liquid 1033 accumulation in the cathode GDL can be observed, which continues 1034 until the next voltage step. In fact, this particular order of liquid build 1035 up in the porous layers (the CL pores followed by those of the MPL 1036 and GDL) is seen under most typical conditions. However, the observ1037 ability of this behavior from measurements of current alone depends 1038 on the water retention capabilities of the different layers as well as the 1039 operating conditions used for the experiments.

1040 As for the membrane water content, the most notable observation 1041 is that for drier conditions where the gas phase in the CL remains un1042 saturated, this voltage step results in better membrane humidification 1043 due to higher rates of water generation (Fig. 5). However, this trend 1044 is reversed for wetter conditions, where the water content drops after 1045 this voltage step. This drop is again attributable to water removal to 1046 the cathode through higher EOD at higher current densities. Addition- ally, the variations in membrane water content with the voltage step 1047 are more significant at lower temperatures as was the case during the 1048 previous step change. Average liquid saturation in the cathode GDL 1049 also exhibits trends similar to those for the previous step (Fig. 6). 1050

Voltage step from 0.4 to $0.6 \mathrm{~V}$ and from 0.6 to $0.8 \mathrm{~V}$.- Similar to 1051 the previous steps, the current response to the step increase in voltage 1052 is either monotonically decreasing (as is the case at $\mathrm{T}=60^{\circ} \mathrm{C}$ and 1053 $\mathrm{RH}=30 \%$ ) or exhibits an undershoot. Again, this behavior can be 1054 directly correlated with membrane water content and further discus- 1055 sion is omitted here. Instead, we focus on the trends during the dry-out 1056 phase when the voltage is increased. In particular, we note that under 1057 some drier conditions, the performance starts to decay after a while. 1058 This is seen, for instance, for all $\mathrm{Pt}$ loadings at $\mathrm{T}=40^{\circ} \mathrm{C}$ and $\mathrm{RH}=1059$ $30 \%$ in Fig. 4. Looking at the membrane water content dynamics in 1060 Fig. 5, we note that this decay in performance is directly related to 1061 membrane water loss. This behavior can be explained by a moving 1062 evaporation front that starts in the GDL and progresses toward the 1063 $\mathrm{CL}$ as time goes on. Therefore, immediately after the step change the 1064 ionomer in the cathode CL is in contact with a liquid reservoir, which 1065 improves water uptake. As the evaporation front reaches the CL and 1066 the accumulated liquid evaporates, the membrane starts to lose water, 1067 which results in further performance decay. In these simulations, the 1068 time delay between the step change in voltage and the evaporation of 1069 CL liquid water depends on the operating conditions as well as the CL 1070 thickness, with hotter conditions and thinner CLs generally resulting 1071 in the shortest time delays. More generally though, this time delay is 1072 determined by the $\mathrm{HI}$ contact angle of the CL as well as the evaporation 1073 rate used in the model. A lower HI contact angle makes evaporation 1074 of water in the HI pores more difficult and prolongs the time delay, 1075 whereas a high evaporation rate reduces this delay.

Finally, it should be mentioned that based on experimental results, 1077 a better performance may be expected at $0.6 \mathrm{~V}$ after the hold at $0.4 \mathrm{~V} 1078$ (220-320 seconds) compared to the performance at $0.6 \mathrm{~V}$ before the 1079 
1080 hold at $0.4 \mathrm{~V}$ (20-120 seconds). This performance gain is attributable to 1081 better membrane hydration as well as clearing of the Pt sites from oxide 1082 coverage at low potentials. This improved performance will diminish 1083 slowly as the membrane dehydrates and oxide species grow on the $\mathrm{Pt}$ 1084 surface again. As explained in the Model Formulation section though, 1085 this work only captures the former dynamics, as the oxide growth is 1086 ignored in our model and steady state coverage values are used.

1087

1088 1089 1090

The characteristic responses observed after the last voltage step are similar to those discussed so far and further discussion is omitted here.

To further investigate the transient phenomena through the cell's thickness, Fig. 7 illustrates the average liquid saturation in the CL and GDL under both channel $(\mathrm{CH})$ and land $(\mathrm{LN})$ regions of the cell, the average ionomer water content in the anode and cathode CLs, and the normalized membrane water flux defined as:

$$
\beta=\frac{N_{\mathrm{w}, \mathrm{mb}}}{i_{\text {cell }} / 2 F},
$$

1094 which is averaged over the area of the membrane. As a convention, a 1095 positive value denotes water flux toward the cathode. The presented 1096 results are for the cold and dry conditions $\left(\mathrm{T}=40^{\circ} \mathrm{C}\right.$ and $\mathrm{RH}=30$ $1097 \%)$ with high $\left(0.4 \mathrm{mg} / \mathrm{cm}^{2}\right)$ and low $\left(0.05 \mathrm{mg} / \mathrm{cm}^{2}\right)$ Pt loading in the 1098 cathode CL.

1099 First, we observe that immediately after the second step decrease in 1100 voltage ( 0.6 to $0.4 \mathrm{~V}$ at 120 seconds), the cathode CL becomes flooded. 1101 This flooding takes place within 10 seconds of the step change. Also, 1102 note that the CL flooding occurs slightly faster under the land location 1103 compared to the channel location. After all the hydrophilic pores in the 1104 CL are filled, water starts to condense in the GDL. Most of the conden1105 sation happens under the land, where lower temperature and higher 1106 resistance to vapor transport promotes the phase change process. This 1107 liquid water then flows toward the channel location. This can be seen 1108 in the figure, as there is a delay between liquid accumulation under the 1109 land and channel regions of the GDL. This delay is governed by the 1110 time it takes for the liquid water condensed under the land to reach the 1111 channel location. After the voltage is increased back to $0.6 \mathrm{~V}$ at 220 1112 seconds, we see that the GDL dry out is initiated under the channel. 1113 The dry out happens at a slower pace under the land location. Once 1114 the GDL is completely dry, the CL starts to lose its liquid water. As 1115 for the ionomer water content in the CL, two main observations can 1116 be made. First, at lower loads the ionomer water contents in both CLs 1117 are close and as the load is increased, a more significant distribution 1118 develops across the membrane thickness with intensified EOD and back diffusion. Second, we note that after the load is decreased, the 1119 CLs maintain a high ionomer water content as long as the liquid water 1120 in the CL has not evaporated. After that liquid water has evaporated 1121 though, the cathode ionomer loses water to its pore space, which also 1122 diminishes the water back diffusion to anode, which in turn results in 1123 dry out of the anode CL. This behavior can also be seen in the last 1124 column of Fig. 7, where the smallest values for $\beta$ are obtained when 1125 the cathode CL has liquid water while the anode CL is dry, which is in 1126 agreement with experimental measurements by Adachi et al. ${ }^{147}$ It is 1127 also seen that this flux is significantly reduced after the liquid reservoir 1128 in the cathode CL has evaporated (see the plots between 220 and $300 \quad 1129$ seconds). This is specially pronounced for the case with low Pt loading. 1130 Another important observation from the normalized water flux plots 1131 is the significant overshoots and undershoots during the step changes. 1132 This behavior is associated with EOD that immediately drives water to 1133 the cathode side, whereas the back diffusion requires time to establish 1134 a balancing water flux to counter EOD. Such transients qualitatively 1135 agree with experimental measurements. ${ }^{148,149}$ In addition, it can be ${ }_{1136}$ seen that higher current densities generally tend to force more water 1137 toward the cathode (larger $\beta$ values) due to intensified EOD, which is 1138 in agreement with experimental results. ${ }^{150,151}$

Finally, the distribution of critical variables for some conditions are 1140 shown in Figs. 8-9. In particular, the distributions for the membrane 1141 and cathode temperatures, cathode liquid saturation, ionomer water 1142 content, and volumetric ORR current density are shown for high (0.4 1143 $\left.\mathrm{mg} / \mathrm{cm}^{2}\right)$ and low $\left(0.05 \mathrm{mg} / \mathrm{cm}^{2}\right)$ Pt loadings. These distributions 1144 are obtained at the end of the hold at $0.4 \mathrm{~V}$. The temperature plots 1145 show a rather significant temperature gradient (about $1.5^{\circ} \mathrm{C}$ ) across 1146 the MPL thickness, which is due to its low thermal conductivity. This 1147 low conductivity also results in heating the CL and enhances water 1148 evaporation. $^{23}$ The cathode MPL and GDL remain free of liquid wa- 1149 ter under these hot conditions, whereas the hydrophilic pores in the 1150 cathode $\mathrm{CL}$ are filled with liquid water for the hot and wet $\left(\mathrm{T}=80^{\circ} \mathrm{C}, 1151\right.$ $\mathrm{RH}=90 \%$ ) conditions. A considerable gradient of water content is 1152 established across the thickness of the CCM, with a dry anode CL and 1153 a wet cathode CL. There is a close correspondence between the loca- 1154 tion of maximum water content in the cathode CL and the volumetric 1155 rate of ORR. In particular, under the dry conditions (Fig. 8), protonic 1156 resistance is a major contributor to performance loss. Therefore, the 1157 highest volumetric current is observed under the land location, where 1158 the membrane water content is highest. At higher humidities (Fig. 9) 1159 the location of maximum current generation moves toward the channel 1160 a)

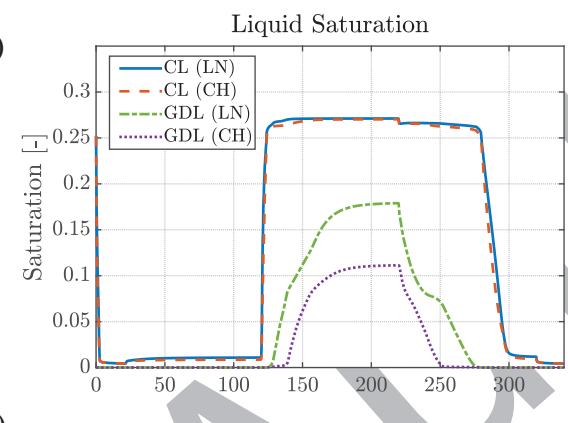

b)

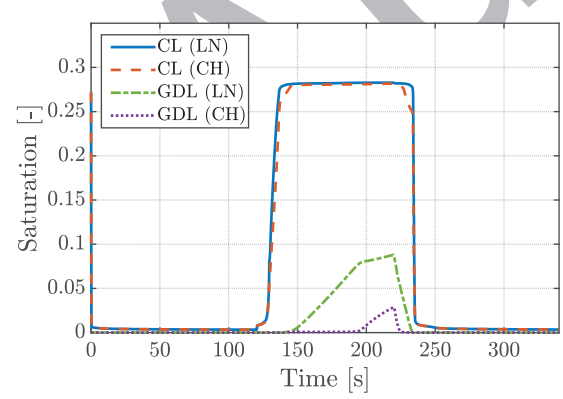

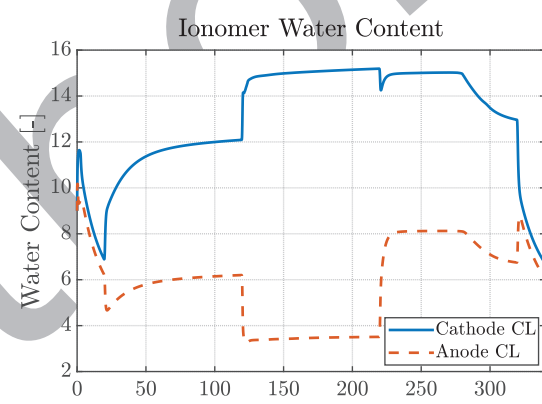

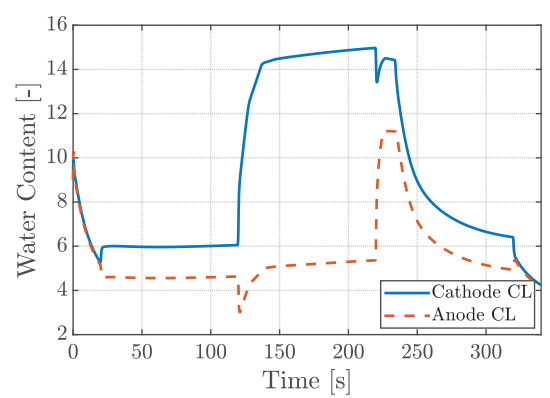

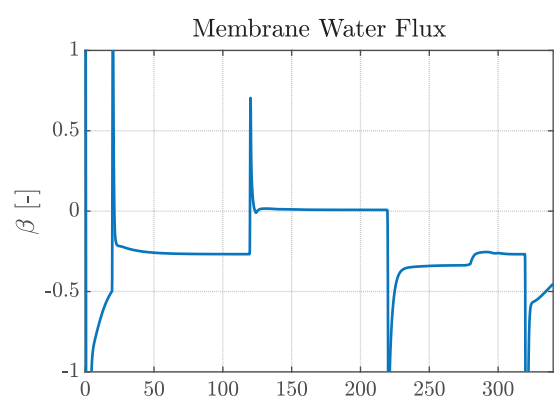

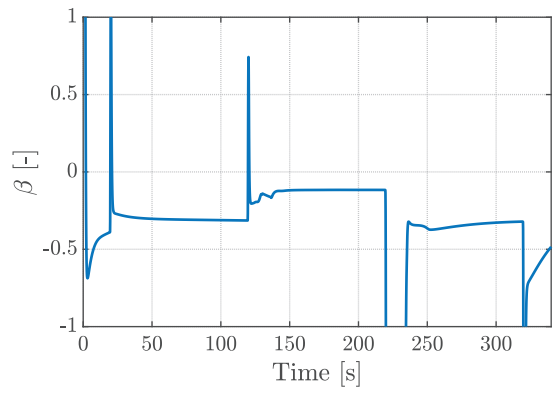

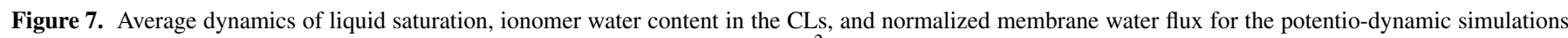
at $\mathrm{T}=40^{\circ} \mathrm{C}$ and $\mathrm{RH}=30 \%$ with cathode $\mathrm{Pt}$ loading of a) 0.4 , and b) $0.05 \mathrm{mg} / \mathrm{cm}^{2}$. 

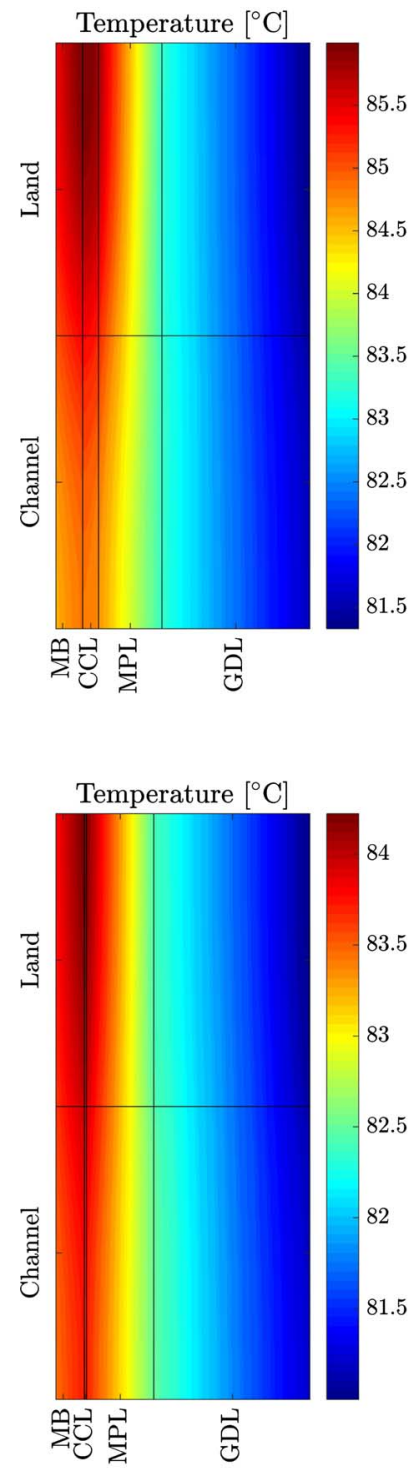

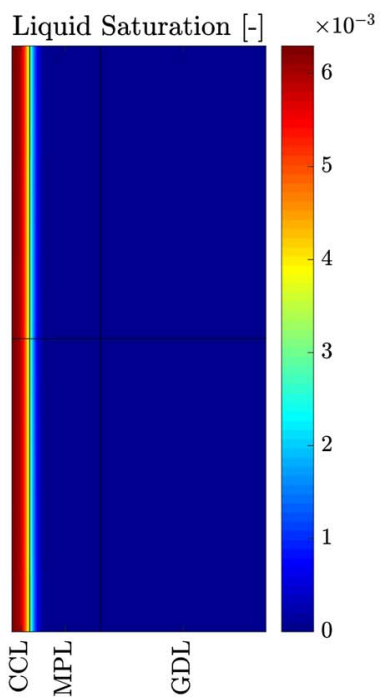

(a)

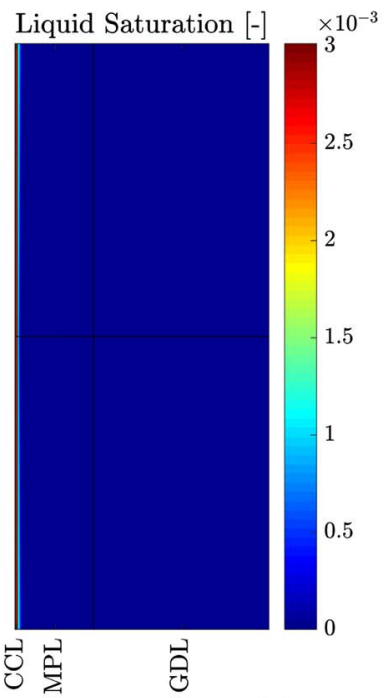

(b)
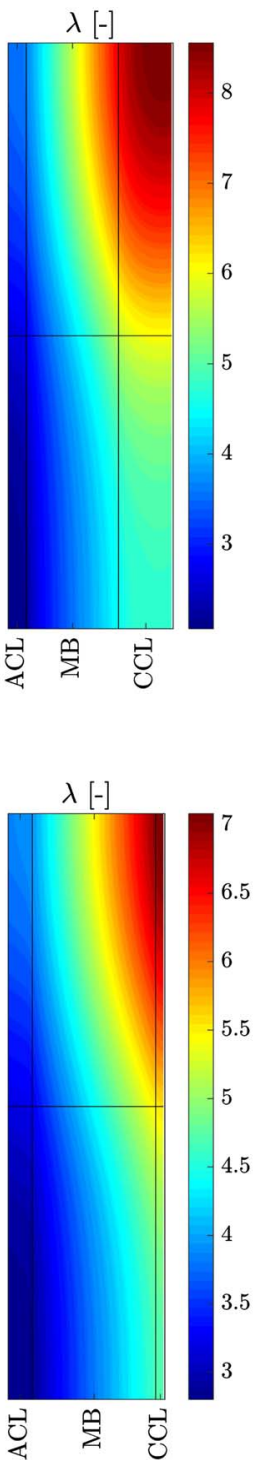

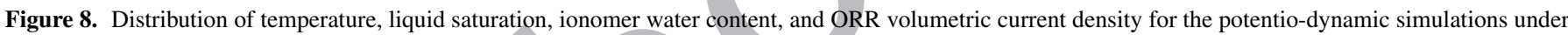

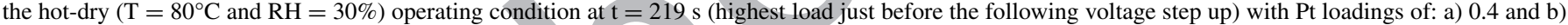
$0.05 \mathrm{mg} / \mathrm{cm}^{2}$.

1161 region, where the mass transport limitations are minimal. Furthermore, 1162 a higher portion of the Pt is utilized, as the region close to the MPL 1163 is not severely limited by proton transport resistance. Comparing the 1164 low and high Pt loading cases, the most notable difference is in the 1165 volumetric current distributions, which stems from the thinness of the ${ }_{1166} \mathrm{CL}$ with low Pt loading and the resulting increase in volumetric cur1167 rent density. In particular, note that the current distribution across the ${ }_{1168} \mathrm{CL}$ thickness is more uniform for the thin $\mathrm{CL}$ as seen previously. ${ }^{72}$

1169 Galvano-dynamic simulations.-For this set of simulations, a 1170 current profile shown in Fig. 3 is applied and the cell voltage is calcu1171 lated. The profile is made up of the following steps: $0.2-1.0 \mathrm{~A} / \mathrm{cm}^{2}$, $11721.0-1.8 \mathrm{~A} / \mathrm{cm}^{2}, 1.8-1.0 \mathrm{~A} / \mathrm{cm}^{2}$, and $1.0-0.2 \mathrm{~A} / \mathrm{cm}^{2}$. The magnitude of 1173 the steps are chosen to be relatively high in order to excite the system 1174 dynamics. Similar to the voltage steps, these step changes are smooth 1175 and happen over a period of 1 second.

1176 Overall, 16 simulations are conducted under the galvano-dynamic 1177 mode with variations in $\mathrm{RH}(60$, and $90 \%)$, operating temperature $(60$ 1178 and $\left.80^{\circ} \mathrm{C}\right)$, and cathode Pt loading $\left(0.4,0.2,0.1,0.05 \mathrm{mg} / \mathrm{cm}^{2}\right)$. The 1179 driest and coldest conditions used for the potentio-dynamic simula- tions could not be simulated in the galvano-dynamic mode with the 1180 selected current profile. This is due to the severe anode dry out with 1181 EOD that occurs during a step change in current density ${ }^{12}$ and results 1182 in numerical issues under these dry conditions, where the membrane 1183 hydration is low prior to the increase in load.

The resulting voltage dynamics for all 16 simulations are shown 1185 in Fig. 10. The corresponding average water content in the membrane 1186 for all the cases are shown in Fig. 11 and the average liquid saturations 1187 in the cathode GDL are shown in Fig. 12. Similar to the analysis for 1188 the potentio-dynamic case, below we organize the discussion in terms 1189 of the current density step.

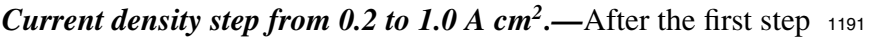
in the current density, the voltage drops and a steady state value is 1192 achieved within 20 seconds. Only the case with $\mathrm{T}=80^{\circ} \mathrm{C}$ and $\mathrm{RH}={ }_{1193}$ $90 \%$ with a Pt loading of $0.4 \mathrm{mg} / \mathrm{cm}^{2}$ demonstrates a slight undershoot 1194 that is a characteristic response of PEM fuel cells due to dry out of 1195 the membrane by EOD as mentioned earlier. ${ }^{146}$ This dry out can also 1196 be observed in Fig. 11. It should be noted that mass transport limita- 1197 tions at higher loads can also contribute to this behavior. ${ }^{152}$ However, 1198 

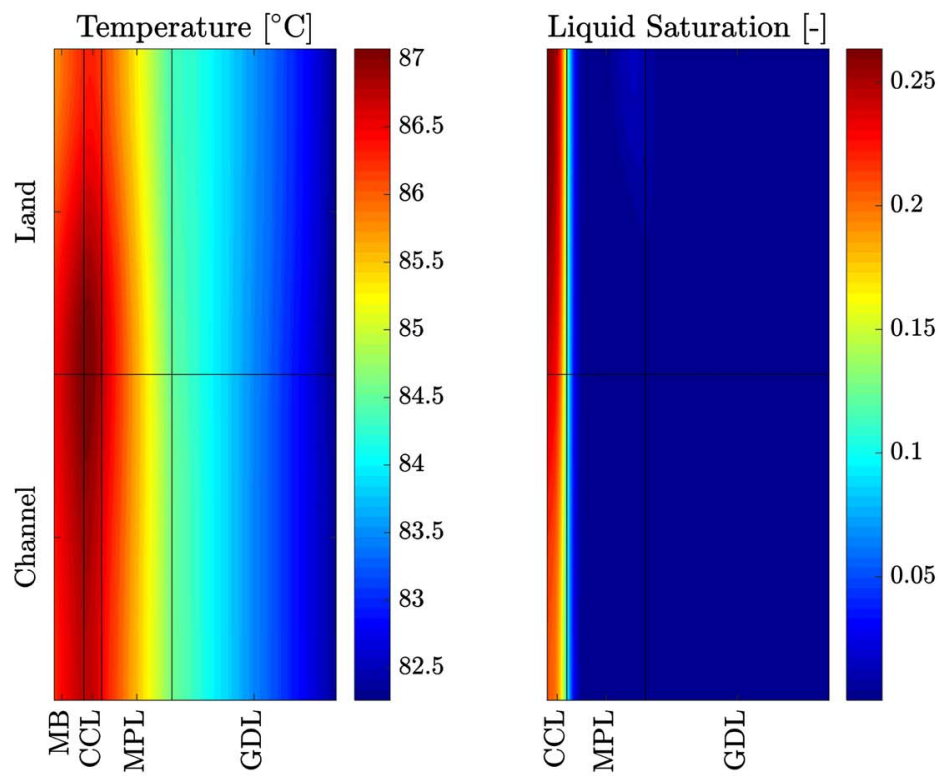

(a)
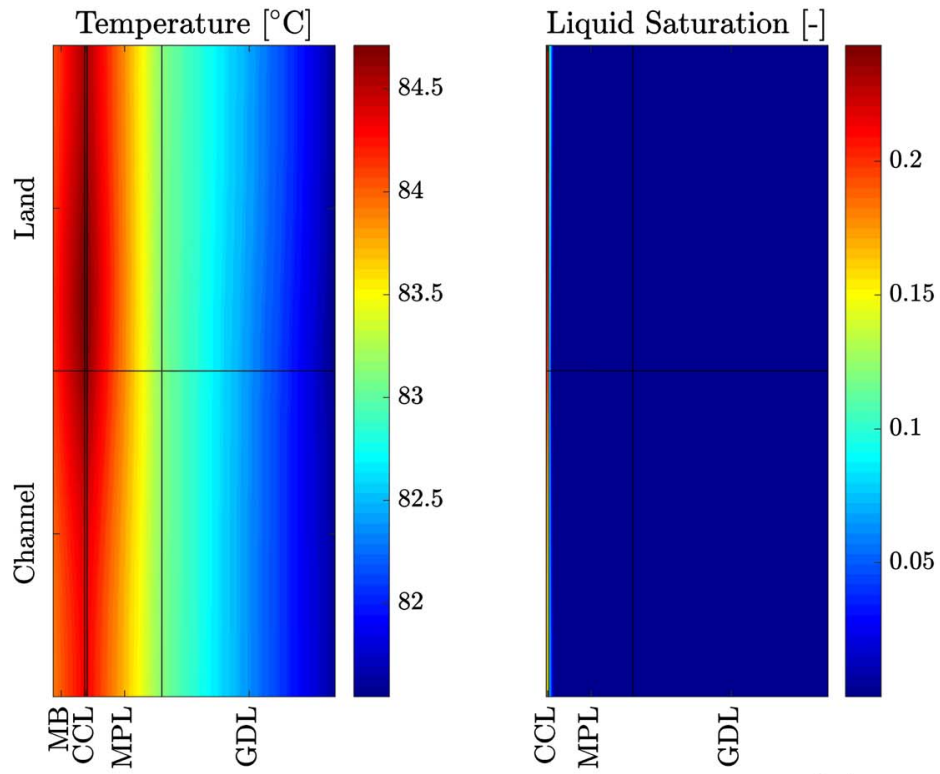
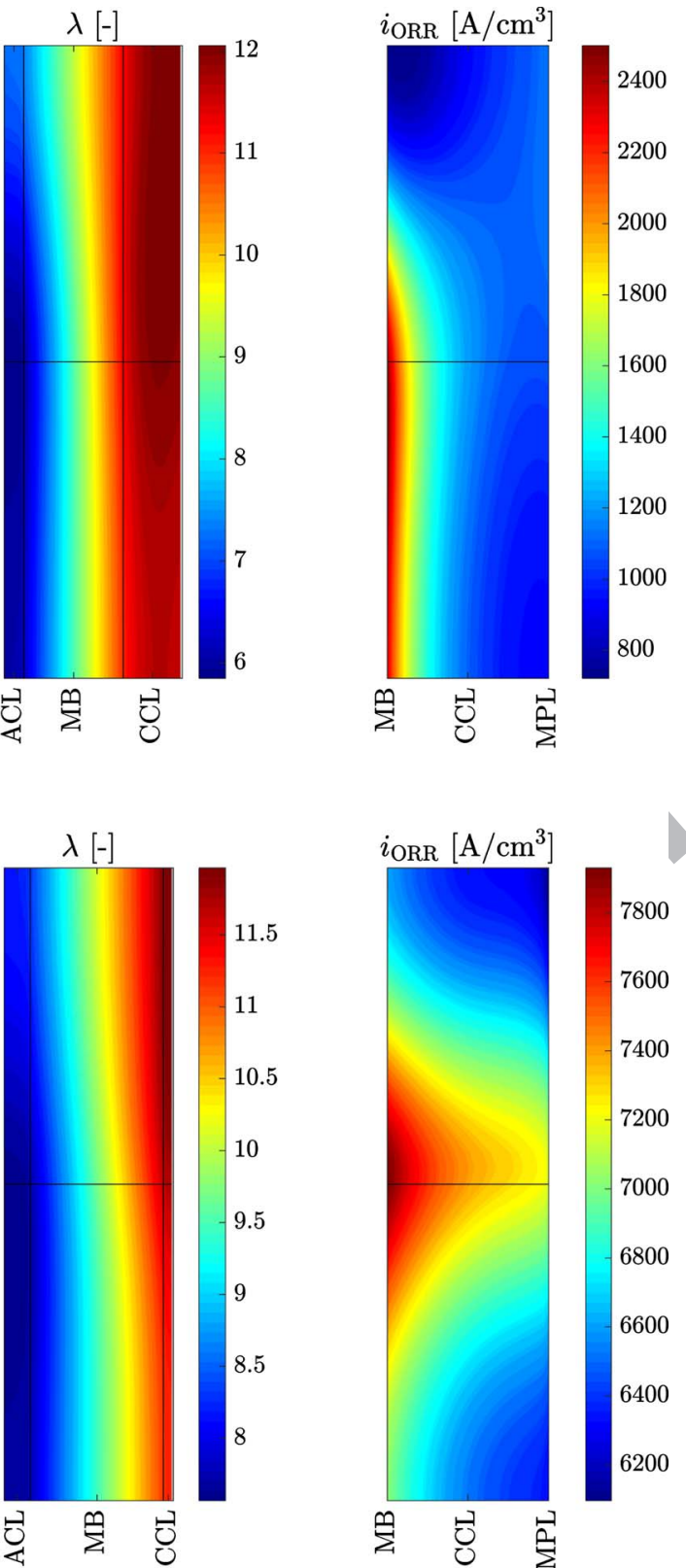

(b)

Figure 9. Distribution of temperature, liquid saturation, ionomer water content, and ORR volumetric current density for the potentio-dynamic simulations under the hot-wet $\left(\mathrm{T}=80^{\circ} \mathrm{C}\right.$ and $\left.\mathrm{RH}=90 \%\right)$ operating condition at $\mathrm{t}=219 \mathrm{~s}$ (highest load just before the following voltage step up) with Pt loadings of: a) 0.4 and $\mathrm{b}$ ) $0.05 \mathrm{mg} / \mathrm{cm}^{2}$.

1199 membrane dry out is the only contributing factor in this case, since the 1200 operation is well within the ohmic region and mass transport effects 1201 are relatively insignificant. To finalize our discussion of the voltage 1202 response, it is worth mentioning that higher Pt loading is observed to 1203 consistently result in improved performance under all four simulated 1204 conditions at $1.0 \mathrm{~A} / \mathrm{cm}^{2}$.

1205 As for the GDL liquid saturation, only the coolest $\left(\mathrm{T}=60^{\circ} \mathrm{C}\right)$ and 1206 most humidified $(\mathrm{RH}=90 \%)$ condition results in vapor condensation 1207 after this step change in the current density (Fig. 12). This condensa1208 tion continues throughout the entire 100 seconds hold at $1.0 \mathrm{~A} / \mathrm{cm}^{2}$, 1209 where the higher Pt loadings result in slightly higher liquid accumula1210 tion in the GDL. This higher liquid saturation is due to the fact that the 1211 thicker catalyst results in higher cell voltage and reduced volumetric 1212 heat generation, which lowers the overall cell temperature by about $12130.4^{\circ} \mathrm{C}$. The average saturation of 0.2 agrees with the in-operando re- sults by Banerjee et al. ${ }^{153}$ They also propose fitting the time evolution 1214 of liquid saturation with a first order dynamic equation and obtain a 1215 time constant of 2.3 minutes for similar operating conditions using an 1216 SGL 25BC diffusion medium. Similar dynamics are observed by oth- 1217 ers as well. ${ }^{154}$ Our results indicate a time constant of about 33 seconds, 1218 which is more than 4 times faster than that reported by Banerjee et al. ${ }^{153}{ }_{1219}$ This discrepancy between the model predictions and experimental re- 1220 sults may be attributed to differences in cell geometry, membrane and 1221 catalyst layers, and thermal properties assumed for SGL 24BC in this 1222 work.

Current density step from 1.0 to $1.8 \mathrm{~A} / \mathrm{cm}^{2}$.- The voltage re- 1224 sponse to the second step increase in current density is seen to be 1225 monotonically decreasing in most cases, while some cases $\left(\mathrm{T}=60^{\circ} \mathrm{C} \quad{ }_{1226}\right.$ and $\mathrm{RH}=60 \%$ in Fig. 10) exhibit the characteristic undershoot dis- 1227 

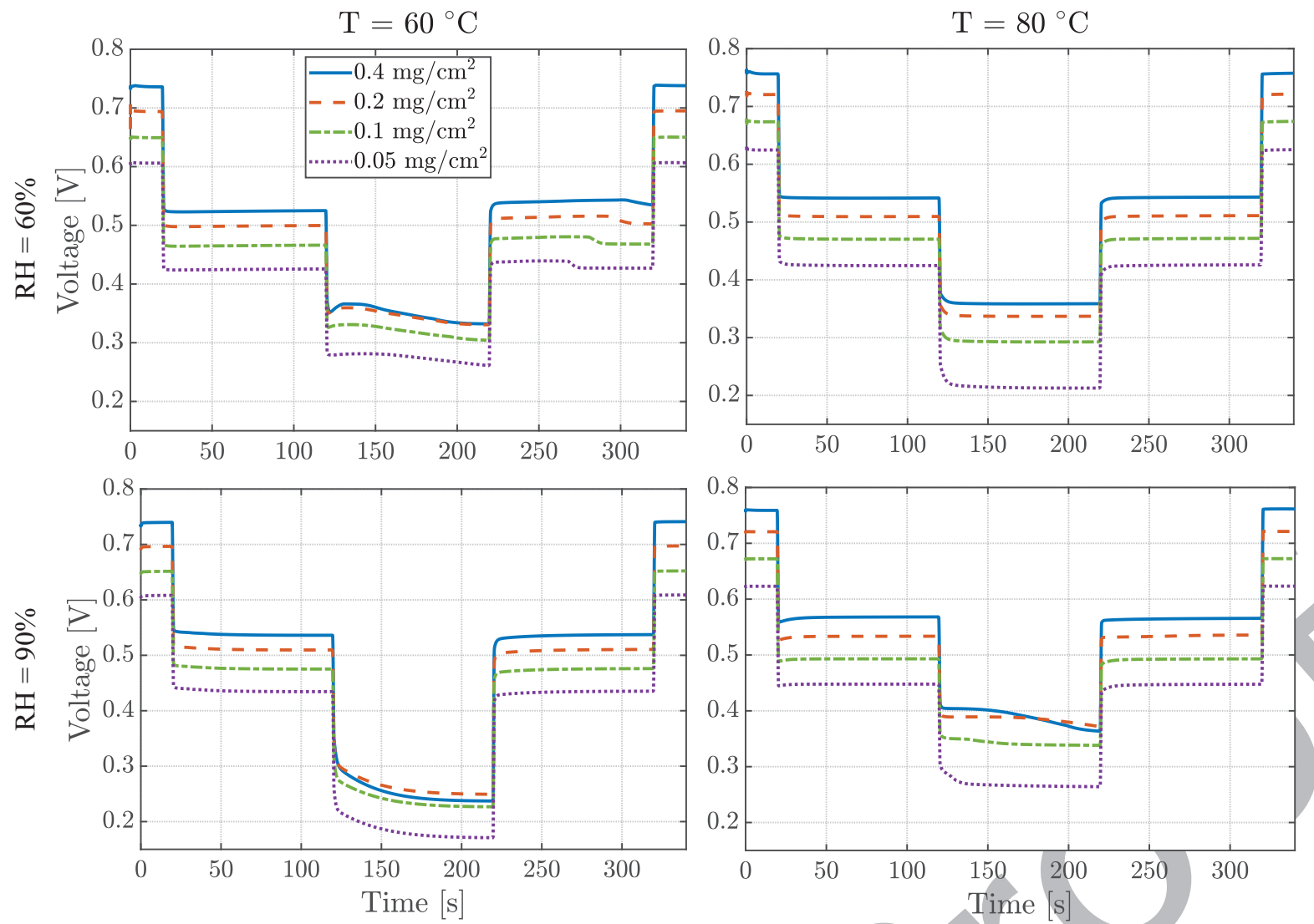

Figure 10. Average voltage dynamics for the galvano-dynamic simulations.
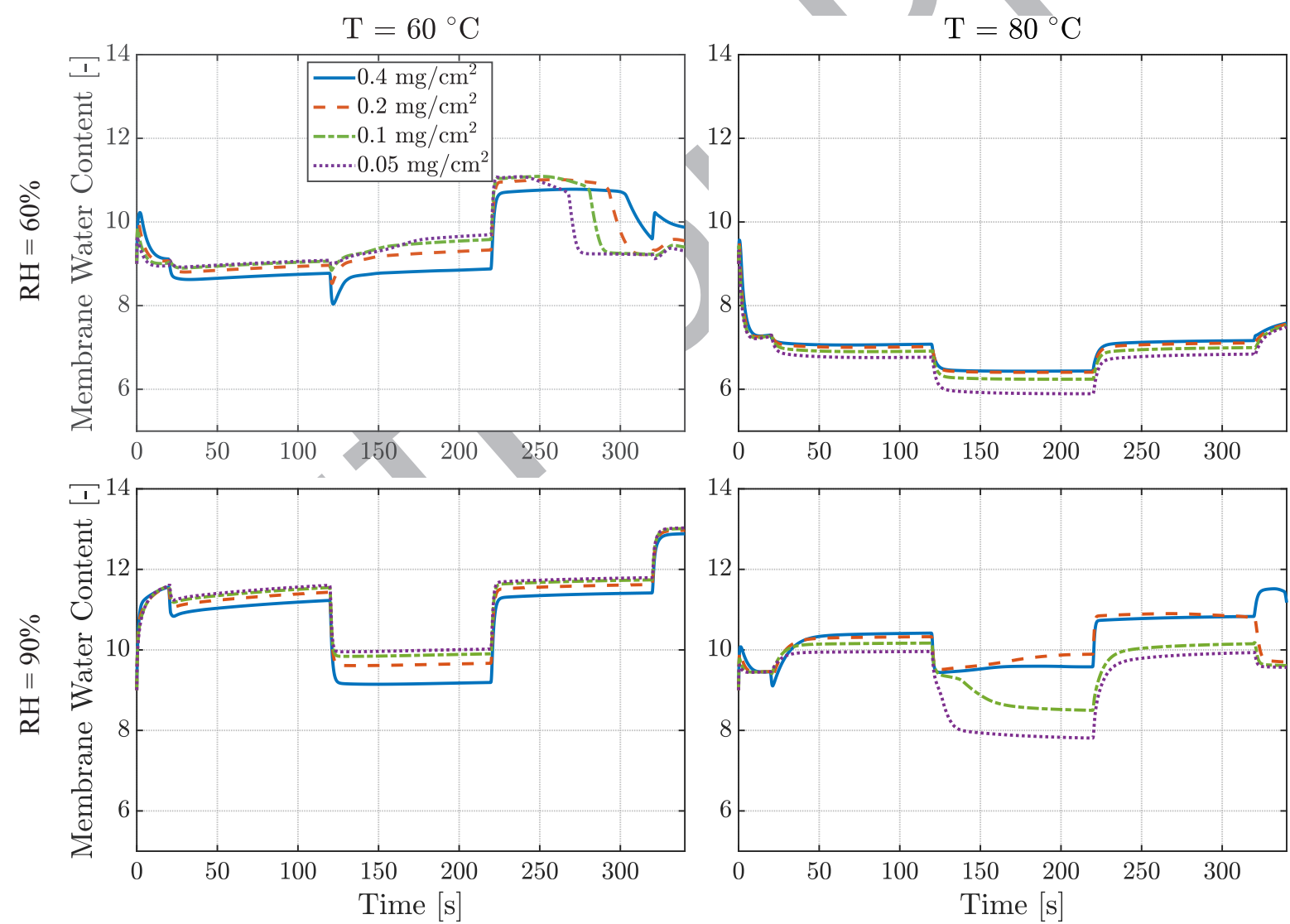

Figure 11. Average membrane water content dynamics for the galvano-dynamic simulations. 

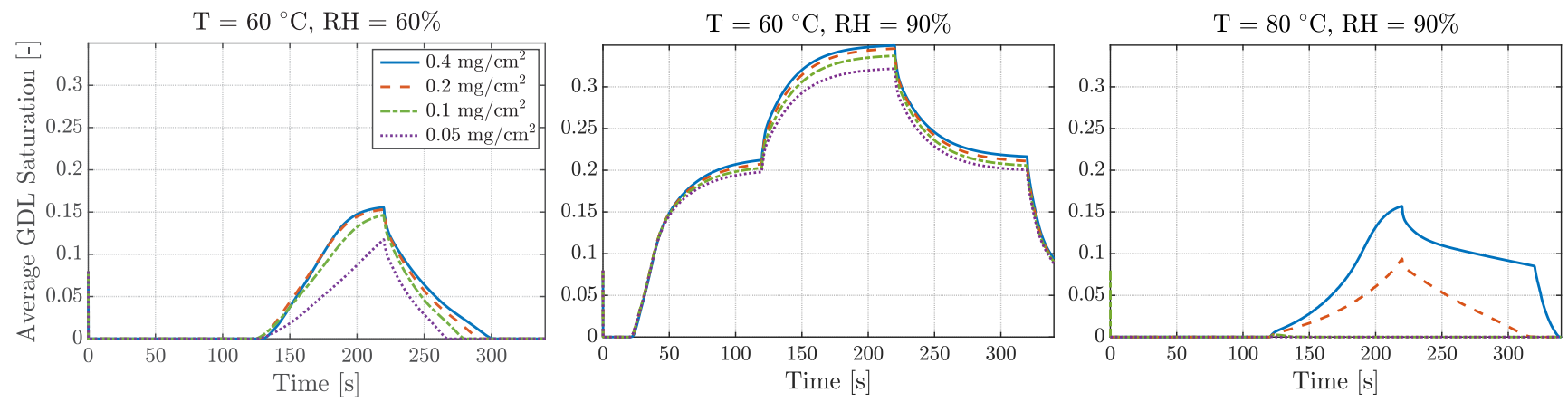

Figure 12. Average liquid saturation dynamics in the cathode GDL for the galvano-dynamic simulations.

1228 cussed earlier. The monotonic voltage decay is a sign of well humidi1229 fied membrane and increasing mass transport limitations with slowly 1230 accumulating liquid water (e.g., $\mathrm{T}=60^{\circ} \mathrm{C}$ and $\mathrm{RH}=90 \%$ in Fig. 10 1231 and Fig. 12). For the operating condition where a voltage undershoot 1232 is observed, the performance recovers to some extent after the step 1233 change with water back diffusion and rehydration of the anode side of 1234 the membrane. However, this voltage recovery is followed by a further 1235 decay as the cathode GDL floods with liquid water (Fig. 12).

An important observation is the fact that at $\mathrm{T}=60^{\circ} \mathrm{C}$ and $\mathrm{RH}=$ $90 \%$, reducing the Pt loading from 0.4 to $0.2 \mathrm{mg} / \mathrm{cm}^{2}$ seems to improve performance. This seemingly peculiar behavior is directly related to the changes in the membrane water content with CL thickness. In particular, Fig. 11 shows that at $60^{\circ} \mathrm{C}$ and $1.8 \mathrm{~A} / \mathrm{cm}^{2}$, thinner catalysts consistently result in better membrane hydration. This is explained further when discussing the water balance in the cell later in this section. The higher membrane water content achieved at $0.2 \mathrm{mg} / \mathrm{cm}^{2}$ reduces the ohmic drop, while the Pt reduction at this level does not impose significant mass transport issues. Therefore, the performance is improved. Yet another interesting observation is related to the impact of Pt loading on voltage dynamics at $\mathrm{T}=80^{\circ} \mathrm{C}$ and $\mathrm{RH}=90 \%$. Specifically, we observe that immediately after the load increase, the highest Pt loading achieves the best performance. But this performance decays more rapidly than the cases with lower Pt loading, to the point that at the end of the 100 second hold at $1.8 \mathrm{~A} / \mathrm{cm}^{2}$, the cell with a Pt loading of $0.2 \mathrm{mg} / \mathrm{cm}^{2}$ has a higher voltage than that with a Pt loading of 0.4 $\mathrm{mg} / \mathrm{cm}^{2}$. This is directly related to faster liquid accumulation in the GDL with a thick CL which is due to lower cell temperatures (Fig. 12). The heat generation in the two thinnest CLs is high enough to inhibit any liquid accumulation (Fig. 12), which results in lower membrane water contents as seen in Fig. 11 and reduced performance.

Current density steps from 1.8 to $1.0 \mathrm{~A} / \mathrm{cm}^{2}$ and from 1.0 to $0.2 \mathrm{~A} / \mathrm{cm}^{2}$.—For the simulated conditions, the step decreases in current density result in monotonic voltage increase with relatively fast dynamics. A hysteresis effect may be expected due to membrane hydration-dehydration and Pt oxide coverage dynamics. The former 1262 effect can be seen to some extent in the simulations results at $\mathrm{T}=1263$ $60^{\circ} \mathrm{C}$ and $\mathrm{RH}=60 \%$. The most notable feature of the voltage re- 1264 sponse to load decreases at this condition is a drop in performance 1265 after a considerable time delay. This is due to evaporation of liquid 1266 water reservoir in the cathode CL and the ensuing loss of membrane ${ }_{1267}$ water (Fig. 11) and was discussed in detail for the potentio-dynamic 1268 simulations. Other conditions show almost no hysteresis, since they 1269 are well humidified. Furthermore, as mentioned in the Model Formula- 1270 tion section, the Pt oxide growth dynamics are neglected in our model, 1271 which further contributes to the lack of hysteresis in our results. $\quad{ }_{1272}$

Further insight about the water balance in the cell can be gained by 1273 comparing the normalized membrane water fluxes $(\beta)$ shown in Fig. 1274 13. The figure illustrates $\beta$ values (defined by Eq. 54) for different 1275 operating conditions and cathode Pt loadings at 119 seconds, which 1276 corresponds to the hold at $1.0 \mathrm{~A} / \mathrm{cm}^{2}$ just before the following step 1277 increase in the load. Some clear trends can be observed in these results. 1278 First, we note that increasing the RH increases $\beta$. This is due to the fact 1279 that the cathode CL typically has a high RH under all conditions due 1280 to the electrochemical water generation. A low RH dries out the anode 1281 $\mathrm{CL}$ and promotes water back diffusion, which explains lower $\beta$ values. 1282 Another important observation is the impact of temperature on $\beta$. At 1283 lower $\mathrm{RH}$ conditions ( $\mathrm{RH}=60 \%$ ), we observe that $\beta$ increases with 1284 temperature. This is due to the fact that parts of the cathode CL remain 1285 subsaturated at low RH and high temperatures, which reduce water 1286 back diffusion and increases $\beta$. At higher $\mathrm{RH}$ conditions $(\mathrm{RH}=90 \%),{ }_{1287}$ the cathode CL remains saturated at both low and high temperatures. 1288 Therefore, the water activity in the anode CL determines the driving 1289 force for water back flow. As this water activity diminishes at higher 1290 temperatures, the water back diffusion is more pronounced, which 1291 yields a lower value of $\beta$.

Similar arguments can be used to explain the seemingly counterin- 1293 tuitive impact of Pt loading on the water balance. In particular, we note 1294 that at lower temperature, $\beta$ increases with Pt loading and the resulting 1295 increase in CL thickness. This trend is reversed at higher temperature, 1296
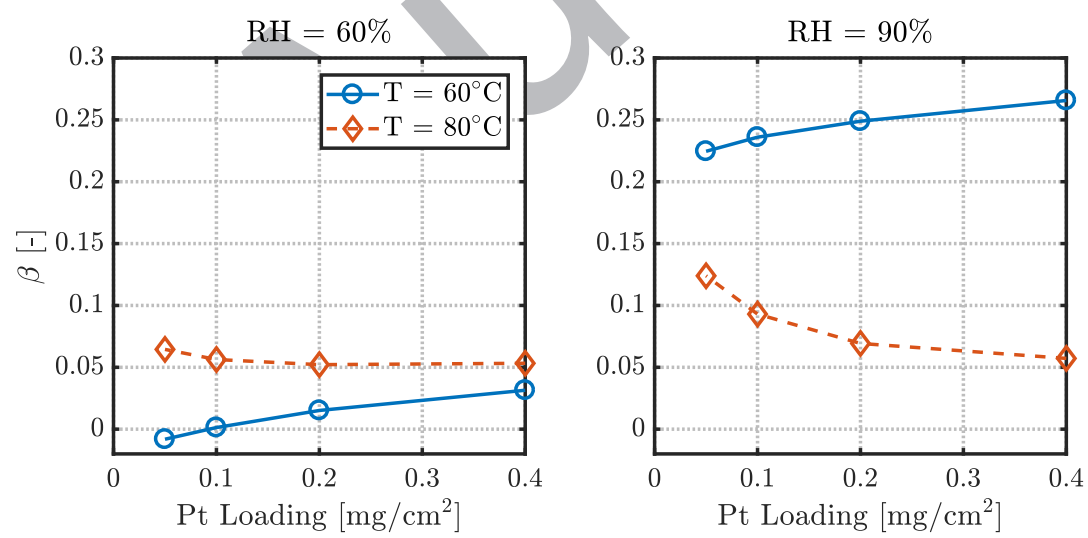

Figure 13. Normalized average water flux in the membrane (positive is toward cathode) at $\mathrm{t}=119 \mathrm{~s}$ (medium load just before the following current step up) for the galvano-dynamic simulations. 
1297 where a higher $\mathrm{Pt}$ loading reduces $\beta$. The trend at $\mathrm{T}=60^{\circ} \mathrm{C}$ can be ex1298 plained by the fact that at this lower temperature, the $\mathrm{CL}$ is saturated 1299 for all Pt loadings. A lower Pt loading means that the water that is 1300 produced in the CL close to the MPL has a lower resistance to diffuse 1301 back to the anode, since the cathode CL is thinner and the diffusion 1302 path is shorter. This means that a thinner CL reduces $\beta$. When the tem1303 perature is increased, subsaturated conditions emerge in parts of the ${ }_{1304} \mathrm{CL}$ as mentioned before. Therefore, an increase in the temperature di1305 minishes the driving force for water back diffusion and increases $\beta$. As 1306 thinner CLs generate more heat, the local CL temperature increases 1307 further, which in turn increases $\beta$. This result bears significance as 1308 it shows that in addition to changes in local transport resistance, $\mathrm{Pt}$ 1309 loading impacts the performance by influencing the water balance in 1310 the cell. This overall observation partially confirms the hypothesis by 1311 Muzaffar et al., ${ }^{77}$ who claimed that the performance changes with $\mathrm{Pt}$ 1312 loading reduction may mostly stem from a tipping water balance in 1313 the cell. However, their conclusion was based on the assumption that the $\mathrm{CL}$ is the main source of vaporization in the cell and a thinner CL 1314 makes the cell inherently more susceptible to flooding. On the other 1315 hand, the phase change rate is assumed to be relatively high in our 1316 model based on the experimental evidence in the literature that sug- 1317 gest the phase change kinetics should be fast enough not to impose 1318 any limitations. ${ }^{143}$ This high rate of phase change allows the GDL to 1319 vaporize a relatively large amount of liquid. Nevertheless, our results 1320 also highlight the role of Pt loading and CL thickness in the cell water 1321 balance.

1322

Our discussion of the galvano-dynamic simulations has focused 1323 on average response of the cell so far. However, the distribution of 1324 temperature, water, and reaction rates are also of critical importance. 1325 An example of such distributions is provided in Fig. 14 for high $(0.41326$ $\left.\mathrm{mg} / \mathrm{cm}^{2}\right)$ and low $\left(0.05 \mathrm{mg} / \mathrm{cm}^{2}\right)$ cathode Pt loading. The figure shows 1327 a rather significant in-plane temperature gradient in the membrane and 1328 $\mathrm{CL}$, where a temperature difference of up to $4^{\circ} \mathrm{C}$ is observable. This 1329 temperature difference is due to the high current generation under the 1330
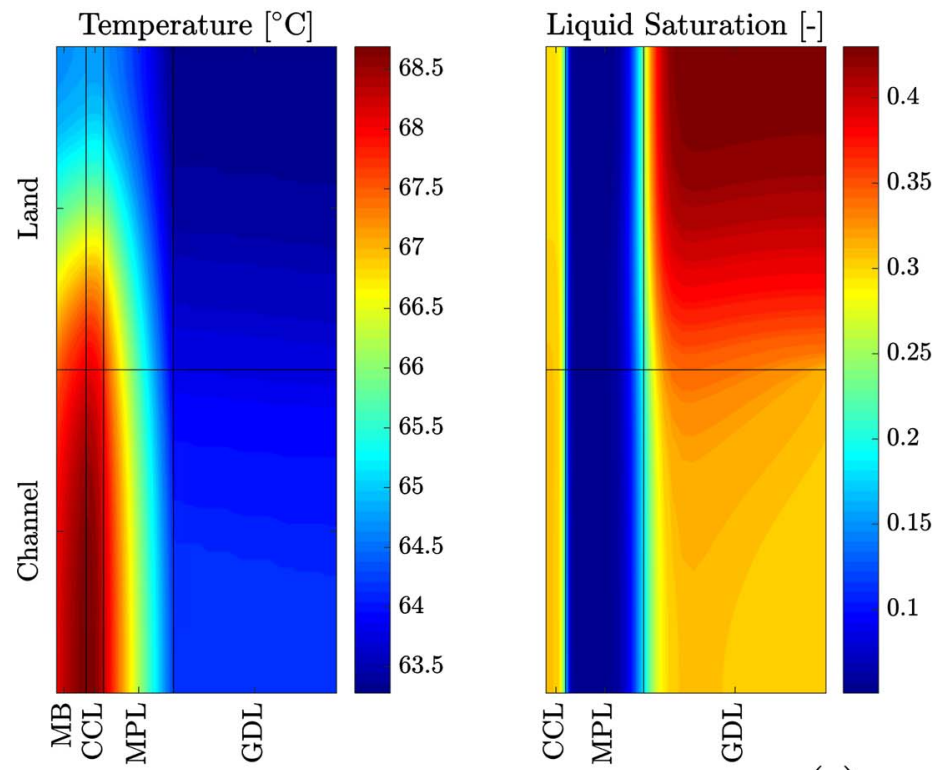

(a)

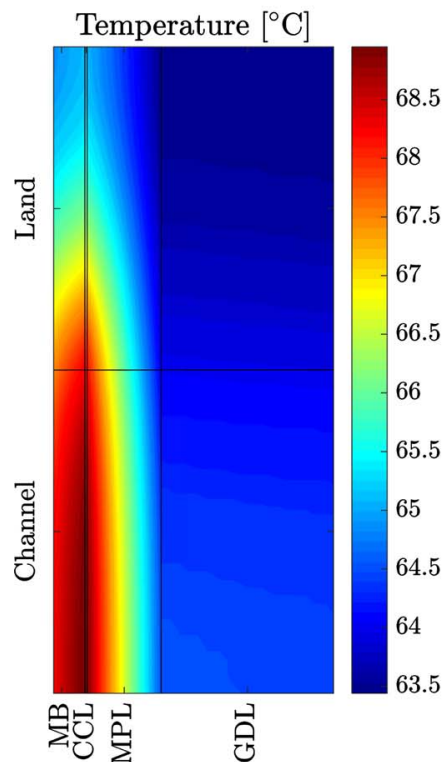

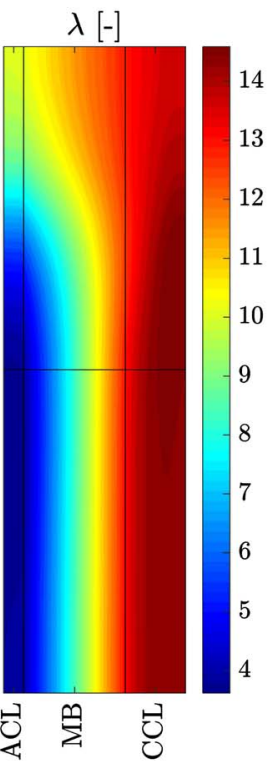
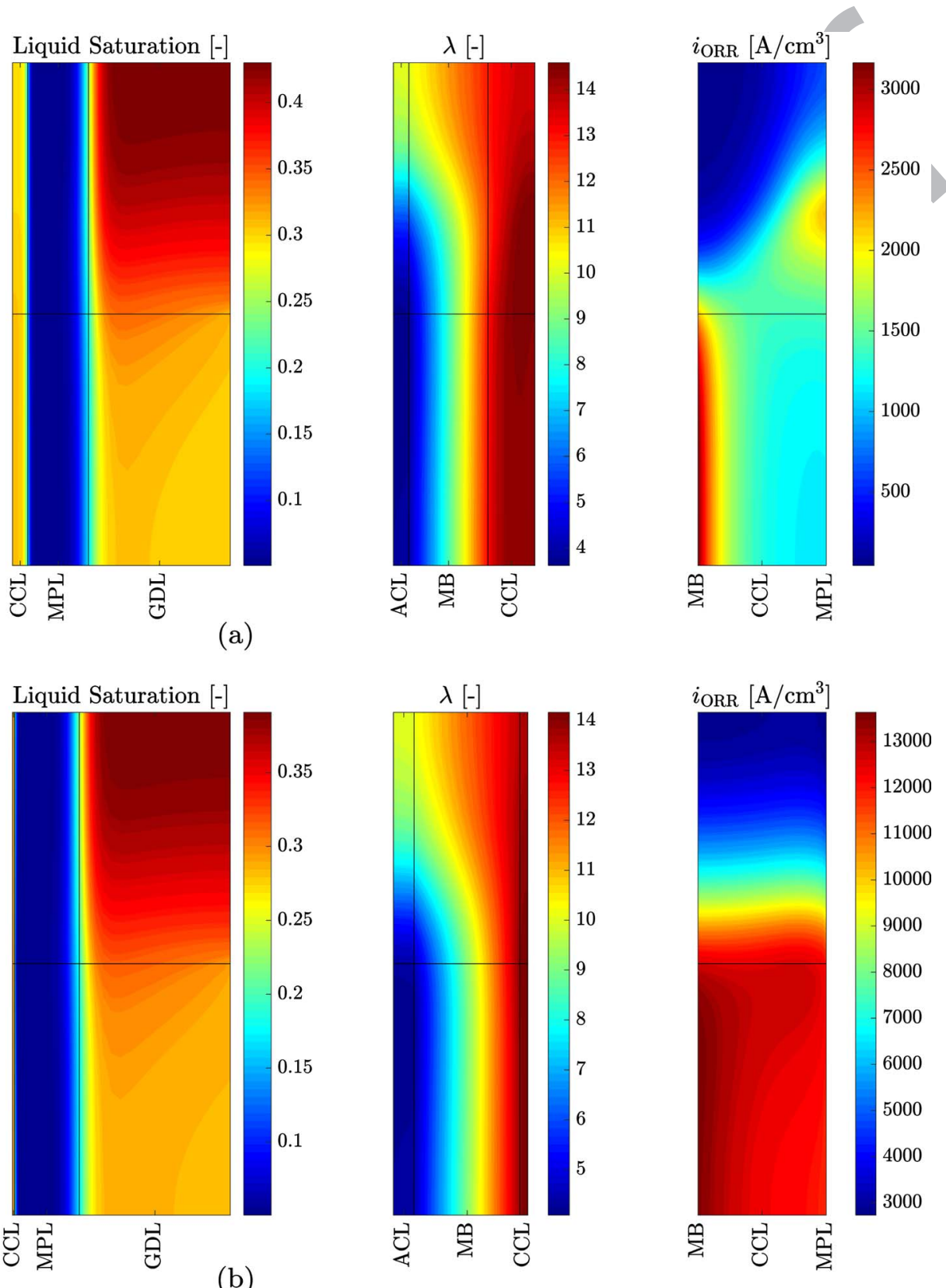

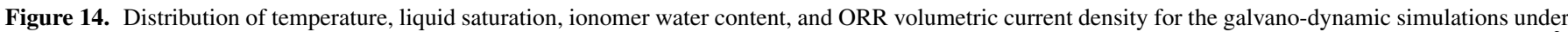

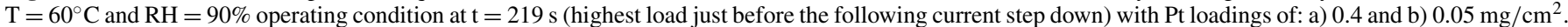


1331 channel location along with the limited heat dissipation through the 1332 channel boundary.

1333 Furthermore, we see that the cathode GDL has a very high sat1334 uration at this operating condition, which imposes significant mass 1335 transport limitations and results in limited current generation under 1336 the land area. It should be pointed out that a higher liquid saturation 1337 is observed under the land while a rather uniform distribution is seen 1338 through the GDL thickness. Zenyuk et al. found a higher liquid sat1339 uration under the channel in a compressed GDL due to the in-plane 1340 porosity distribution resulting from land compression. ${ }^{155}$ However, 1341 the temperature distribution in an operating fuel cell usually shifts the 1342 water accumulation toward the land region. ${ }^{153}$ This flooding under the 1343 land has much less pronounced impact on the overall performance 1344 compared to flooding under the channel, ${ }^{156}$ since the land region is 1345 already transport limited by the longer diffusion paths. In terms of 1346 the through-plane liquid distributions, there is evidence in the litera1347 ture for increased saturation in higher porosity regions of the GDL. ${ }^{113}$ 1348 Furthermore, Banerjee et al. ${ }^{153}$ found the highest level of saturation 1349 to occur close to the land. Finally, capillary fingering is believed to 1350 be a major transport mechanism for liquid water. ${ }^{155,157}$ The model in 1351 this work assumes a constant GDL porosity through the thickness, so 1352 the pooling effects cannot be captured. The rather uniform through1353 plane liquid distribution stems from the temperature distributions in 1354 our simulations. Finally, the macro-homogeneous model in this work 1355 does not allow for simulation of capillary fingering. Therefore, the liq1356 uid saturations predicted by the proposed model are only insightful on 1357 an aggregate level and detailed knowledge about the micro-structures 1358 are needed to obtain accurate distributions. ${ }^{16}$

1359 The non-uniform current generation pattern also affects water dis1360 tribution in the ionomer phase. In particular, we see that under the 1361 land, the water content is more uniform across the thickness of the 1362 CCM, whereas significant gradients emerge under the channel, where 1363 current generation is high. Comparing the low and high Pt loading 1364 cases, we observe that the lower Pt loading results in slightly higher 1365 temperatures, which in turn reduce liquid saturation in the cathode 1366 GDL. Moreover, the current distribution through the thickness of the 1367 cathode CL is more uniform for the lower loaded CL as discussed 1368 earlier. $^{72}$
The preceding analysis provides some insight about the quasi 1369 steady state distributions of critical variables. To better understand 1370 the water transport transients during the following current step down, 1371 the distributions of liquid pressure in the cathode CL and the mem- 1372 brane water content before and after the step change are shown in Fig. 1373 15 and Fig. 16, respectively, for the high Pt loaded CL $\left(0.4 \mathrm{mg} / \mathrm{cm}^{2}\right) .1374$ Fig. 15 shows that immediately before the step change at $219.5 \mathrm{sec}-1375$ onds, liquid pressure is highest under the channel. The flow directions 1376 provided in the figure show an interesting pattern, where the liquid 1377 water is found to flow mostly toward the membrane in the land re- 1378 gion and mostly toward the MPL in the channel region. This behavior 1379 is closely tied to a similar flow pattern in the membrane as seen in 1380 Fig. 16, where a recirculation is observed at 219.5 seconds. More 1381 specifically, it is seen that at the furthest location under the land, the 1382 membrane water flux is toward the anode. As we move closer to the 1383 channel location, the flux turns progressively toward the cathode. As 1384 the load is reduced to $1.0 \mathrm{~A} / \mathrm{cm}^{2}$, EOD is relieved and water back 1385 diffusion dominates during the transients (as was observed in Fig. 71386 for the potentio-dynamic simulations). This results in the membrane 1387 water flux to be dominantly toward the anode (Fig. 16 at 221 seconds), 1388 which also pushes liquid water toward the membrane to compensate 1389 for the back diffusion (Fig. 15 at 221 seconds). Two seconds after 1390 the step change, a smoother water profile is established across the 1391 membrane thickness and water back diffusion has diminished (Fig. 1392 16 at 222.5 seconds). This creates a dominant flux toward the cath- 1393 ode. At the same time, a higher liquid pressure is observed in the 1394 cathode CL, where a stagnation front has emerged in the middle (Fig. 1395 15 at 222.5 seconds). In particular, in the half of the CL close to the 1396 membrane, the flow is found to be toward the membrane, whereas in 1397 the other half to the right of the stagnation front, the flow is found 1398 to be toward the MPL. As time goes on and a quasi steady state is 1399 achieved at this reduced load, the stagnation front moves further to- 1400 ward the membrane (Fig. 15 at 230 seconds), while the membrane 1401 water flux turns toward the cathode throughout the membrane thick- 1402 ness (Fig. 16 at 230 seconds). The existence of the stagnation front 1403 is in agreement with our earlier observation that a thick catalyst layer 1404 increases the resistance to water flow toward the anode. The transients 1405 during a step increase in the load are the reverse of those presented 1406 here.
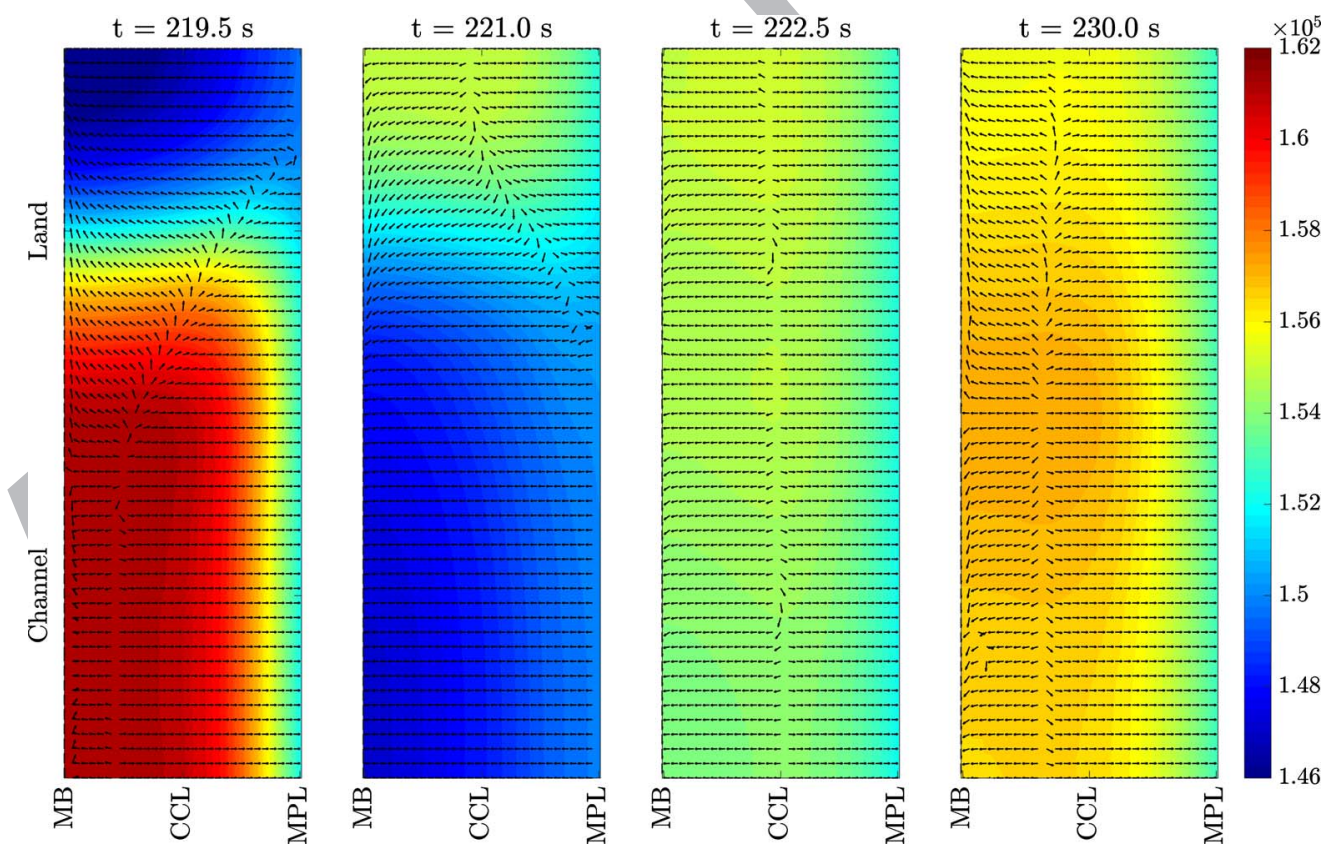

Figure 15. Liquid pressure (in [Pa]) and flow in the cathode CL during load decrease from 1.8 to $1 \mathrm{~A} / \mathrm{cm}^{2}$ at T $=60^{\circ} \mathrm{C}$ and $\mathrm{RH}=90 \%\left(\mathrm{Pt}\right.$ loading of $\left.0.4 \mathrm{mg} / \mathrm{cm}^{2}\right)$. From left to right: immediately before the step change, 0.5 seconds after the step change, 2 seconds after the step change, the quasi steady state achieved after the step change. 

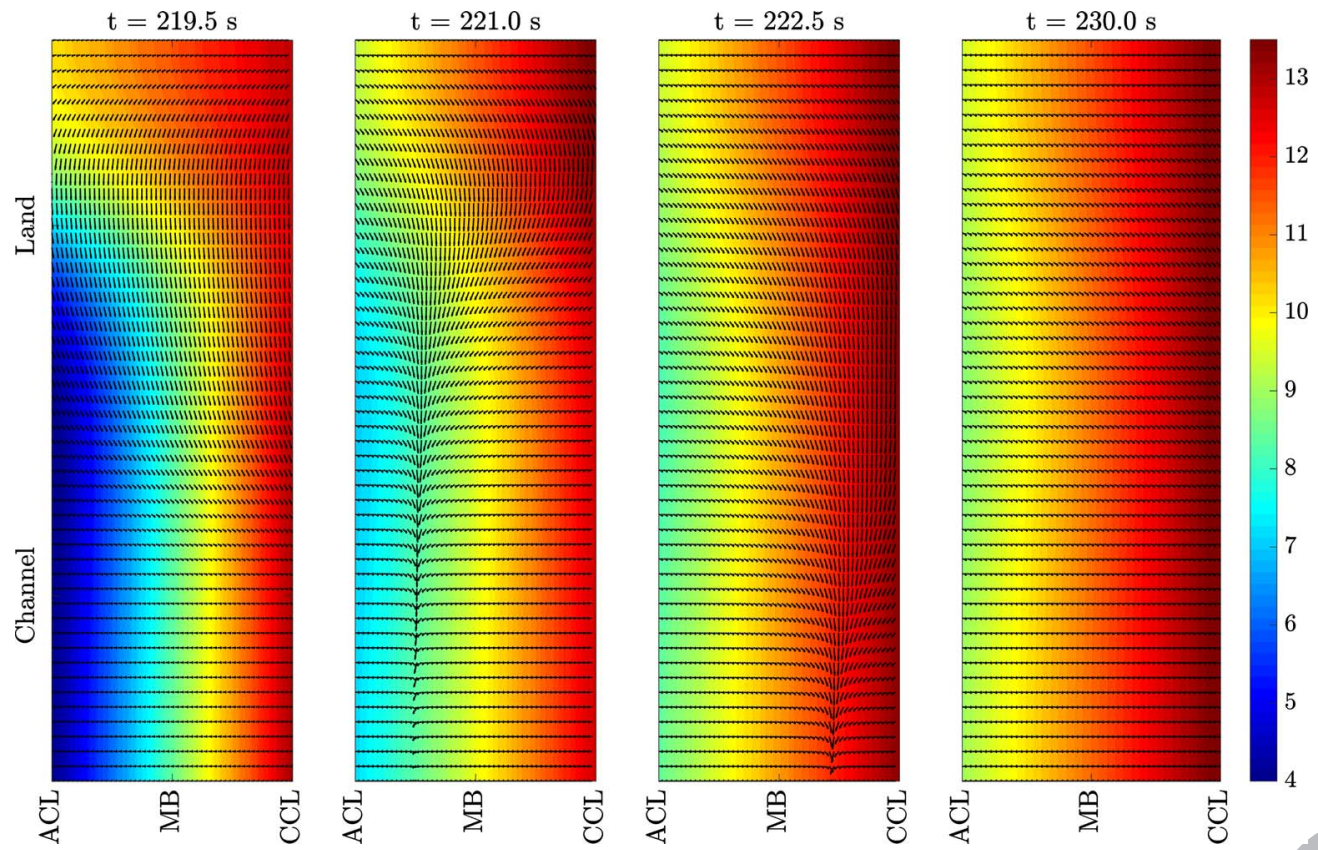

Figure 16. Membrane water content and flow during load decrease from 1.8 to $1 \mathrm{~A} / \mathrm{cm}^{2}$ at $\mathrm{T}=60^{\circ} \mathrm{C}$ and $\mathrm{RH}=90 \%\left(\mathrm{Pt}\right.$ loading of $\left.0.4 \mathrm{mg} / \mathrm{cm}^{2}\right)$. From left to right: immediately before the step change, 0.5 seconds after the step change, 2 seconds after the step change, the quasi steady state achieved after the step change. 1409 changes can also improve understanding of the transient phenomena. 1410 To this end, the corresponding distributions for the hot and wet operat1411 ing condition $\left(\mathrm{T}=80^{\circ} \mathrm{C}\right.$ and $\left.\mathrm{RH}=90 \%\right)$ during the load increase from 14121.0 to $1.8 \mathrm{~A} / \mathrm{cm}^{2}$ are shown in Fig. 17 for both low $\left(0.05 \mathrm{mg} / \mathrm{cm}^{2}\right)$ and 1413 high $\left(0.4 \mathrm{mg} / \mathrm{cm}^{2}\right)$ cathode Pt loading. We see that immediately before 1414 the step change, both Pt loadings result in a relatively uniform in-plane 1415 current distribution. However, as the load is increased to $1.8 \mathrm{~A} / \mathrm{cm}^{2}$ the region under the channel tends to generate more current with both 1416 Pt loadings. It can be seen, however, that the in-plane distribution is 1417 more uniform for the lower Pt loading case. This is attributable to the 1418 fact that the thinner CL results in higher cell temperatures and lower 1419 liquid build up, which reduces the mass transport limitations under the 1420 land region. We also note that current generation under the land is low 1421 even immediately after the load increase and before any liquid accu- 1422 mulation. This agrees with experimental results by Schneider et al., 1423
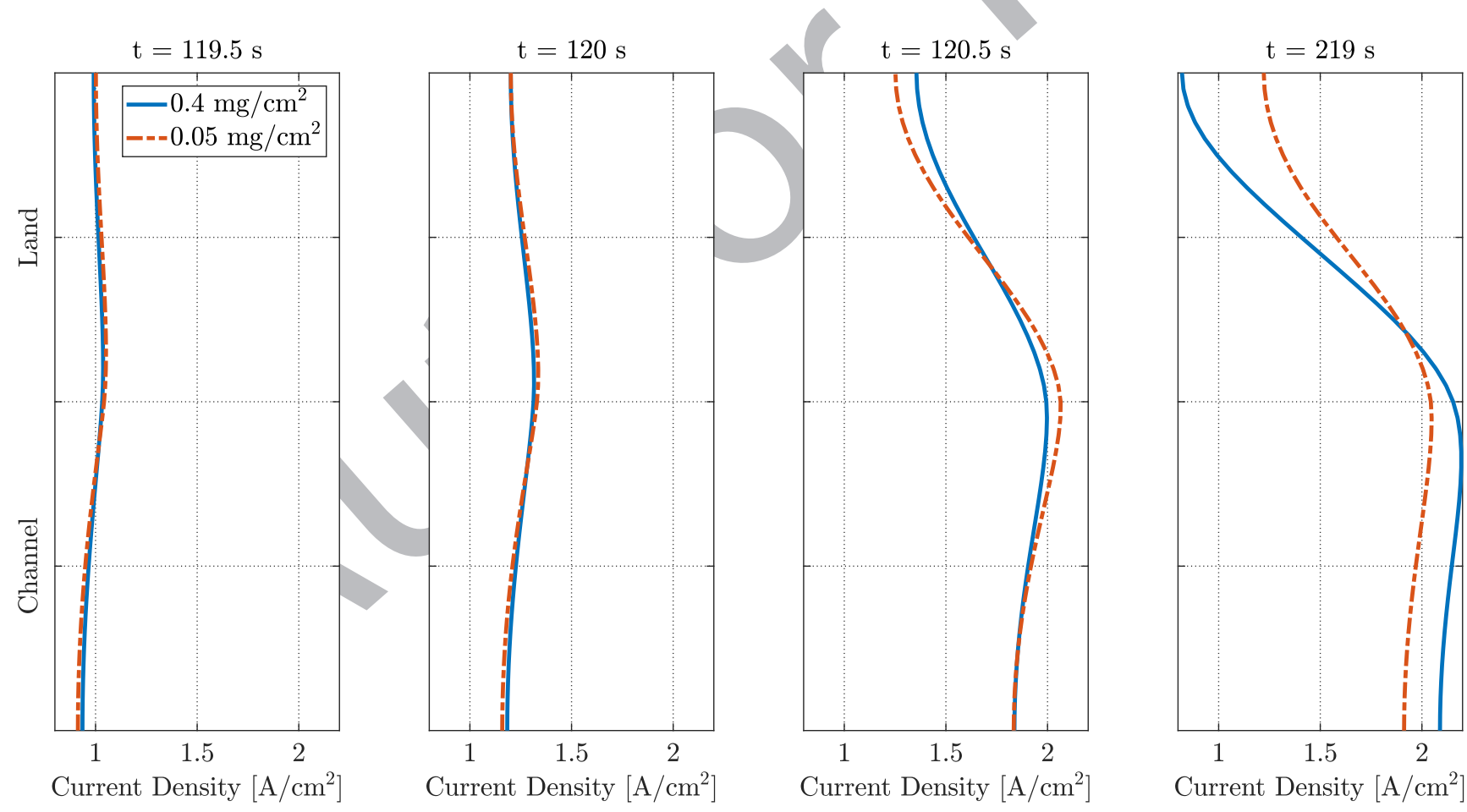

Figure 17. In-Plane current density distribution for the galvano-dynamic simulations during load increase from 1 to $1.8 \mathrm{~A} / \mathrm{cm}^{2}$ at $\mathrm{T}=80{ }^{\circ} \mathrm{C}$ and $\mathrm{RH}=90 \%$ for high and low cathode Pt loadings. From left to right: immediately before the step change, mid-way through the step change, immediately after the step change has completed, the quasi steady state achieved after the step change. 

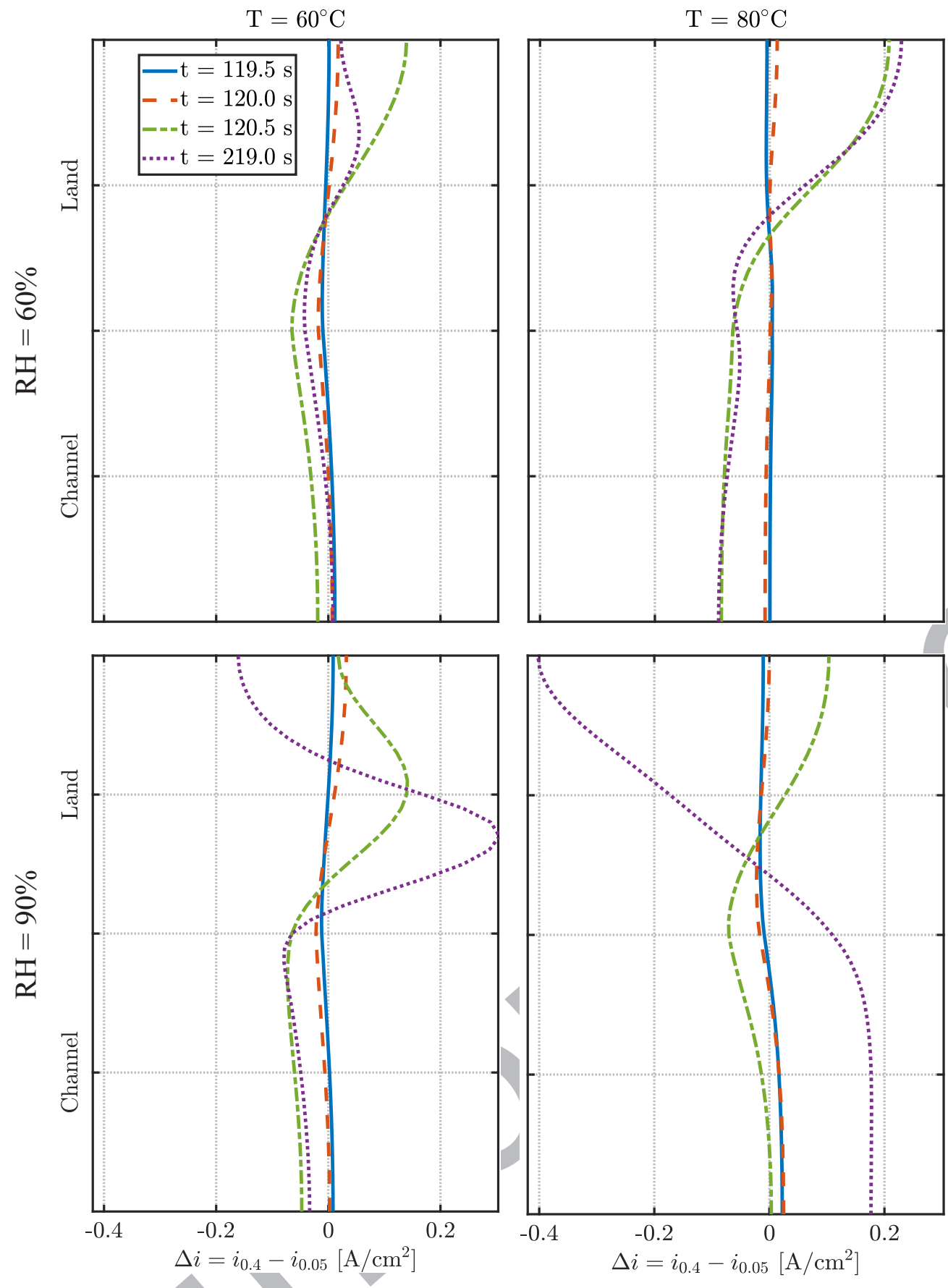

Figure 18. In-Plane current density distribution difference between high- and low-loaded CLs during load increase from 1 to $1.8 \mathrm{~A} / \mathrm{cm}^{2}$.

1424 who found the land region to be transport limited even prior to any 1425 liquid build up in the GDL. 158,159

1426

1427 in-plane current distribution, the difference betwe

1428 sities with high and low Pt loadings during the same load change are

1429 shown in Fig. 18 for all simulated operating conditions. The figure

1430 shows that at $1.0 \mathrm{~A} / \mathrm{cm}^{2}$ the difference between the current distri-

1431 butions is relatively insignificant as was seen earlier. As the load in-

1432 creases, however, the cathode Pt loading and CL thickness seem to

1433 have varying impacts on the current distribution at different operat-

1434 ing conditions. In particular, under drier conditions $(\mathrm{RH}=60 \%)$, the

1435 higher Pt loading and CL thickness result in improved performance

1436 under the land region immediately after the step change. At $\mathrm{T}=60^{\circ} \mathrm{C}$

1437 this performance enhancement under the land fades toward the new quasi equilibrium state, as more liquid builds up in the GDL when a 1438 thicker $\mathrm{CL}$ is used. However, at the higher temperature $\left(\mathrm{T}=80^{\circ} \mathrm{C}\right){ }_{1439}$ that inhibits liquid accumulation, the new equilibrium results in a dis- 1440 tribution difference that is close to that obtained immediately after 1441 the load change. When the RH is increased to $90 \%$, the response is 1442 dominated by liquid accumulation dynamics in the GDL. More specif- 1443 ically, thicker CLs make the GDL more susceptible to rapid liquid 1444 build up, as they generate less heat. Therefore, the performance is 1445 diminished under the land region. This results in a particularly sig- 1446 nificant difference at $\mathrm{T}=80^{\circ} \mathrm{C}$ and $\mathrm{RH}=90 \%$, where the thick CL 1447 prompts considerable GDL liquid saturation at 219 seconds, whereas 1448 the thin CL leads to a relatively dry GDL. Therefore, the high Pt 1449 loaded cathode CL shows a remarkable performance drop in the land 1450 region. 

1460 with experimental data obtained through voltammetry and voltage step 1461 experiments under a variety of conditions and a good agreement is ob1462 tained.

1463 The developed model is executed with different humidity and tem1464 perature conditions under both current and voltage control operational 1465 modes and varying Pt loadings in the cathode CL. The results of these 1466 simulations shed light into the transient processes that determine the 1467 dynamic response of PEM fuel cells to load changes. In particular, we 1468 have found the transient response to be dominated by water redistri1469 bution in the cell. The timescales of this redistribution are dependent 1470 on the operating conditions and are controlled by the membrane wa1471 ter uptake and two phase flow in the DM for dry and wet conditions, 1472 respectively. Furthermore, the modeling results suggest that changing 1473 the cathode Pt loading, and thereby, the cathode CL thickness, can 1474 influence the performance by affecting the water balance in the cell. 1475 Specifically, the thiner CL results in higher rates of heat generation on 1476 a volumetric basis while leading to a shorter diffusion path for water 1477 transport toward the anode. Our simulation results suggest that, based 1478 on the operating conditions, the combination of these effects lead to 1479 distinctly observable trends in normalized membrane water flux with 1480 respect to changes in the cathode Pt loading. Additionally, we have 1481 found that through its effect on water balance in the cell, the cathode $1482 \mathrm{Pt}$ loading can have a profound impact on the transient response to 1483 load changes for some operating conditions. These findings can fur1484 ther improve understanding of the impacts of Pt reduction on various 1485 aspects of PEM fuel cell performance and its transient response. More 1486 broadly, the model can be used to develop further insight into spatio1487 temporal distribution of variables that are critical to performance and 1488 degradation. 1493 (MINECO/FEDER, UE), the research grant Ayudas a la Investigacin 1494 en Energa y Medio Ambiente of the Spanish Iberdrola Foundation 1495 and the US-Spain Fulbright Commission. Krishan Talukdar is thank1496 ful to DLR.DAAD research fellowship of Germany for funding his $1497 \mathrm{PhD}$ research.

\section{ORCID}

1498 Alireza Goshtasbi (D) https://orcid.org/0000-0002-9575-6091

1499 Jixin Chen (1) https://orcid.org/0000-0002-5020-8024

1500 Tulga Ersal (i) https://orcid.org/0000-0002-6811-8529 4ources, 359, 634 (2017).
C. Ziegler, T. Heilmann, and D. Gerteisen, "Experimental study of two-phase transients in PEMFCs," Journal of the Electrochemical Society, 155(4), B349 (2008).
5. A. Sorrentino, T. Vidakovic-Koch, R. Hanke-Rauschenbach, and K. Sundmacher, 1514 "Concentration-alternating frequency response: A new method for studying poly- 1515 mer electrolyte membrane fuel cell dynamics," Electrochimica Acta, 243, 531516 (2017)

6. I. K. P. Arias, P. Trinke, R. Hanke-Rauschenbach, and K. Sundmacher, "Understand- 1518 ing PEM fuel cell dynamics: The reversal curve," International Journal of Hydrogen 1519 Energy, 42(24), 15818 (2017).

7. M. Heinzmann, A. Weber, and E. Ivers-Tiffée, "Advanced impedance study of poly- 1521 mer electrolyte membrane single cells by means of distribution of relaxation times," 1522 Journal of Power Sources, 402, 24 (2018).

8. M. Göbel, S. Kirsch, L. Schwarze, L. Schmidt, H. Scholz, J. Haußmann, M. Klages, 1524 J. Scholta, H. Markötter, S. Alrwashdeh et al., "Transient limiting current measure- 1525 ments for characterization of gas diffusion layers," Journal of Power Sources, 402, 1526 237 (2018).

9. D. Gerteisen, T. Heilmann, and C. Ziegler, "Modeling the phenomena of dehydration 1528 and flooding of a polymer electrolyte membrane fuel cell," Journal of Power Sources, 1529 187(1), 165 (2009).

10. R. J. Balliet and J. Newman, "Cold start of a polymer-electrolyte fuel cell i. develop- 1531 ment of a two-dimensional model," Journal of the Electrochemical Society, 158(8), 1532 B927 (2011).

11. Y. Wang and C.-Y. Wang, "Two-phase transients of polymer electrolyte fuel cells," 1534 Journal of The Electrochemical Society, 154(7), B636 (2007).

12. A. Verma and R. Pitchumani, "Influence of membrane properties on the transient 1536 behavior of polymer electrolyte fuel cells," Journal of Power Sources, 268, 7331537 (2014).

13. H. Wu, P. Berg, and X. Li, "Steady and unsteady 3d non-isothermal modeling of 1539 PEM fuel cells with the effect of non-equilibrium phase transfer," Applied Energy, 1540 87(9), 2778 (2010)

14. P. O. Olapade, J. P. Meyers, R. Mukundan, J. R. Davey, and R. L. Borup, "Modeling 1542 the dynamic behavior of proton-exchange membrane fuel cells," Journal of the 1543 Electrochemical Society, 158(5), B536 (2011).

15. M. Zaglio, Model Based Transient Analysis of Polymer Electrolyte Fuel Cells. PhD 1545 thesis, ETH Zurich, 2011.

16. P. A. García-Salaberri, I. V. Zenyuk, A. D. Shum, G. Hwang, M. Vera, A. Z. Weber, 1547 and J. T. Gostick, "Analysis of representative elementary volume and through-plane 1548 regional characteristics of carbon-fiber papers: diffusivity, permeability and electri- 1549 cal/thermal conductivity," International Journal of Heat and Mass Transfer, 127, 1550 687 (2018).

17. I. V. Zenyuk, D. Y. Parkinson, L. G. Connolly, and A. Z. Weber, "Gas-diffusion- 1552 layer structural properties under compression via X-ray tomography," Journal of 1553 Power Sources, 328, 364 (2016).

18. P. A. García-Salaberri, I. V. Zenyuk, G. Hwang, M. Vera, A. Z. Weber, and 1555 J. T. Gostick, "Implications of inherent inhomogeneities in thin carbon fiber-based 1556 gas diffusion layers: A comparative modeling study," Electrochimica Acta, 295, 8611557 (2019).

19. J. Zhou, A. Putz, and M. Secanell, "A mixed wettability pore size distribution based 1559 mathematical model for analyzing two-phase flow in porous electrodes i. mathemat- 1560 ical model," Journal of The Electrochemical Society, 164(6), F530 (2017). 1561

20. P. A. Mateo Villanueva, "A mixed wettability pore size distribution model for the 1562 analysis of water transport in PEMFC materials," Master's thesis, University of 1563 Alberta, 2013.

21. M. Hasan, A. Goshtasbi, J. Chen, M. H. Santare, and T. Ersal, "Model-based analysis 1565 of PFSA membrane mechanical response to relative humidity and load cycling in 1566 PEM fuel cells," Journal of The Electrochemical Society, 165(6), F3359 (2018). 1567

22. I. V. Zenyuk, P. K. Das, and A. Z. Weber, "Understanding impacts of catalyst-layer 1568 thickness on fuel-cell performance via mathematical modeling," Journal of the Elec- 1569 trochemical Society, 163(7), F691 (2016)

23. J. Zhou, S. Shukla, A. Putz, and M. Secanell, "Analysis of the role of the microporous 1571 layer in improving polymer electrolyte fuel cell performance," Electrochimica Acta, 1572 268, 366 (2018).

24. S. Kim and M. Mench, "Investigation of temperature-driven water transport in poly- 1574 mer electrolyte fuel cell: Thermo-osmosis in membranes," Journal of Membrane 1575 Science, 328(12), 113 (2009).

25. T. F. Fuller and J. Newman, "Experimental determination of the transport number 1577 of water in Nafion 117 membrane," Journal of The Electrochemical Society, 139(5), 1578 1332 (1992).

26. V. Liso, S. S. Araya, A. C. Olesen, M. P. Nielsen, and S. K. Kær, "Modeling and ex- 1580 perimental validation of water mass balance in a PEM fuel cell stack," International 1581 Journal of Hydrogen Energy, 2015.

27. S. Ge, X. Li, B. Yi, and I-M. Hsing "Absorption, desorption, and transport of water 1583 in polymer electrolyte membranes for fuel cells," Journal of the Electrochemical 1584 Society, 152(6), A1149 (2005).

28. J. T. Hinatsu, M. Mizuhata, and H. Takenaka, "Water uptake of perfluorosulfonic 1586 acid membranes from liquid water and water vapor," Journal of the Electrochemical 1587 Society, 141(6), 1493 (1994).

29. T. E. Springer, T. Zawodzinski, and S. Gottesfeld, "Polymer electrolyte fuel cell 1589 model," Journal of the electrochemical society, 138(8), 2334 (1991).

30. A. Z. Weber and J. Newman, "Coupled thermal and water management in polymer 1591 electrolyte fuel cells," Journal of The Electrochemical Society, 153(12), A2205 1592 (2006).

31. T. Silverman, J. Meyers, and J. Beaman, "Dynamic thermal, transport and mechan- 1594 ical model of fuel cell membrane swelling," Fuel Cells, 11(6), 875 (2011). 1595

32. D. M. Bernardi and M. W. Verbrugge, "Mathematical model of a gas diffusion elec- 1596 trode bonded to a polymer electrolyte," AIChE journal, 37(8), 1151 (1991). 1597

33. Q. Zhao, P. Majsztrik, and J. Benziger, "Diffusion and interfacial transport of water 1598 in nafion," The Journal of Physical Chemistry B, 115(12), 2717 (2011). 
34. M. B. Satterfield and J. Benziger, "Non-fickian water vapor sorption dynamics by Nafion membranes," The Journal of Physical Chemistry B, 112(12), 3693 (2008).

35. D. T. Hallinan Jr and Y. A. Elabd, "Diffusion of water in Nafion using time-resolved fourier transform infrared- attenuated total reflectance spectroscopy," The Journal of Physical Chemistry B, 113(13), 4257 (2009).

36. A. Kongkanand, "Interfacial water transport measurements in Nafion thin films using a quartz-crystal microbalance," The Journal of Physical Chemistry C, 115(22), 11318 (2011)

37. A. Kusoglu, A. Kwong, K. T. Clark, H. P. Gunterman, and A. Z. Weber, "Water uptake of fuel-cell catalyst layers," Journal of The Electrochemical Society, 159(9), F530 (2012).

38. A. Kusoglu and A. Z. Weber, "Water transport and sorption in Nafion membrane," in Polymers for Energy Storage and Delivery: Polyelectrolytes for Batteries and Fuel Cells, ch. 11, pp. 175-199.

39. T. J. Silverman, J. P. Meyers, and J. J. Beaman, "Modeling water transport and swelling in polymer electrolyte membranes," Journal of The Electrochemical Society, 157(10), B1376 (2010).

40. Y.-H. Lai, G. W. Fly, and S. Clapham, "In-situ membrane hydration measurement of proton exchange membrane fuel cells," Journal of Power Sources, 274, 324 (2015).

41. L. Onishi, J. Prausnitz, and J. Newman, "Modeling Nafion: Water diffusion and polymer relaxation," ECS Transactions, 16(50), 139 (2009).

42. A. Goshtasbi, B. L. Pence, and T. Ersal, "A real-time pseudo-2D bi-domain mode of PEM fuel cells for automotive applications," in ASME 2017 Dynamic Systems and Control Conference, pp. V001T25A001-V001T25A001, American Society of Mechanical Engineers, 2017.

43. P. Mangiagli, C. Ewing, K. Xu, Q. Wang, and M. Hickner, "Dynamic water uptake of flexible ion-containing polymer networks," Fuel Cells, 9(4), 432 (2009).

44. A. Kusoglu, B. L. Kienitz, and A. Z. Weber, "Understanding the effects of compression and constraints on water uptake of fuel-cell membranes," Journal of the Electrochemical Society, 158(12), B1504 (2011).

45. S. Jomori, N. Nonoyama, and T. Yoshida, "Analysis and modeling of PEMFC degradation: Effect on oxygen transport," Journal of Power Sources, 215, 18 (2012).

46. S. Jomori, K. Komatsubara, N. Nonoyama, M. Kato, and T. Yoshida, "An experimental study of the effects of operational history on activity changes in a PEMFC,' Journal of The Electrochemical Society, 160(9), F1067 (2013).

47. D. R. Baker, D. A. Caulk, K. C. Neyerlin, and M. W. Murphy, "Measurement of oxygen transport resistance in PEM fuel cells by limiting current methods," Journal of The Electrochemical Society, 156(9), B991 (2009).

48. T. A. Greszler, D. Caulk, and P. Sinha, "The impact of platinum loading on oxy gen transport resistance," Journal of The Electrochemical Society, 159(12), F831 (2012).

49. J. P. Owejan, J. E. Owejan, and W. Gu, "Impact of platinum loading and catalyst layer structure on PEMFC performance," Journal of The Electrochemical Society, 160(8), F824 (2013).

50. Y. Ono, T. Mashio, S. Takaichi, A. Ohma, H. Kanesaka, and K. Shinohara, "The analysis of performance loss with low platinum loaded cathode catalyst layers," Ecs Transactions, 28(27), 69 (2010)

51. Y. Ono, A. Ohma, K. Shinohara, and K. Fushinobu, "Influence of equivalent weight of ionomer on local oxygen transport resistance in cathode catalyst layers," Journal of The Electrochemical Society, 160(8), F779 (2013).

52. M.-J. Choo, K.-H. Oh, J.-K. Park, and H.-T. Kim, "Analysis of oxygen transport in cathode catalyst layer of low-Pt-loaded fuel cells," ChemElectroChem, 2(3), 382 (2015).

53. A. Chowdhury, C. J. Radke, and A. Z. Weber, "Transport resistances in fuel-cel catalyst layers," ECS Transactions, 80(8), 321 (2017).

54. N. Nonoyama, S. Okazaki, A. Z. Weber, Y. Ikogi, and T. Yoshida, "Analysis of oxygen-transport diffusion resistance in proton-exchange-membrane fuel cells," Journal of The Electrochemical Society, 158(4), B416 (2011).

55. N. Ramaswamy and S. Kumaraguru, "Materials and design selection to improve high current density performance in PEMFC," ECS Transactions, 85(13), 835 (2018).

56. A. Z. Weber and A. Kusoglu, "Unexplained transport resistances for low-loaded fuel-cell catalyst layers," Journal of Materials Chemistry A, 2(41), 17207 (2014).

57. E. Sadeghi, A. Putz, and M. Eikerling, "Hierarchical model of reaction rate distributions and effectiveness factors in catalyst layers of polymer electrolyte fuel cells," Journal of the Electrochemical Society, 160(10), F1159 (2013).

58. Q. Wang, M. Eikerling, D. Song, and Z. Liu, "Structure and performance of different types of agglomerates in cathode catalyst layers of PEM fuel cells," Journal of Electroanalytical Chemistry, 573(1), 61 (2004).

59. M. Moore, P. Wardlaw, P. Dobson, J. Boisvert, A. Putz, R. Spiteri, and M. Secanell, "Understanding the effect of kinetic and mass transport processes in cathode agglomerates," Journal of the Electrochemical Society, 161(8), E3125 (2014).

60. M. Secanell, K. Karan, A. Suleman, and N. Djilali, "Multi-variable optimization of PEMFC cathodes using an agglomerate model," Electrochimica Acta, 52(22), 6318 (2007).

61. P. Dobson, C. Lei, T. Navessin, and M. Secanell, "Characterization of the PEM fuel cell catalyst layer microstructure by nonlinear least-squares parameter estimation," Journal of the Electrochemical Society, 159(5), B514 (2012).

62. L. Hao, K. Moriyama, W. Gu, and C.-Y. Wang, "Modeling and experimental validation of Pt loading and electrode composition effects in PEM fuel cells," Journal of The Electrochemical Society, 162(8), F854 (2015).

63. F. C. Cetinbas, R. K. Ahluwalia, N. Kariuki, V. De Andrade, D. Fongalland, L. Smith, J. Sharman, P. Ferreira, S. Rasouli, and D. J. Myers, "Hybrid approach combining multiple characterization techniques and simulations for microstructural analysis of proton exchange membrane fuel cell electrodes," Journal of Power Sources 344, 62 (2017).
64. F. C. Cetinbas, R. K. Ahluwalia, N. N. Kariuki, and D. J. Myers, "Agglomerates in 1686 polymer electrolyte fuel cell electrodes: Part i. structural characterization," Journal 1687 of The Electrochemical Society, 165(13), F1051 (2018).

65. T. Suzuki, K. Kudo, and Y Morimoto, "Model for investigation of oxygen transport limitation in a polymer electrolyte fuel cell," Journal of Power Sources, 222, 3791690 (2013).

66. T. Mashio, H. Iden, A. Ohma, and T. Tokumasu, "Modeling of local gas transport 1692 in catalyst layers of PEM fuel cells," Journal of Electroanalytical Chemistry, 790, 1693 27 (2017).

67. R. Jinnouchi, K. Kudo, N. Kitano, and Y. Morimoto, "Molecular dynamics simula- 1695 tions on $\mathrm{O} 2$ permeation through nafion ionomer on platinum surface," Electrochim- 1696 ica Acta, 188, 767 (2016)

68. H. Liu, W. K. Epting, and S. Litster, "Gas transport resistance in polymer electrolyte 1698 thin films on oxygen reduction reaction catalysts," Langmuir, 31(36), 9853 (2015). 1699

69. E. M. Davis, C. M. Stafford, and K. A. Page, "Elucidating water transport mecha- 1700 nisms in Nafion thin films," ACS Macro Letters, 3(10), 1029 (2014).

70. S. A. Eastman, S. Kim, K. A. Page, B. W. Rowe, S. Kang, C. L. Soles, and 1702 K. G. Yager, "Effect of confinement on structure, water solubility, and water trans- 1703 port in Nafion thin films," Macromolecules, 45(19), 7920 (2012).

71. S. C. DeCaluwe, A. M. Baker, P. Bhargava, J. E. Fischer, and J. A. Dura "Structure- 1705 property relationships at Nafion thin-film interfaces: Thickness effects on hydration 1706 and anisotropic ion transport," Nano energy, 46, 91 (2018).

72. A. Ohma, T Mashio, K. Sato, H. Iden, Y. Ono, K. Sakai, K. Akizuki, S. Takaichi, 1708 and K. Shinohara, "Analysis of proton exchange membrane fuel cell catalyst layers 1709 for reduction of platinum loading at Nissan," Electrochimica Acta, 56(28), 108321710 (2011).

73. S. Holdcroft, "Fuel cell catalyst layers: a polymer science perspective", Chemistry 1712 of materials, 26(1), 381 (2013).

74. R. M. Darling, "A hierarchical model for oxygen transport in agglomerates in the 1714 cathode catalyst layer of a polymer-electrolyte fuel cell," Journal of The Electro- 1715 chemical Society, 165(9), F571 (2018).

75. F. C. Cetinbas, S. G. Advani, and A. K. Prasad, "A modified agglomerate model 1717 with discrete catalyst particles for the PEM fuel cell catalyst layer," Journal of The 1718 Electrochemical Society, 160(8), F750 (2013)

76. F. C. Cetinbas, S. G. Advani, and A. K. Prasad, "An improved agglomerate model 1720 for the PEM catalyst layer with accurate effective surface area calculation based 1721 on the sphere-packing approach," Journal of The Electrochemical Society, 161(6), 1722 F803 (2014)

77. T. Muzaffar, T. Kadyk, and M. Eikerling, "Tipping water balance and the Pt loading 172 effect in polymer electrolyte fuel cells: a model-based analysis," Sustainable Energy 1725 \& Fuels, 2(6), 1189 (2018).

78. A. Kulikovsky, "A physically-based analytical polarization curve of a PEM fuel 1727 cell," Journal of The Electrochemical Society, 161(3), F263 (2014).

79. H. Iden and A. Ohma, "An in situ technique for analyzing ionomer coverage in 1729 catalyst layers," Journal of Electroanalytical Chemistry, 693, 34 (2013).

80. K. Malek, T. Mashio, and M. Eikerling, "Microstructure of catalyst layers in PEM 1731 fuel cells redefined: a computational approach," Electrocatalysis, 2(2), 141 (2011). 1732

81. K. Malek, M. Eikerling, Q. Wang, T. Navessin, and Z. Liu, "Self-organization in 1733 catalyst layers of polymer electrolyte fuel cells," The Journal of Physical Chemistry 1734 C, 111(36), 13627 (2007) A. Srouji, L. Zheng, R. Dross, D. Aaron, and M. Mench, The role of water man- 173 agement on the oxygen transport resistance in polymer electrolyte fuel cell with 1737 ultra-low precious metal loading," Journal of Power Sources, 364, 92 (2017). 1738 A. Kulikovsky, "How important is oxygen transport in agglomerates in a PEM fuel 1739 cell catalyst layer?," Electrochimica Acta, 130, 826 (2014).

84. J. X. Wang, T. E. Springer, and R. R. Adzic, "Dual-pathway kinetic equation for 174 the hydrogen oxidation reaction on Pt electrodes," Journal of the Electrochemical 1742 Society, 153(9), A1732 (2006)

85. N. Subramanian, T. Greszler, J. Zhang, W. Gu, and R. Makharia, "Pt-oxide coverage- 1744 dependent oxygen reduction reaction (ORR) kinetics," Journal of The Electrochem- 1745 ical Society, 159(5), B531 (2012).

86. J. X. Wang, J. Zhang, and R. R. Adzic, "Double-trap kinetic equation for the oxygen 1747 reduction reaction on Pt (111) in acidic media," The Journal of Physical Chemistry 1748 A, 111(49), 12702 (2007)

87. J. X. Wang, F. A. Uribe, T. E. Springer, J. Zhang, and R. R. Adzic, "Intrinsic kinetic 1750 equation for oxygen reduction reaction in acidic media: the double Tafel slope and 1751 fuel cell applications," Faraday discussions, 140, 347 (2009).

88. M. Moore, A. Putz, and M. Secanell, "Investigation of the ORR using the double- 1753 trap intrinsic kinetic model," Journal of the Electrochemical Society, 160(6), F670 1754 (2013).

89. M. Markiewicz, C. Zalitis, and A. Kucernak, "Performance measurements and mod- 1756 eling of the ORR on fuel cell electrocatalysts-the modified double trap model," 1757 Electrochimica Acta, 179, 126 (2015).

90. B. Jayasankar and K. Karan, "O2 electrochemistry on Pt: A unified multi-step model 1759 for oxygen reduction and oxide growth," Electrochimica Acta, 273, 367 (2018).

91. L. M. Pant and A. Z. Weber, "Communicationmodeling polymer-electrolyte fuel- 176 cell agglomerates with double-trap kinetics," Journal of The Electrochemical Soci- 1762 ety, 164(11), E3102 (2017).

92. M. Mathias, D. Baker, J. Zhang, Y. Liu, and W. Gu, "Frontiers in application of 1764 impedance diagnostics to $H_{2}$-fed polymer electrolyte fuel cells," ECS Transactions, 1765 13(13), 129 (2008)

93. E. L. Redmond, B. P. Setzler, F. M. Alamgir, and T. F. Fuller, "Elucidating the ox- 1767 ide growth mechanism on platinum at the cathode in PEM fuel cells," Physical 1768 Chemistry Chemical Physics, 16(11), 5301 (2014).

94. S. Arisetty, Y. Liu, W. Gu, and M. Mathias, "Modeling platinum oxide growth of 1770 PEMFC cathode catalysts," ECS Transactions, 69(17), 273 (2015). (1) . 1702 (703 8 1

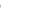


95. B. P. Setzler and T. F. Fuller, "A physics-based impedance model of proton exchange membrane fuel cells exhibiting low-frequency inductive loops," Journal of The Electrochemical Society, 162(6), F519 (2015).

96. J. Chlistunoff and B. Pivovar, "Effects of ionomer morphology on oxygen reduction on Pt," Journal of The Electrochemical Society, 162(8), F890 (2015).

97. Y. Furuya, H. Iden, T. Mashio, A. Ohma, and K. Shinohara, "Effect of ionomer coverage on pt-based catalyst on ORR activity," in Meeting Abstracts, no. 40, pp. 1522-1522, The Electrochemical Society, 2012.

98. K. Shinozaki, Y. Morimoto, B. S. Pivovar, and S. S. Kocha, "Suppression of oxygen reduction reaction activity on Pt-based electrocatalysts from ionomer incorporation," Journal of Power Sources, 325, 745 (2016).

99. H. Xu, Y. Song, H. R. Kunz, and J. M. Fenton, "Effect of elevated temperature and reduced relative humidity on ORR kinetics for PEM fuel cells," Journal of The Electrochemical Society, 152(9), A1828 (2005).

100. H. Xu, H. R. Kunz, and J. M. Fenton, "Analysis of proton exchange membrane fuel cell polarization losses at elevated temperature $120 \mathrm{C}$ and reduced relative humidity,' Electrochimica Acta, 52(11), 3525 (2007).

101. Y. Liu, M. W. Murphy, D. R. Baker, W. Gu, C. Ji, J. Jorne, and H. A. Gasteiger, "Proton conduction and oxygen reduction kinetics in PEM fuel cell cathodes: effects of ionomer-to-carbon ratio and relative humidity," Journal of The Electrochemical Society, 156(8), B970 (2009).

102. K. Neyerlin, H. A. Gasteiger, C. K. Mittelsteadt, J. Jorne, and W. Gu, "Effect of relative humidity on oxygen reduction kinetics in a PEMFC," Journal of The Electrochemical Society, 152(6), A1073 (2005).

103. H. Xu, R. Kunz, and J. M. Fenton, "Investigation of platinum oxidation in PEM fuel cells at various relative humidities," Electrochemical and Solid-State Letters, 10(1), B1 (2007).

104. E. Padgett, N. Andrejevic, Z. Liu, A. Kongkanand, W. Gu, K. Moriyama, Y. Jiang, S. Kumaraguru, T. E. Moylan, R. Kukreja et al., "Editors' choiceconnecting fuel cell catalyst nanostructure and accessibility using quantitative cryo-STEM tomography," Journal of The Electrochemical Society, 165(3), F173 (2018).

105. M. Aghighi, M. A. Hoeh, W. Lehnert, G. Merle, and J. Gostick, "Simulation of a full fuel cell membrane electrode assembly using pore network modeling," Journal of The Electrochemical Society, 163(5), F384 (2016).

106. J. Hermann and C. Ziegler, "Modeling the dynamic water transport in the porous layers of PEM fuel cells based on numerical upscaling," Journal of The Electrochemical Society, 155(10), B1066 (2008).

107. A. Z. Weber, R. M. Darling, and J. Newman, "Modeling two-phase behavior in PEFCs," Journal of the Electrochemical Society, 151(10), A1715 (2004).

108. M. Eikerling, "Water management in cathode catalyst layers of PEM fuel cells a structure-based model," Journal of The Electrochemical Society, 153(3), E58 (2006).

09. A. Z. Weber, "Improved modeling and understanding of diffusion-media wettability on polymer-electrolyte-fuel-cell performance," journal of Power Sources, 195(16), 5292 (2010).

110. P. Cheung, J. D. Fairweather, and D. T. Schwartz, "Characterization of internal wetting in polymer electrolyte membrane gas diffusion layers," Journal of Power Sources, 187(2), 487 (2009).

111. T. Mashio, K. Sato, and A. Ohma, "Analysis of water adsorption and condensation in catalyst layers for polymer electrolyte fuel cells," Electrochimica Acta, 140, 238 (2014).

112. C. Simon, F. Hasché, and H. A. Gasteiger, "Influence of the gas diffusion layer compression on the oxygen transport in PEM fuel cells at high water saturation levels," Journal of The Electrochemical Society, 164(6), F591 (2017).

113. D. Muirhead, R. Banerjee, M. G. George, N. Ge, P. Shrestha, H. Liu, J. Lee, and A. Bazylak, "Liquid water saturation and oxygen transport resistance in polymer electrolyte membrane fuel cell gas diffusion layers," Electrochimica Acta, 274, 250 (2018).

114. E. Wargo, V. Schulz, A. Çeçen, S. Kalidindi, and E. Kumbur, "Resolving macro-and micro-porous layer interaction in polymer electrolyte fuel cells using focused ion beam and X-ray computed tomography," Electrochimica Acta, 87, 201 (2013).

115. G. Xu, J. LaManna, J. Clement, and M. Mench, "Direct measurement of throughplane thermal conductivity of partially saturated fuel cell diffusion media," Journal of Power Sources, 256, 212 (2014).

116. R. H. Perry, D. W. Green, J. O. Maloney et al., "Perrys chemical engineers handbook," 1997.

117. R. B. Bird, W. E. Stewart, and E. N. Lightfoot, Transport phenomena. John Wiley \& Sons, 2007

118. P. A. García-Salaberri, J. T. Gostick, G. Hwang, A. Z. Weber, and M. Vera, "Effective diffusivity in partially-saturated carbon-fiber gas diffusion layers: Effect of local saturation and application to macroscopic continuum models," Journal of Power Sources, 296, 440 (2015)

119. Z. Niu, J. Wu, Y. Wang, and K. Jiao, "Investigating the in-/through-plane effective diffusivities of dry and partially-saturated gas diffusion layers," Journal of The Electrochemical Society, 165(11), F986 (2018).

120. N. Zamel and X. Li, "Effective transport properties for polymer electrolyte membrane fuel cells-with a focus on the gas diffusion layer," Progress in energy and combustion science, 39(1), 111 (2013).

121. L. Holzer, O. Pecho, J. Schumacher, P. Marmet, O. Stenzel, F. Büchi, A. Lamibrac, and B. Münch, "Microstructure-property relationships in a gas diffusion layer (GDL) for polymer electrolyte fuel cells, part i: effect of compression and anisotropy of dry GDL," Electrochimica Acta, 227, 419 (2017)

122. P. A. García-Salaberri, G. Hwang, M. Vera, A. Z. Weber, and J. T. Gostick, "Effective diffusivity in partially-saturated carbon-fiber gas diffusion layers: Effect of throughplane saturation distribution," International Journal of Heat and Mass Transfer, $\mathbf{8 6}$ 319 (2015).
123. L. Holzer, O. Pecho, J. Schumacher, P. Marmet, F. Büchi, A. Lamibrac, and 1858 B. Münch, "Microstructure-property relationships in a gas diffusion layer (GDL) 1859 for polymer electrolyte fuel cells, part ii: pressure-induced water injection and liq- 1860 uid permeability," Electrochimica Acta, 241, 414 (2017).

124. L. M. Pant, S. K. Mitra, and M. Secanell, "Absolute permeability and knudsen diffu- 1862 sivity measurements in pemfc gas diffusion layers and micro porous layers," Journal 1863 of Power Sources, 206, 153 (2012).

125. R. Alink and D. Gerteisen, "Coupling of a continuum fuel cell model with a discrete 1865 liquid water percolation model," International Journal of Hydrogen Energy, 39(16), 1866 8457 (2014).

126. M. Khandelwal and M. Mench, "Direct measurement of through-plane thermal con- 1868 ductivity and contact resistance in fuel cell materials," Journal of Power Sources, 1869 161(2), 1106 (2006)

127. O. Burheim, G. Ellila, J. Fairweather, A. Labouriau, S. Kjelstrup, and J. Pharoah, 1871 "Ageing and thermal conductivity of porous transport layers used for PEM fuel 1872 cells," Journal of Power Sources, 221, 356 (2013).

128. J. Ramousse, S. Didierjean, O. Lottin, and D. Maillet, "Estimation of the effec- 1874 tive thermal conductivity of carbon felts used as PEMFC gas diffusion layers," 1875 International Journal of Thermal Sciences, 47(1), 1 (2008).

129. M. Andisheh-Tadbir, E. Kjeang, and M. Bahrami, "Thermal conductivity of micro- 1877 porous layers: Analytical modeling and experimental validation," Journal of Power 1878 Sources, 296, 344 (2015).

130. H. Sadeghifar, N. Djilali, and M. Bahrami, "Effect of polytetrafluoroethylene (PTFE) 1880 and micro porous layer (MPL) on thermal conductivity of fuel cell gas diffusion 188 layers: Modeling and experiments," Journal of Power Sources, 248, 632 (2014). 1882

131. P. Teertstra, G. Karimi, and X. Li, "Measurement of in-plane effective thermal con- 1883 ductivity in PEM fuel cell diffusion media," Electrochimica Acta, 56(3),1670 (2011). 1884

132. N. Alhazmi, M. Ismail, D. Ingham, K. Hughes, L. Ma, and M. Pourkashanian, "The 1885 in-plane thermal conductivity and the contact resistance of the components of the 1886 membrane electrode assembly in proton exchange membrane fuel cells," Journal of 1887 Power Sources, 241, 136 (2013).

133. S. F. Burlatsky, V. V. Atrazhev, M. Gummalla, D. A. Condit, and F. Liu, "The impact 1889 of thermal conductivity and diffusion rates on water vapor transport through gas 1890 diffusion layers," Journal of Power Sources, 190(2), 485 (2009). 1891

134. O. S. Burheim, G. A. Crymble, R. Bock, N. Hussain, S. Pasupathi, A. Du Plessis, 1892 S. le Roux, F. Seland, H. Su, and B. G. Pollet, "Thermal conductivity in the three 1893 layered regions of micro porous layer coated porous transport layers for the PEM 1894 fuel cell," international journal of hydrogen energy, 40(46), 16775 (2015). 1895

135. M. Sassin, Y. Garsany, B. Gould, and K. Swider-Lyons, "Impact of compressive 1896 stress on mea pore structure and its consequence on pemfc performance," Journal 1897 of The Electrochemical Society, 163(8), F808 (2016).

136. O. S. Burheim, H. Su, H. H. Hauge, S. Pasupathi, and B. G. Pollet, "Study of thermal 1899 conductivity of PEM fuel cell catalyst layers," international journal of hydrogen 1900 energy, 39(17), 9397 (2014)

137. N. Alhazmi, D. Ingham, M. Ismail, K. Hughes, L. Ma, and M. Pourkashanian, "The 1902 through-plane thermal conductivity and the contact resistance of the components 1903 of the membrane electrode assembly and gas diffusion layer in proton exchange 1904 membrane fuel cells," Journal of Power Sources, 270, 59 (2014).

138. O. Burheim, P. Vie, J. Pharoah, and S. Kjelstrup, "Ex situ measurements of through- 1906 plane thermal conductivities in a polymer electrolyte fuel cell," Journal of Power 1907 Sources, 195(1), 249 (2010).

139. N. Zamel, E. Litovsky, S. Shakhshir, X. Li, and J. Kleiman, "Measurement of in- 1909 plane thermal conductivity of carbon paper diffusion media in the temperature range 1910 of- 20 C to+ 120 C," Applied energy, 88(9), 3042 (2011).

140. R. R. Rashapov, J. Unno and J. T. Gostick, "Characterization of PEMFC gas diffusion 1912 layer porosity," Journal of The Electrochemical Society, 162(6), F603 (2015). 1913

141. H. Sadeghifar, "In-plane and through-plane electrical conductivities and contact 1914 resistances of a Mercedes-Benz catalyst-coated membrane, gas diffusion and micro- 1915 porous layers and a Ballard graphite bipolar plate: Impact of humidity, compressive 1916 load and polytetrafluoroethylene," Energy Conversion and Management, 154, 1911917 (2017).

142. H. K. Shim, D. K. Paul, and K. Karan, "Resolving the contradiction between anoma- 1919 lously high water uptake and low conductivity of nanothin Nafion films on SiO2 1920 substrate," Macromolecules, 48(22), 8394 (2015).

143. I. V. Zenyuk, A. Lamibrac, J. Eller, D. Y. Parkinson, F. Marone, F. N. Buchi, and 1922 A. Z. Weber, "Investigating evaporation in gas diffusion layers for fuel cells with X- 1923 ray computed tomography," The Journal of Physical Chemistry C, 120(50), 287011924 (2016).

144. R. Marek and J. Straub, "Analysis of the evaporation coefficient and the condensation 1926 coefficient of water," International Journal of Heat and Mass Transfer, 44(1), 391927 (2001).

145. A. Goshtasbi, B. L. Pence, and T. Ersal, "Computationally efficient pseudo-2D non- 1929 isothermal modeling of polymer electrolyte membrane fuel cells with two-phase 1930 phenomena," Journal of The Electrochemical Society, 163(13), F1412 (2016). 1931

146. I. S. Hussaini and C.-Y. Wang, "Transients of water distribution and transport in 1932 PEM fuel cells," Journal of The Electrochemical Society, 156(12), B1394 (2009). 1933

147. M. Adachi, T. Navessin, Z. Xie, F. H. Li, S. Tanaka, and S. Holdcroft, "Thickness 1934 dependence of water permeation through proton exchange membranes," Journal of 1935 Membrane Science, 364(1), 183 (2010).

148. G. He, K. Shibata, Y. Yamazaki, and A. Abudula, "The real time dynamic water 1937 transport investigation due to net water transport coefficient (NWTC) based on mea- 1938 surement of water content in the outlet gas in a PEFC," international journal of 1939 hydrogen energy, 36(12), 7183 (2011).

149. R. Shimokawa, H. Nagai, Y. Sugesawa, H. Minakuchi, and M. Sudoh, "Real time 1941 measurement of water transport in polymer electrolyte fuel cell," ECS Transactions, 1942 58(1), 1659 (2013). 
1944 150. M. Hickner, N. Siegel, K. Chen, D. Hussey, D. Jacobson, and M. Arif, "Understand1945 1946 1947 1948 1949 ing liquid water distribution and removal phenomena in an operating PEMFC via neutron radiography," Journal of The Electrochemical Society, 155(3), B294 (2008).

151. A. Thomas, G. Maranzana, S. Didierjean, J. Dillet, and O. Lottin, "Thermal effect on water transport in proton exchange membrane fuel cell," Fuel Cells, 12(2), 212 (2012).

152. J. Cho, H.-S. Kim, and K. Min, "Transient response of a unit proton-exchange membrane fuel cell under various operating conditions," Journal of Power Sources, 185(1), 118 (2008)

153. R. Banerjee, N. Ge, J. Lee, M. G. George, S. Chevalier, H. Liu, P. Shrestha, D. Muirhead, and A. Bazylak, "Transient liquid water distributions in polymer electrolyte membrane fuel cell gas diffusion layers observed through in-operando synchrotron X-ray radiography,” Journal of The Electrochemical Society, 164(2), F154 (2017).

154. P. Deevanhxay, T. Sasabe, S. Tsushima, and S. Hirai, "Observation of dynamic liquid water transport in the microporous layer and gas diffusion layer of an operating PEM fuel cell by high-resolution soft X-ray radiography," Journal of Power Sources, 230 , 38 (2013).
155. I. V. Zenyuk, D. Y. Parkinson, G. Hwang, and A. Z. Weber, "Probing water distri- 1962 bution in compressed fuel-cell gas-diffusion layers using X-ray computed tomogra- 1963 phy," Electrochemistry Communications, 53, 24 (2015).

156. P. Boillat, P. Oberholzer, A. Kaestner, R. Siegrist, E. Lehmann, G. Scherer, and 1965 A. Wokaun, "Impact of water on PEFC performance evaluated by neutron imaging 1966 combined with pulsed helox operation," Journal of The Electrochemical Society, 1967 159(7), F210 (2012).

157. S. Litster, D. Sinton, and N. Djilali, "Ex situ visualization of liquid water trans- 1969 port in pem fuel cell gas diffusion layers," Journal of Power Sources, 154(1), 951970 (2006).

158. I. A. Schneider, S. v. Dahlen, M. H. Bayer, P. Boillat, M. Hildebrandt, 1972 E. H. Lehmann, P. Oberholzer, G. G. Scherer, and A. Wokaun, "Local transients 1973 of flooding and current in channel and land areas of a polymer electrolyte fuel cell," 1974 The Journal of Physical Chemistry C, 114(27), 11998 (2010).

159. I. Schneider, M. Bayer, and S. von Dahlen, "Locally resolved electrochemi- 1976 cal impedance spectroscopy in channel and land areas of a differential poly- 1977 mer electrolyte fuel cell," Journal of The Electrochemical Society, 158(3), B343 1978 (2011) 


\section{Query}

Q1 AU: Please provide a digital object identifier (doi) for Ref(s) R58. For additional information on doi's please select this link: http://www.doi.org/. If a doi is not available, no other information is needed from you. 